University of Tennessee Health Science Center UTHSC Digital Commons

\title{
$5-2008$
}

\section{Influence of Tooth Crown Size on Malocclusion}

Michael Kelly Agenter

University of Tennessee Health Science Center

Follow this and additional works at: https://dc.uthsc.edu/dissertations

Part of the Orthodontics and Orthodontology Commons

\section{Recommended Citation}

Agenter, Michael Kelly , "Influence of Tooth Crown Size on Malocclusion" (2008). Theses and Dissertations (ETD). Paper 10. http://dx.doi.org/10.21007/etd.cghs.2008.0005.

This Thesis is brought to you for free and open access by the College of Graduate Health Sciences at UTHSC Digital Commons. It has been accepted for inclusion in Theses and Dissertations (ETD) by an authorized administrator of UTHSC Digital Commons. For more information, please contact jwelch30@uthsc.edu. 


\title{
Influence of Tooth Crown Size on Malocclusion
}

\begin{abstract}
Malocclusion is an increasingly common, multifactorial problem in industrialized countries. Although the causes of dental malocclusion are obscure in most instances, one contributing factor may be tooth size. While several researchers have studied whether tooth size contributes to malocclusion, there still is no consensus. Some have found that the mesiodistal widths of the mandibular incisor teeth are significantly larger in subjects with anterior crowding, while others have been unable to support this conclusion. Study designs often have been confounded by combining the sexes, which confuses sexual dimorphism with the supposed effect of tooth size on crowding. The present study tested whether tooth crown dimensions (mesiodistal and buccolingual) differed in a sample of American white adult males with naturallyoccurring good occlusions $(n=42)$ versus otherwise similar individuals who required orthodontic treatment to correct their malocclusions $(n=90)$. Crown dimensions were measured with digital sliding calipers. As assessed from our data, the sample means of 23 of the 24 tooth crown diameters tested were significantly larger in subjects with malocclusions versus those with naturally-occurring good occlusions. Multivariate analysis showed that mesiodistal diameter of the maxillary lateral incisor produced the most significant difference between the two samples, but this may reflect the American white composition of the sample, where this lateral incisor is notoriously small. Importantly, none of the individuals in either group had a significant Bolton discrepancy. Controlling for intercorrelations among crown dimensions, only mesiodistal crown diameters were predictive of crowding. Indeed, buccolingual crown diameters were only indirectly related to TSASD due to their high positive correlation with mesiodistal crown diameters. As such, the MD/BL crown ratio was not shown to be predictive of crowding.
\end{abstract}

\section{Document Type}

Thesis

Degree Name

Master of Dental Science (MDS)

Program

Orthodontics

Research Advisor

Edward Harris, Ph.D.

Keywords

Malocclusion, Tooth Size, Crowding, TSASD, Dental Cast, Mesiodistal, Buccolingual, Crown Index

Subject Categories

Dentistry | Orthodontics and Orthodontology 


\title{
INFLUENCE OF TOOTH CROWN SIZE ON MALOCCLUSION
}

\author{
A Thesis \\ Presented for \\ The Graduate Studies Council \\ The University of Tennessee \\ Health Science Center
}

\author{
In Partial Fulfillment \\ Of the Requirements for the Degree \\ Master of Dental Science \\ From The University of Tennessee
}

\author{
By \\ Michael Kelly Agenter, D.D.S. \\ May 2008
}


Copyright (c) 2008 Michael Kelly Agenter All rights reserved 


\section{ACKNOWLEDGEMENTS}

I would like to thank my wife, Kelly, for her loving support during my residency and during this thesis. I would also like to thank Dr. Edward Harris for all of his support and leadership during the writing of this manuscript. Without the help of Dr. Harris, this project would not have been possible. I would also like to thank Dr. Cheryl DeWood and Dr. Quinton Robinson for

serving on my committee. I appreciate their guidance, support, and friendship. 


\begin{abstract}
Malocclusion is an increasingly common, multifactorial problem in industrialized countries. Although the causes of dental malocclusion are obscure in most instances, one contributing factor may be tooth size. While several researchers have studied whether tooth size contributes to malocclusion, there still is no consensus. Some have found that the mesiodistal widths of the mandibular incisor teeth are significantly larger in subjects with anterior crowding, while others have been unable to support this conclusion. Study designs often have been confounded by combining the sexes, which confuses sexual dimorphism with the supposed effect of tooth size on crowding. The present study tested whether tooth crown dimensions (mesiodistal and buccolingual) differed in a sample of American white adult males with naturallyoccurring good occlusions $(n=42)$ versus otherwise similar individuals who required orthodontic treatment to correct their malocclusions $(n=90)$. Crown dimensions were measured with digital sliding calipers. As assessed from our data, the sample means of 23 of the 24 tooth crown diameters tested were significantly larger in subjects with malocclusions versus those with naturallyoccurring good occlusions. Multivariate analysis showed that mesiodistal diameter of the maxillary lateral incisor produced the most significant difference between the two samples, but this may reflect the American white composition
\end{abstract}


of the sample, where this lateral incisor is notoriously small. Importantly, none of the individuals in either group had a significant Bolton discrepancy. Controlling for intercorrelations among crown dimensions, only mesiodistal crown diameters were predictive of crowding. Indeed, buccolingual crown diameters were only indirectly related to TSASD due to their high positive correlation with mesiodistal crown diameters. As such, the MD/BL crown ratio was not shown to be predictive of crowding. 


\section{TABLE OF CONTENTS}

Chapter

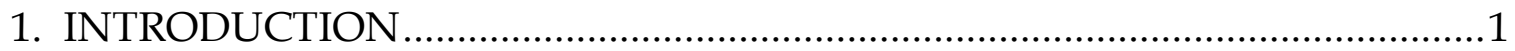

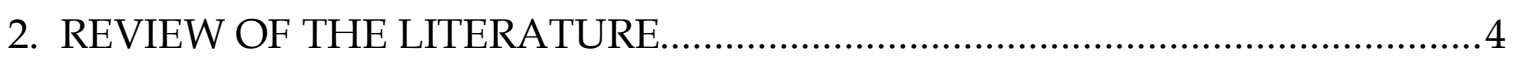

Increased Tooth Size Related to Dental Crowding ......................................4

Tooth Size Independent of Dental Crowding .............................................25

Masticatory Stress During Development and Jaw Size ................................35

Arch Length and Dental Crowding...........................................................40

TSASD as a Measure of Crowding ..............................................................46

Normative Increases in Dental Crowding with Age .................................46

Facial Type and Dental Crowding .............................................................49

Dental Proportionality and the Bolton Index .............................................52

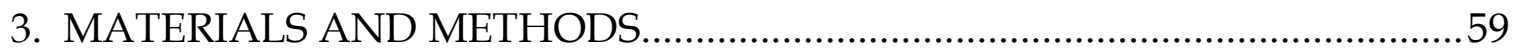

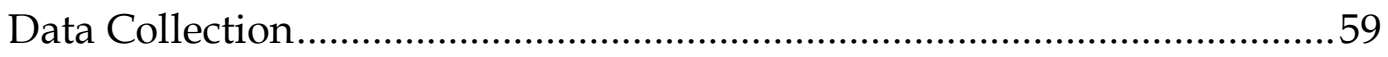

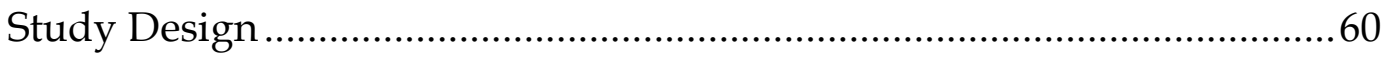

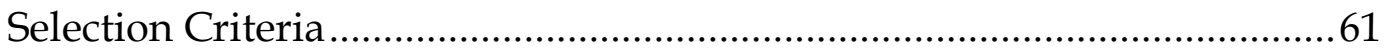

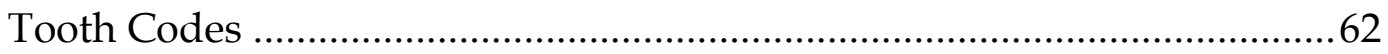

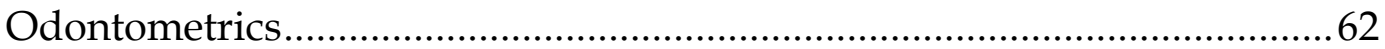

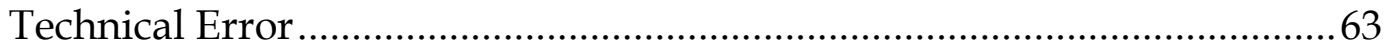

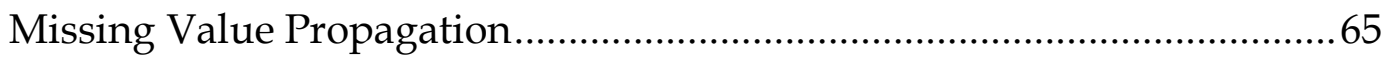




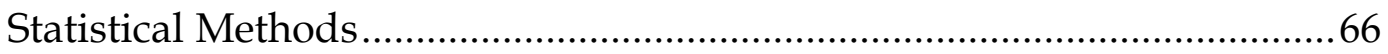

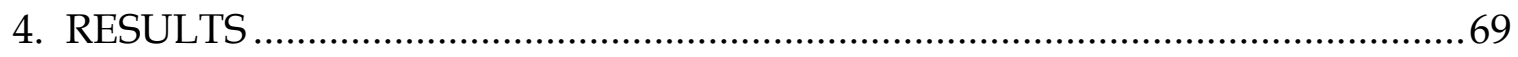

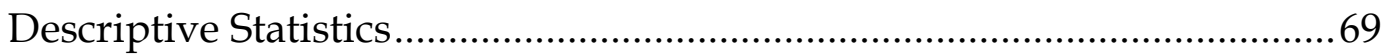

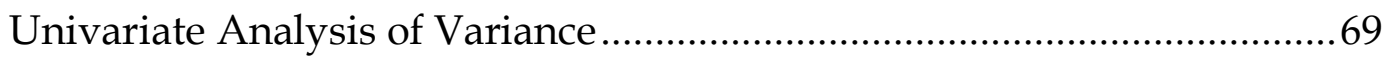

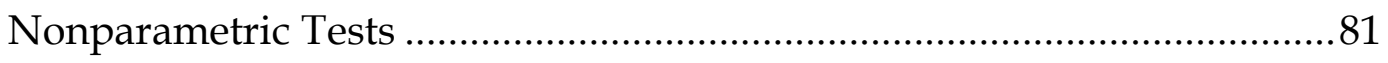

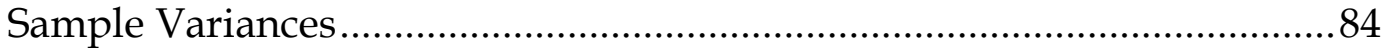

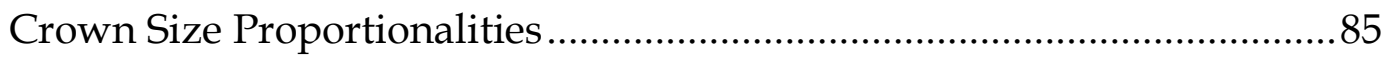

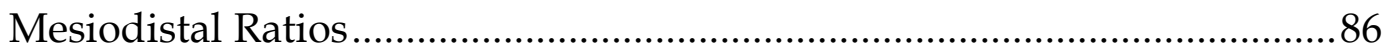

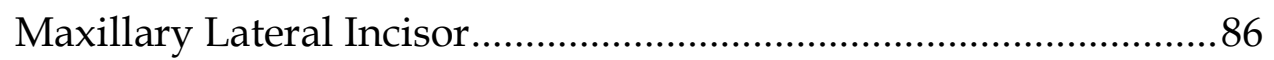

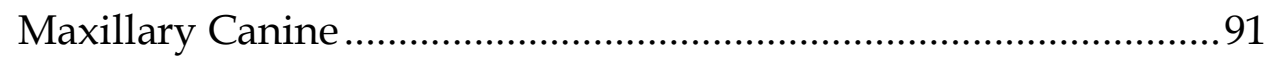

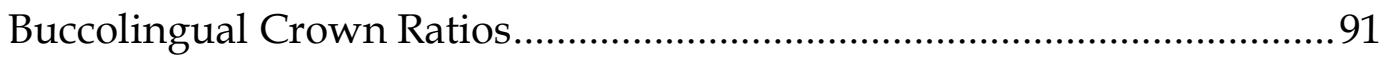

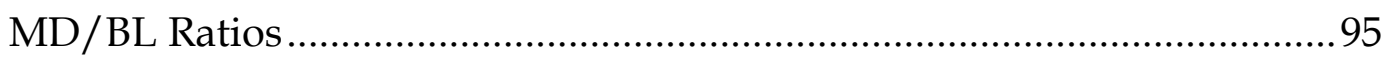

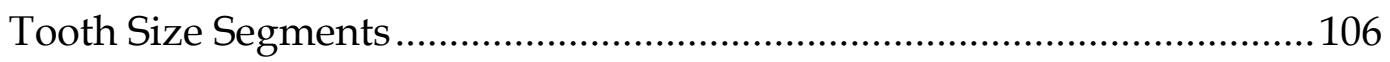

Multivariable Analyses ......................................................................... 110

Principal Components Analysis ............................................................116

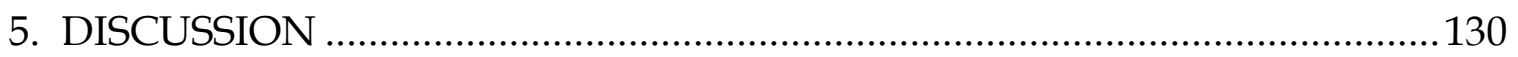

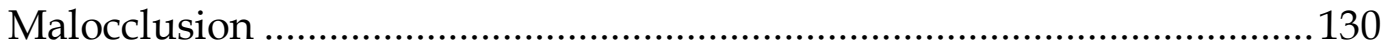

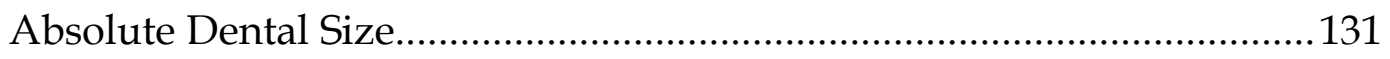

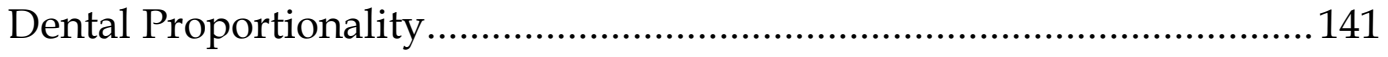

Secular Changes in Arch Size ................................................................ 144

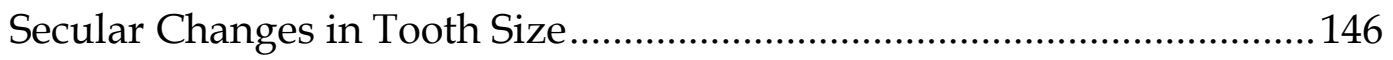




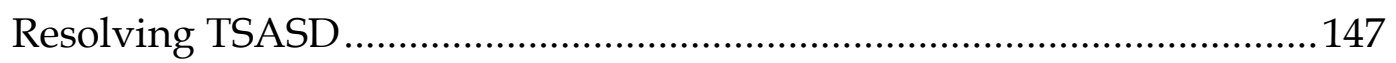

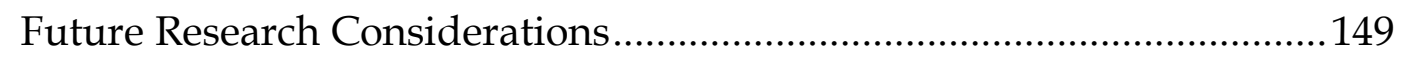

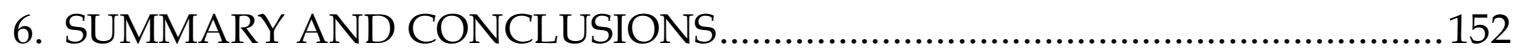

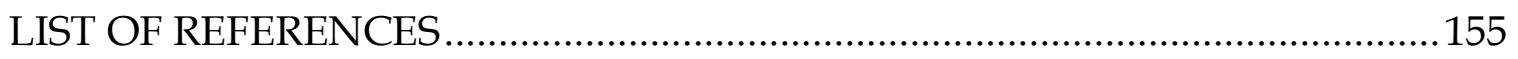

APPENDIX. DESCRIPTIVE STATISTICS …………………...........................167

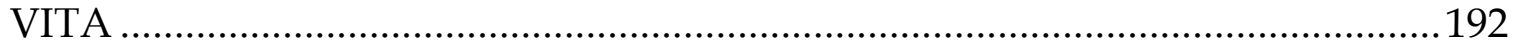




\section{LIST OF TABLES}

Table

2-1. Comparison of mesiodistal widths of individual teeth between the two groups

2-2. Comparison of individual teeth between the two groups (mesiodistal width, in $\mathrm{mm}$ )

2-3. Comparison of mesiodistal tooth widths between normal occlusion and malocclusion (sexes pooled) in the upper jaw

2-4. Comparison of mesiodistal tooth widths between normal occlusion and malocclusion (sexes pooled) in the lower jaw

2-5. Statistical comparison for arch dimensions between normal occlusion and malocclusion (sexes pooled)

4-1. Descriptive statistics for the mesiodistal crown diameters of the sample with naturally-occurring good occlusion

4-2. Descriptive statistics for the buccolingual crown diameters of the sample with naturally-occurring good occlusion

4-3. Descriptive statistics for the mesiodistal crown diameters of the sample that received orthodontic treatment

4-4. Descriptive statistics for the buccolingual crown diameters of the sample that received orthodontic treatment

4-5. Univariate descriptive statistics for mesiodistal crown dimensions and analysis of variance tests for group differences

4-6. Univariate descriptive statistics for buccolingual crown dimensions and analysis of variance tests for group differences 
4-7. Results of the Wilcoxon sign test for group differences for the mesiodistal dimensions and two tests of whether the sample variances differ between groups

4-8. Results of the Wilcoxon sign test for group differences for the buccolingual dimensions and two tests of whether the sample variances differ between groups

4-9. Univariate tests for group differences in mesiodistal tooth size ratios

4-10. Univariate tests for group differences in buccolingual tooth size ratios

4-11. ANOVA results testing for differences in crown shape (MD/BL)

4-12. Mean crown dimensions of the teeth with different crown indexes between groups

4-13. Results of nominal logistic test for the predictive contributions of the mesiodistal and buccolingual crown diameters to the risk of orthodontic treatment

4-14. Tests for group differences in mesiodistal ratios of groupings of crown dimensions

4-15. Tests for group differences in buccolingual ratios of groupings of crown dimensions

4-16. Stepwise discriminant functions analysis: results at step zero

4-17. Stepwise discriminant functions analysis: results at step one, after entering MD U2

4-18. Stepwise discriminant functions analysis: results at step two, after entering MD U2 and BL L6

4-19. Full matrix of Pearson correlation coefficients among the 24 tooth crown diameters. 
4-20. Unrotated results of principal components analysis on the 24 crown dimensions ( $\mathrm{n}=91$ individuals)

4-21. Descriptive statistics and tests for group differences in PC scores.

5-1. Prior studies investigating mesiodistal tooth diameters in relation to occlusion.

A-1. Comparison of descriptive statistics for mesiodistal diameter of UI1 for the two groups, namely those with naturallyoccurring good occlusions and those who received orthodontic treatment

A-2. Comparison of descriptive statistics for mesiodistal diameter of UI2 for the two groups, namely those with naturallyoccurring good occlusions and those who received orthodontic treatment.

A-3. Comparison of descriptive statistics for mesiodistal diameter of UC for the two groups, namely those with naturallyoccurring good occlusions and those who received orthodontic treatment

A-4. Comparison of descriptive statistics for mesiodistal diameter of UP1 for the two groups, namely those with naturallyoccurring good occlusions and those who received orthodontic treatment

A-5. Comparison of descriptive statistics for mesiodistal diameter of UP2 for the two groups, namely those with naturallyoccurring good occlusions and those who received orthodontic treatment

A-6. Comparison of descriptive statistics for mesiodistal diameter of UM1 for the two groups, namely those with naturallyoccurring good occlusions and those who received orthodontic treatment 
A-7. Comparison of descriptive statistics for mesiodistal diameter of LI1 for the two groups, namely those with naturallyoccurring good occlusions and those who received orthodontic treatment

A-8. Comparison of descriptive statistics for mesiodistal diameter of LI2 for the two groups, namely those with naturallyoccurring good occlusions and those who received orthodontic treatment

A-9. Comparison of descriptive statistics for mesiodistal diameter of LC for the two groups, namely those with naturallyoccurring good occlusions and those who received orthodontic treatment

A-10. Comparison of descriptive statistics for mesiodistal diameter of LP1 for the two groups, namely those with naturallyoccurring good occlusions and those who received orthodontic treatment

A-11. Comparison of descriptive statistics for mesiodistal diameter of LP2 for the two groups, namely those with naturallyoccurring good occlusions and those who received orthodontic treatment

A-12. Comparison of descriptive statistics for mesiodistal diameter of LM1 for the two groups, namely those with naturallyoccurring good occlusions and those who received orthodontic treatment

A13. Comparison of descriptive statistics for buccolingual diameter of UI1 for the two groups, namely those with naturallyoccurring good occlusions and those who received orthodontic treatment

A-14. Comparison of descriptive statistics for buccolingual diameter of UI2 for the two groups, namely those with naturallyoccurring good occlusions and those who received orthodontic treatment. 
A-15. Comparison of descriptive statistics for buccolingual diameter of UC for the two groups, namely those with naturallyoccurring good occlusions and those who received orthodontic treatment

A-16. Comparison of descriptive statistics for buccolingual diameter of UP1 for the two groups, namely those with naturallyoccurring good occlusions and those who received orthodontic treatment

A-17. Comparison of descriptive statistics for buccolingual diameter of UP2 for the two groups, namely those with naturallyoccurring good occlusions and those who received orthodontic treatment.

A-18. Comparison of descriptive statistics for buccolingual diameter of UM1 for the two groups, namely those with naturallyoccurring good occlusions and those who received orthodontic treatment.

A-19. Comparison of descriptive statistics for buccolingual diameter of LI1 for the two groups, namely those with naturallyoccurring good occlusions and those who received orthodontic treatment

A-20. Comparison of descriptive statistics for buccolingual diameter of LI2 for the two groups, namely those with naturallyoccurring good occlusions and those who received orthodontic treatment

A-21. Comparison of descriptive statistics for buccolingual diameter of LC for the two groups, namely those with naturallyoccurring good occlusions and those who received orthodontic treatment

A-22. Comparison of descriptive statistics for buccolingual diameter of LP1 for the two groups, namely those with naturallyoccurring good occlusions and those who received orthodontic treatment. 
A-23. Comparison of descriptive statistics for buccolingual diameter of LP2 for the two groups, namely those with naturallyoccurring good occlusions and those who received orthodontic treatment

A-24. Comparison of descriptive statistics for buccolingual diameter of LM1 for the two groups, namely those with naturallyoccurring good occlusions and those who received orthodontic treatment.. 


\section{LIST OF FIGURES}

Figure

Page

2-1. Results published by Peck and Peck (1972) showing (A) that mesiodistal incisor diameters were significantly smaller in the perfect-alignment group but (B) buccolingual widths were significantly larger

2-2. Maxillary mesiodistal crown dimensions published by Norderval et al. (1975), where their sample of young adults with optimum interdigitation had smaller crown dimensions, on the average, than their other group with TSASD

2-3. Mandibular mesiodistal crown dimensions published by Norderval et al. (1975), where their sample of young adults with optimum interdigitation had smaller crown dimensions, on the average, than their other group with TSASD

2-4. Results published by Doris et al. (1981), where their sample of adolescents with little crowding had smaller mesiodistal crown dimensions, on the average, than their other group with at least 4 millimeters of crowding.....

2-5. Plot of mean mesiodistal tooth crown diameters, by sex, showing the 3 to $6 \%$ sexual dimorphism in tooth size of contemporary American whites

2-6. Summation of the 12 mesiodistal crown diameters in the maxilla (M1 through M1) in males depending on whether the person exhibited excellent occlusion or crowding....

2-7. Results published by Melo et al. (2001), where their sample of adolescents with little crowding had smaller mesiodistal primary crown dimensions, on the average, than their other group with at least 4 millimeters of crowding in the permanent dentition

2-8. Mean crown diameters (maxilla) in samples with good occlusion and with malocclusion 
2-9. Mean crown diameters (mandible) in samples with good occlusion and with malocclusion.

2-10. Summation of the 12 mesiodistal crown diameters in the maxilla (M1 through M1) in British white boys depending on whether the person exhibited "noncrowding" or crowding. 28

2-11. Summation of the 12 mesiodistal crown diameters in the maxilla (M1 through M1) in Pakistani boys living in Britain depending on whether the person exhibited "noncrowding" or crowding.

2-12. Results published by Howe et al. (1983) for boys ..................................... 42

2-13. Results published by Howe et al. (1983) for girls ....................................... 43

2-14. Schematic representation of the incisor "irregularity index" published by Little (1975). 47

4-1. Bar chart of mean tooth size by tooth type for the mesiodistal maxillary crown diameters

4-2. Bar chart of mean tooth size by tooth type for the mesiodistal mandibular crown diameters. 78

4-3. Bar chart of mean tooth size by tooth type for the buccolingual maxillary crown diameters.

4-4. Bar chart of mean tooth size by tooth type for the buccolingual mandibular crown diameters.

4-5. A schematic illustration of two complementary scenarios of how crown dimensions influence the risk of TSASD

4-6. Loadings of the 24 crown size variables on Factor I …..........................121

4-7. Loadings of the 24 crown size variables on Factor II .............................122

4-8. Loadings of the 24 crown size variables on Factor III............................123

4-9. Loadings of the 24 crown size variables on Factor IV ............................124

4-10. Loadings of the 24 crown size variables on Factor V ............................. 125

4-11. Loadings of the 24 crown size variables on Factor VI …......................... 126 
4-12. Loadings of the 24 crown size variables on Factor VII

5-1. Schematic view of the perceived relationship between tooth crown size (the normal curve) and the imposed dichotomy of those treated or untreated orthodontically because of TSASD 


\section{CHAPTER 1}

\section{INTRODUCTION}

Malocclusion is an increasingly common problem encountered in industrialized countries. Indeed, malocclusion has been described as a "disease of civilization" (Corruccini and Kaul 1984) because of its high prevalence in contemporary industrialized countries as compared to historic populations and, even, isolated cultures that continue to subsist on less-processed diets (Corruccini 1984). Skeletal remains show that the present prevalence of malocclusion is several times greater than it was as little as a millennium ago (Proffit 1999). Epidemiological estimates are that more than half of U.S. adolescents would decidedly benefit from orthodontic treatment (Kelly and Harvey 1977). These national statistics show that only about 1 in 10 American youths have naturally-occurring good occlusions. Comparably, Buschang and Schulman (2003) reported that only one-fifth of the U.S. population between 8 and 50 years of age is without some degree of incisor irregularity.

A relevant issue in this context is causation: what factors are driving this high frequency of malocclusion? There is no single cause of malocclusion; most people develop occlusal problems because of a number of interacting developmental issues (e.g., Proffit 1986; Hartsfield 2000). Research suggests that malocclusion is an environmentally-induced disease acquired during growth 
and development (e.g., Corruccini 1984, 1999). Others have shown that even when teeth erupt into proper alignment, they frequently become crowded as arch dimensions change with age (e.g., Little et al. 1981, 1988; Driscoll-Gilliland et al. 2001).

Although the causes of dental malocclusion are obscure in most instances, one contributing factor may be tooth size. Some previous studies have found the mesiodistal width of mandibular incisor teeth to be significantly greater in subjects with anterior dental crowding compared to subjects with ideal anterior alignment (Peck and Peck 1972a,b; Norderval et al. 1975; Adams 1982). In contrast, others have been unable to distinguish between crowded and noncrowded dentitions on the basis of mesiodistal tooth widths (Howe et al. 1983; Gilmore and Little 1984). To complicate matters further, Peck and Peck actually found the buccolingual width of mandibular incisors to be greater in subjects without anterior crowding. The present study tests whether tooth crown dimensions (mesiodistal and buccolingual) differ in a sample of young adults with naturally-occurring good occlusions versus a sample of otherwise similar individuals who required orthodontic treatment to correct their malocclusions. The aim was to determine whether people with bigger tooth crown diameters are at greater risk of having malocclusions assessed as tooth-size arch-size discrepancies. In testing this hypothesis, we measured tooth crown diameters from maxillary and mandibular dental casts of dental students from the College 
of Dentistry, University of Tennessee. We hypothesized that greater tooth crown dimensions would be positively related with dental crowding, and as such, positively associated with the group of students who underwent orthodontic treatment. 


\section{CHAPTER 2}

\section{REVIEW OF THE LITERATURE}

Previous authors have examined the various etiological explanations for the increasing prevalence of dental malocclusion in industrialized countries. This review focuses on several of the more prevalent causes cited in the literature today. Increased tooth size, decreased masticatory stress during development, and decreased dental arch length, are a few of the described secular changes that are investigated. Additionally, measures of dental proportionality (e.g., the Bolton index; Bolton 1962) and other potential trends, such as increased dental crowding with age, are also discussed.

\section{Increased Tooth Size Related to Dental Crowding}

Various authors have tested whether tooth size and arch length are risk factors for malocclusion. One of the first studies in the recent English literature to suggest a positive association between tooth size and malocclusion was by Peck and Peck (1972a,b). They compared two groups of young adult white females from the Northeastern United States. One group consisted of 45 subjects with "perfect" incisor alignment (no overlapping teeth or tooth rotations), while the second group consisted of 70 subjects selected without consideration for incisor alignment. No subject had received orthodontic treatment, and the two 
groups were deemed comparable with the exception of incisor alignment. The maximum mesiodistal and buccolingual dimensions of the mandibular incisors were measured directly in the mouth because the authors contend that, in most cases, the greatest buccolingual diameter is located subgingivally. This would make buccolingual measurements made on dental casts suspect (Peck 2007). Peck and Peck found that the mesiodistal diameter of the mandibular central and lateral incisors was significantly smaller in the "perfect" alignment group, while the buccolingual diameter was significantly larger (Fig. 2-1). They concluded that greater mesiodistal and, ironically, lesser buccolingual tooth dimensions appeared to be associated with a greater degree of lower incisor crowding.

Norderval et al. (1975) investigated mandibular anterior crowding in relation to mesiodistal crown widths, intercanine width, third molar presence and craniofacial morphology. Their sample consisted of 66 adults (48 males; 18 females) from 20 to 30 years of age with Angle Class I occlusions. The sample was divided into two groups based upon the presence or absence of anterior crowding: 27 subjects had sufficient or excess space, while 39 subjects had slight crowding. The mesiodistal widths of mandibular incisors were measured from plaster casts as was intercanine width (from the maximum buccal prominence of the canine crowns). Third molar presence was scored from panoramic radiographs. Various craniofacial measurements were made from lateral 


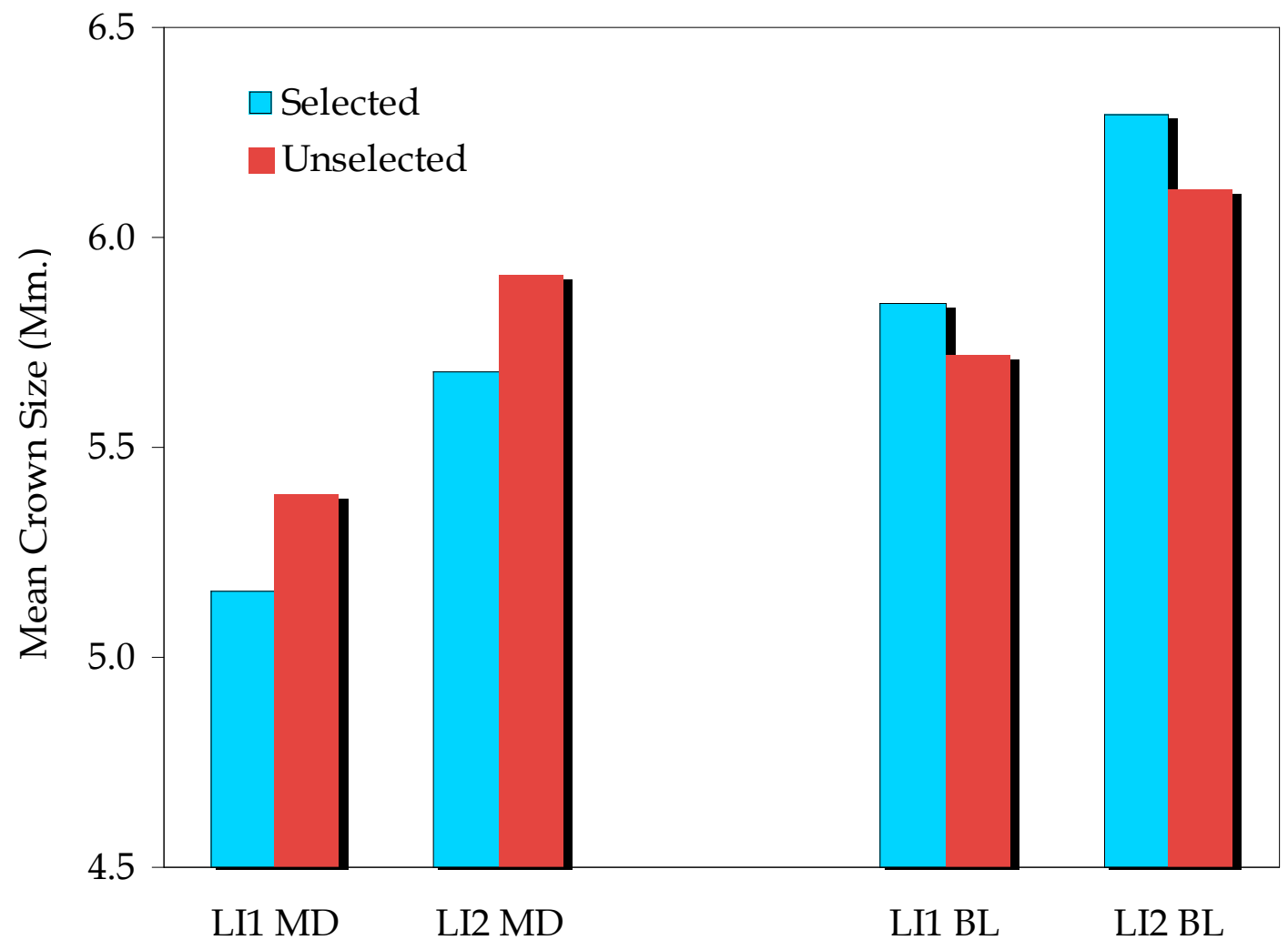

Fig. 2-1. Results published by Peck and Peck (1972) showing (A) that mesiodistal incisor diameters were significantly smaller in the perfectalignment group but (B) buccolingual widths were significantly larger.

Source: Peck S, Peck H. Crown dimensions and mandibular incisor alignment. Angle Orthod 1972;42:148-53. 
cephalometric radiographs. From among their craniofacial findings, only the basal sagittal jaw relationship (ANB angle) and the mandibular inclination (FMA) differed significantly between the groups. The group with crowding displayed a significantly greater ANB angle, and the inclination of the inferior border of the mandible in relation to the palatal plane was also greater. They found that intercanine width and the frequency of third molar presence were the same in the two groups. In the crowded group, mesiodistal widths of the four mandibular incisors were significantly greater $(\mathrm{P}<0.05)$, as was the combined width of the six mandibular anterior teeth $(\mathrm{P}<0.05)$ (Figs. 2-2 and 2-3).

Bolton's Index (Bolton 1958), which is a ratio of mandibular to maxillary tooth structure, was also affected by the "excess" mandibular tooth structure in the crowded group. Indeed, subjects in the crowded group displayed a significantly higher Bolton ratio $(\mathrm{P}<0.01)$. Despite these findings, Norderval et al. concluded that no significant association was observed between the presence or absence of mandibular anterior crowding and any of the variables studied.

Doris et al. (1981) compared mesiodistal tooth crown dimensions of orthodontically treated patients with marked dental crowding with a sample displaying little or no crowding. The patients were North American whites selected from the records of the orthodontic department at the University of Louisville, Kentucky. Eighty subjects (40 males, 40 females) ranging in age from 11 to 18 years (mean age of 14.0 years) were divided into two groups based on 


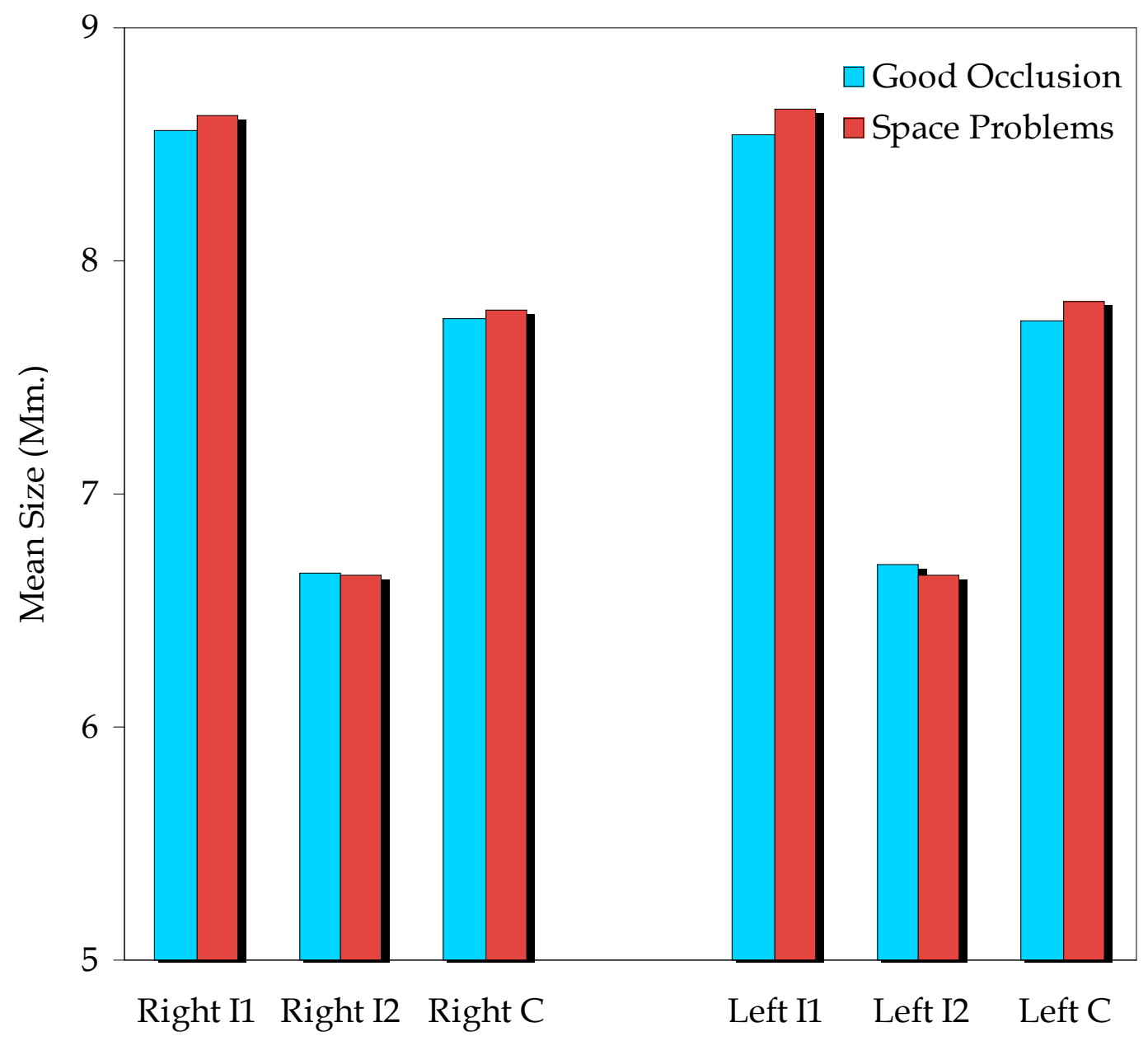

Fig. 2-2. Maxillary mesiodistal crown dimensions published by Norderval et al. (1975), where their sample of young adults with optimum interdigitation had smaller crown dimensions, on the average, than their other group with TSASD.

Source: Norderval K, Wisth PJ, Böe OE. Mandibular anterior crowding in relation to tooth size and craniofacial morphology. Scand J Dent Res 1975;83:267-73. 


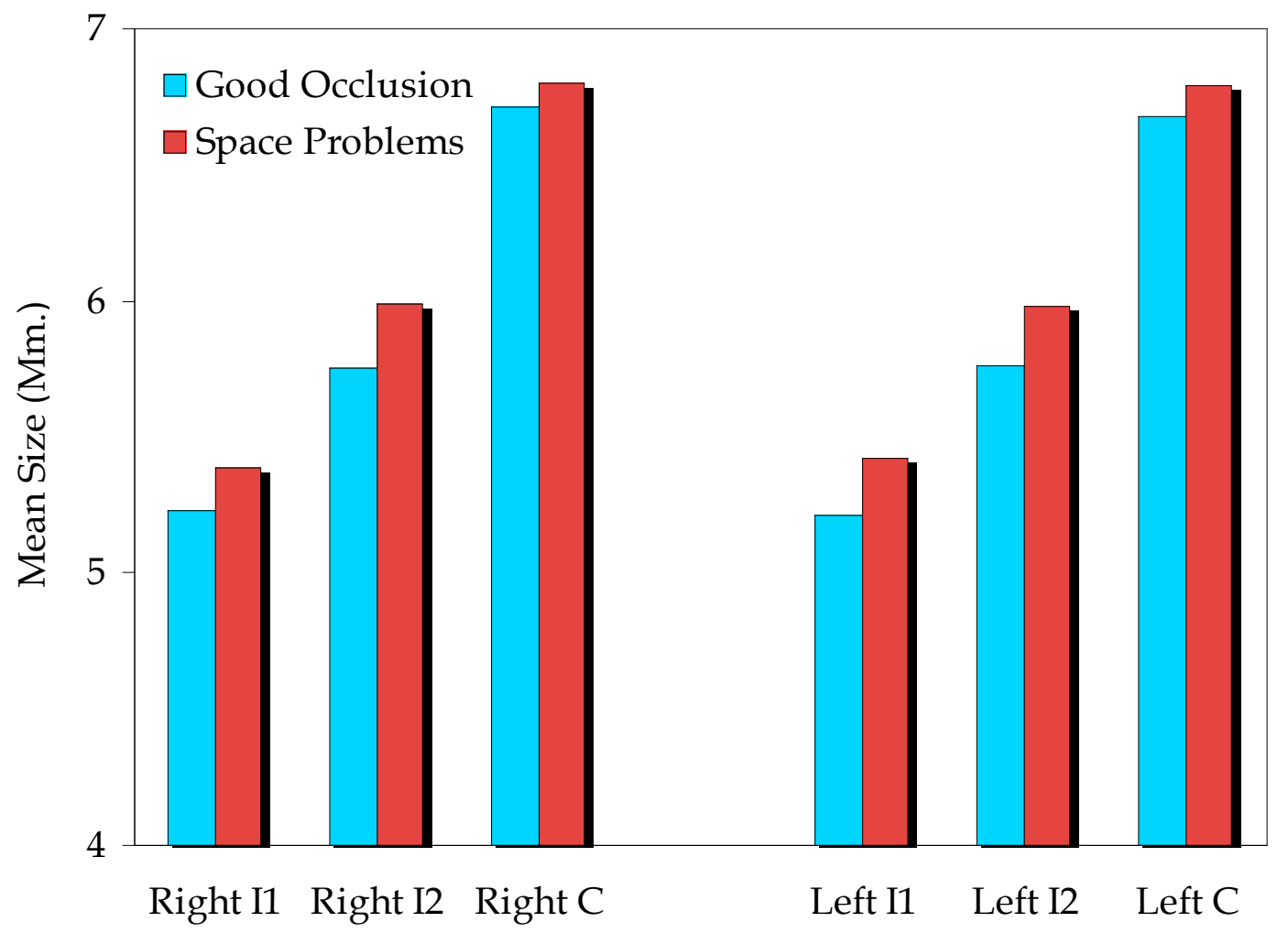

Fig. 2-3. Mandibular mesiodistal crown dimensions published by Norderval et al. (1975), where their sample of young adults with optimum interdigitation had smaller crown dimensions, on the average, than their other group with TSASD.

Source: Norderval K, Wisth PJ, Böe OE. Mandibular anterior crowding in relation to tooth size and craniofacial morphology. Scand J Dent Res 1975;83:267-73. 
the degree of dental crowding. One group consisted of individuals with up to 4 $\mathrm{mm}$ of lower anterior crowding, while the other individuals had more than $4 \mathrm{~mm}$ of lower anterior crowding. As seen in Figure 2-4 (Table 2-1), the mesiodistal crown diameters of five tooth types, from central incisor through second premolar, were each significantly larger in the crowded arches. Although their results appear significant, boys and girls were combined in their statistical tests, which probably confounded their intended test because of the well-known sexual dimorphism in human tooth dimensions (e.g., Garn et al. 1964, 1966; Lavelle 1972). An example of the larger crown dimensions characteristically found in males is shown in Figure 2-5 (Garn et al. 1967).

Adams (1982) wrote that, “Boys and girls with crowded teeth have a larger mean total tooth size than boys and girls with well arranged teeth." He investigated the relationship between cephalometric dimensions and tooth size in boys and girls from 15 to 16 years of age. The study consisted of 47 subjects with excellent occlusion and 91 with crowded dentitions. Adams analyzed lateral and posteroanterior cephalometric radiographs in addition to dental casts. Of note, he did report results separately for boys and girls. Not surprisingly, he found that girls' faces and tooth dimensions were significantly smaller than boys regardless of the presence of crowding. Most pertinently, he found that boys and girls with crowding had significantly larger teeth than those without (Fig. 2-6). 


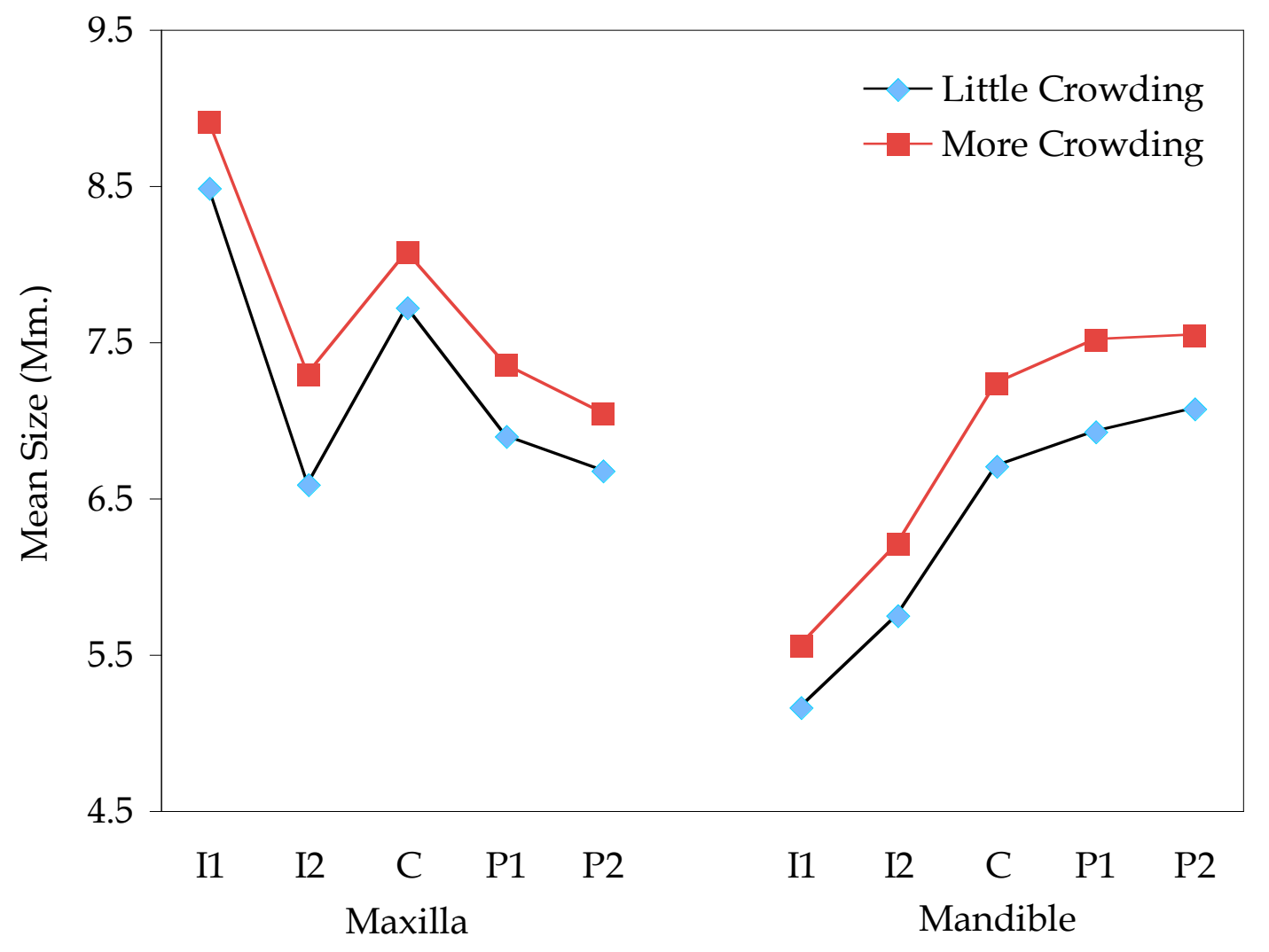

Fig. 2-4. Results published by Doris et al. (1981), where their sample of adolescents with little crowding had smaller mesiodistal crown dimensions, on the average, than their other group with at least 4 millimeters of crowding.

Source: Doris JM, Bernard BW, Kuftinec MM. A biometric study of tooth size and dental crowding. Am J Orthod 1981;79:326-36. 
Table 2-1. Comparison of mesiodistal widths of individual teeth between the two groups. ${ }^{1}$

\begin{tabular}{|c|c|c|c|c|c|c|c|c|}
\hline \multirow[b]{2}{*}{ Tooth } & \multicolumn{3}{|c|}{ Little Crowding } & \multicolumn{3}{|c|}{ More Crowding } & \multirow[b]{2}{*}{$\mathrm{t}$} & \multirow[b]{2}{*}{$\mathrm{P}$} \\
\hline & $\bar{x}$ & $\mathrm{sd}$ & range & $\bar{x}$ & sd & range & & \\
\hline \multicolumn{9}{|c|}{ Maxilla } \\
\hline I1 & 8.49 & 0.47 & $7.4-9.8$ & 8.91 & 0.48 & $8.0-10.2$ & -3.94 & 0.000 \\
\hline $\mathrm{I} 2$ & 6.59 & 0.63 & $5.3-7.8$ & 7.29 & 0.53 & $6.1-8.5$ & -5.32 & 0.000 \\
\hline C & 7.72 & 0.49 & $6.5-9.0$ & 8.07 & 0.46 & $6.9-9.4$ & -3.26 & 0.002 \\
\hline P1 & 6.90 & 0.37 & $6.1-7.7$ & 7.36 & 0.48 & $6.4-9.0$ & -4.82 & 0.000 \\
\hline P2 & 6.67 & 0.41 & $5.7-7.5$ & 7.05 & 0.42 & $6.5-8.0$ & -4.10 & 0.000 \\
\hline \multicolumn{9}{|c|}{ Mandible } \\
\hline I1 & 5.16 & 0.32 & $4.1-6.0$ & 5.56 & 0.41 & $4.9-6.8$ & -4.89 & 0.000 \\
\hline I2 & 5.75 & 0.46 & $5.0-6.9$ & 6.21 & 0.35 & $5.5-7.1$ & -5.08 & 0.000 \\
\hline C & 6.70 & 0.43 & $5.8-7.4$ & 7.23 & 0.84 & $6.0-11.6$ & -3.53 & 0.001 \\
\hline P1 & 6.92 & 0.39 & $5.9-7.8$ & 7.52 & 0.49 & $6.7-9.0$ & -6.01 & 0.000 \\
\hline P2 & 7.08 & 0.38 & $6.3-7.7$ & 7.54 & 0.39 & $6.7-8.2$ & -5.37 & 0.000 \\
\hline
\end{tabular}

${ }^{1}$ Tooth codes: I1 indicates the central incisor; I2, the lateral incisor; C, the canine; $\mathrm{P} 1$, the first premolar; and P2, the second premolar.

Source: Doris JM, Bernard BW, Kuftinec MM. A biometric study of tooth size and dental crowding. Am J Orthod 1981;79:326-36. 


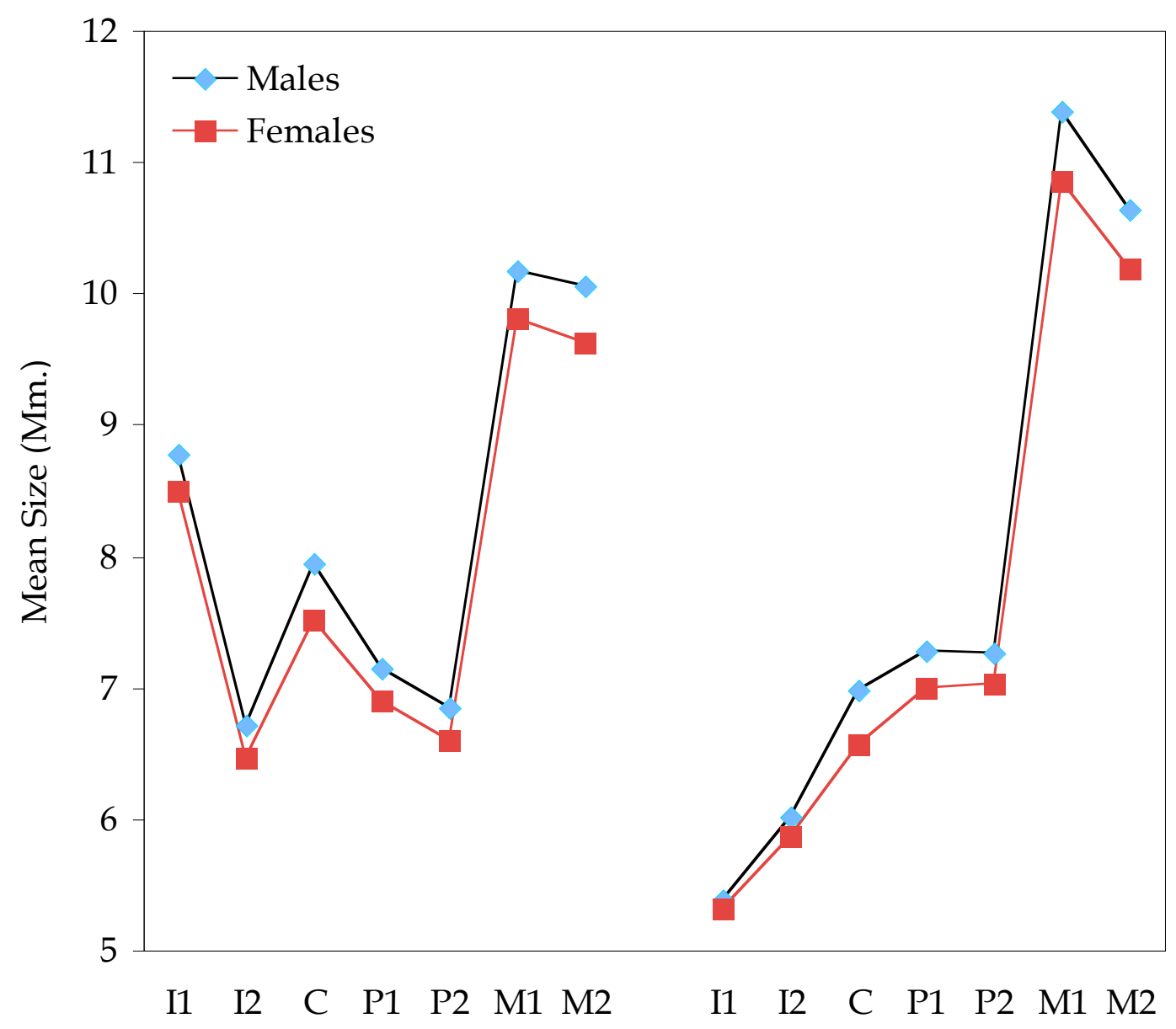

Fig. 2-5. Plot of mean mesiodistal tooth crown diameters, by sex, showing the 3 to $6 \%$ sexual dimorphism in tooth size of contemporary American whites.

Source: Garn SM, Lewis AB, Kerewsky RS. Genetic control of sexual dimorphism in tooth size. J Dent Res 1967;46:963-72. 


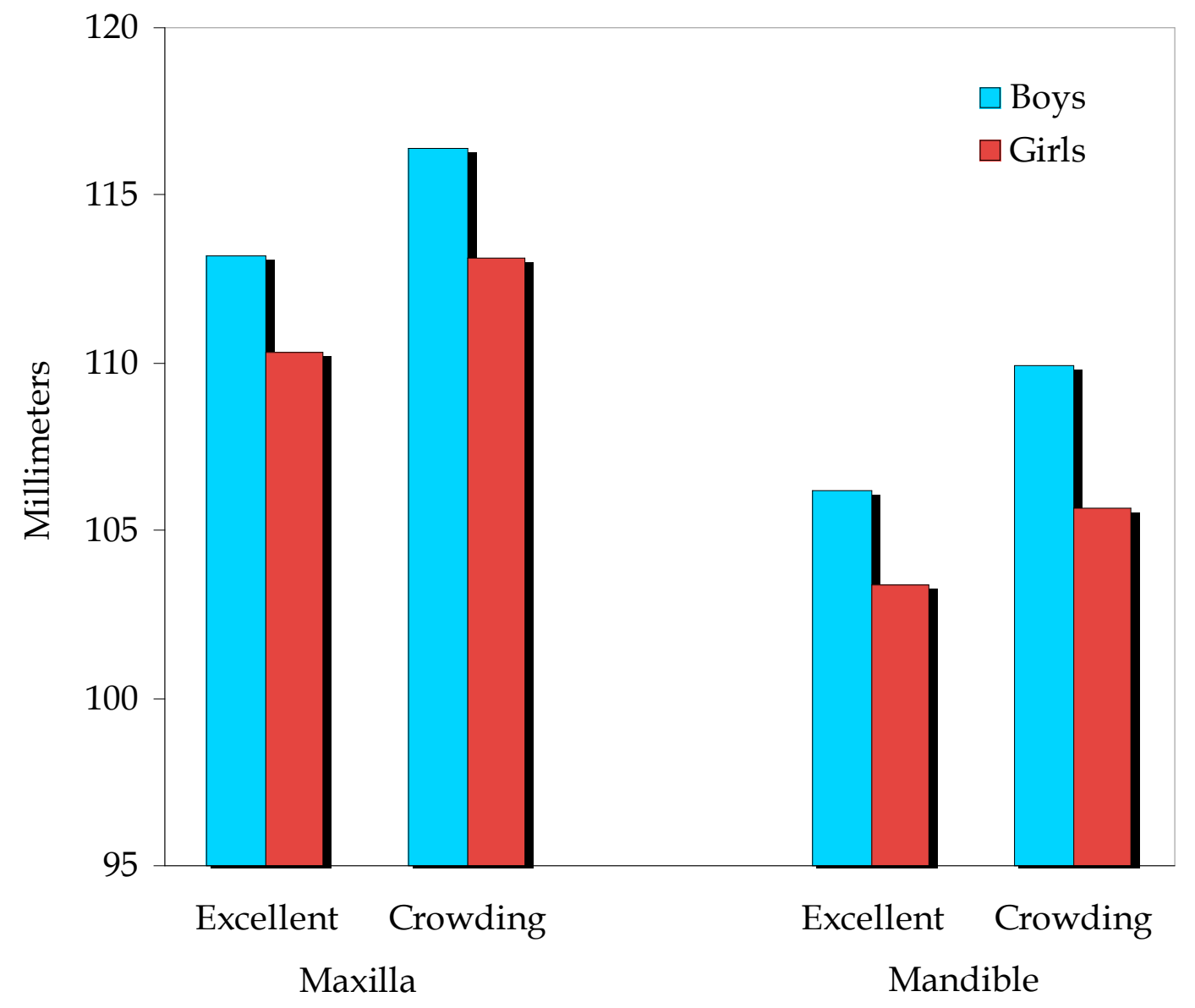

Fig. 2-6. Summation of the 12 mesiodistal crown diameters in the maxilla (M1 through M1) in males depending on whether the person exhibited excellent occlusion or crowding. Differences between groups were significant statistically.

Source: Adams CP. A comparison of 15 year old children with excellent occlusion and with crowding of the teeth, Angle Class I malocclusion, in respect of face size and shape and tooth size. Swed Dent J Suppl 1982;15:11-26. 
Unfortunately, Adams did not mention where in the arch crowding was located or how much was present.

Looking at the problem of dental crowding in a different way, McCann and Burden (1996) investigated the role of tooth size in the etiology of bimaxillary dental protrusion. They compared two groups of white Northern Irish people, one with bimaxillary protrusion and one without. Both groups consisted of 30 subjects (14 males, 16 females) with an average age of 12.8 years and 14.3 years, respectively. Bimaxillary protrusion was determined by analysis of pretreatment cephalometric radiographs and was defined by an interincisal angle less than $125^{\circ}$, maxillary incisors proclined beyond $115^{\circ}$ relative to the palatal plane, and mandibular incisors proclined beyond $99^{\circ}$ relative to the mandibular plane. In passing, another difference in this study was that mesiodistal measurements of all teeth from first molar to first molar were made with a Baker Vernier microscope rather than calipers. They found that individuals exhibiting bimaxillary protrusion had 5.7\% larger teeth (from first molar to first molar) than those without protrusion. McCann and Burden concluded that although tooth size may play a part, the etiology of bimaxillary protrusion is complex, but, evidently, tooth size was a discernible risk factor.

Melo et al. (2001) compared two groups of Japanese children distinguished by their degree of crowding in the primary dentition (5 years of age). Their subjects $(n=23)$ were selected from the Growth Study of Twins of the 
Department of Pediatric Dentistry at the Tokyo Medical and Dental University. The mesiodistal dimensions of maxillary and mandibular teeth and arch length were measured from dental casts. Applying Little's irregularity index (Little 1975), 11 subjects were assigned to their "crowded" group (irregularity index greater than $4.0 \mathrm{~mm}$ ), while 12 subjects comprised their normal group (irregularity index less than $2.0 \mathrm{~mm}$ ). The subjects were evaluated again at 9 years of age in the mixed dentition. They found that the crowded group remained "crowded" while the normal group remained "normal." As depicted in Table 2-2, Melo et al. found statistically significant differences between the two groups in the average mesiodistal diameter of the maxillary primary first molar, canine and lateral incisor as well as the mandibular primary second molar, canine and central incisor (Fig. 2-7).

Hashim and Al-Ghamdi (2005) compared mesiodistal crown diameters and arch dimensions between "normal" and "malocclusion" samples. Their subjects consisted of 120 pairs of dental casts from Saudi orthodontic patients (ages 15 to 25 years). The sample was divided into 30 pairs each of Class I normal occlusion, Class I malocclusion, Class II malocclusion, and Class III malocclusion. Males and females were equally distributed. From dental casts, they measured mesiodistal tooth width (from first molar to first molar), intercanine width, intermolar width and arch length (distance from the distal surface of the second premolar to the mesial surface of the central incisor). As 
Table 2-2. Comparison of individual teeth between the two groups (mesiodistal width, in $\mathrm{mm}$ ). ${ }^{1}$

\begin{tabular}{|c|c|c|c|c|}
\hline \multirow[b]{2}{*}{ Tooth } & \multicolumn{2}{|c|}{ Normal } & \multicolumn{2}{|c|}{ Crowded } \\
\hline & $\overline{\mathrm{x}}$ & $\mathrm{sd}$ & $\overline{\mathrm{x}}$ & $\mathrm{sd}$ \\
\hline & \multicolumn{2}{|c|}{ Maxilla } & & \\
\hline A & 6.3 & 0.4 & 6.6 & 0.3 \\
\hline B & 5.2 & 0.3 & 5.5 & $0.4^{*}$ \\
\hline C & 6.2 & 0.3 & 6.7 & $0.3^{*}$ \\
\hline D & 7.0 & 0.3 & 7.3 & $0.3^{*}$ \\
\hline \multirow[t]{2}{*}{ E } & 9.2 & 0.3 & 9.5 & 0.5 \\
\hline & \multicolumn{2}{|c|}{ Mandible } & & \\
\hline A & 3.9 & 0.2 & 4.1 & $0.3^{*}$ \\
\hline B & 4.5 & 0.3 & 4.7 & 0.4 \\
\hline C & 5.6 & 0.4 & 5.9 & $0.3^{*}$ \\
\hline $\mathrm{D}$ & 7.8 & 0.3 & 8.1 & 0.4 \\
\hline E & 10.1 & 0.4 & 10.5 & $0.3^{*}$ \\
\hline
\end{tabular}

${ }^{1}$ Tooth codes: $\mathrm{E}$ represents the second primary molar; $\mathrm{D}$, the first primary molar; $\mathrm{C}$, the primary canine; $\mathrm{B}$, the primary lateral incisor; and $\mathrm{A}$, the primary central incisor. $* \mathrm{P}<0.05$

Source: Melo L, Ono Y, Takagi Y. Indicators of mandibular dental crowding in the mixed dentition. Pediatr Dent 2001;23:118-22. 


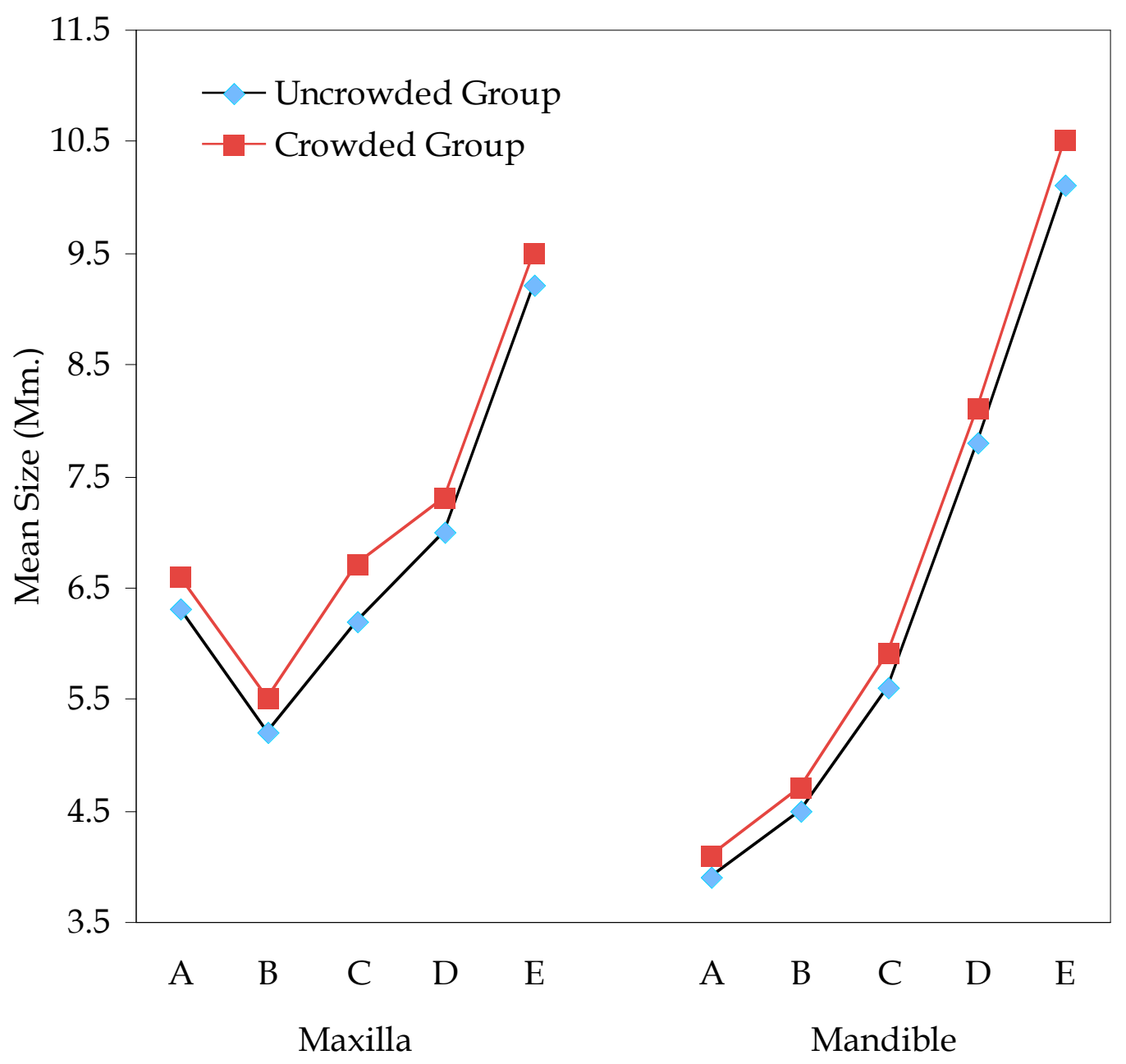

Fig. 2-7. Results published by Melo et al. (2001), where their sample of adolescents with little crowding had smaller mesiodistal primary crown dimensions, on the average, than their other group with at least 4 millimeters of crowding in the permanent dentition.

Source: Melo L, Ono Y, Takagi Y. Indicators of mandibular dental crowding in the mixed dentition. Pediatr Dent 2001;23:118-22. 
indicated in Tables 2-3 and 2-4, Hashim and Al-Ghamdi found a significant difference between normal occlusion and malocclusion groups in mesiodistal tooth widths. In the malocclusion group, the mesiodistal width of the upper and lower central incisors, lower left lateral incisor, and lower first molars were significantly larger than in the normal occlusion group (Figs. 2-8 and 2-9). However, as seen in Table 2-5, they did not find a significant difference in arch dimensions between the groups. Not surprisingly, they also found significantly larger mesiodistal tooth widths and significantly greater arch dimensions in males compared to females. Evidently their reliance on two-sample t-tests prevented them from simultaneously testing for group differences while controlling for the well-known sex difference. As it stands, sex differences in tooth size confounds their tests between groups.

In a slightly different approach, Bernabé and Flores-Mir (2006) used a multivariate analysis of variance (MANOVA) to compare the mesiodistal and buccolingual crown dimensions in crowded versus noncrowded dentitions. They compared crown dimensions (from first molar to first molar) in the permanent dentition of 200 school children from Lima, Peru (12 to 16 years of age). Mesiodistal and buccolingual crown dimensions were measured in dental arches with moderate, mild, and no crowding. Additionally, they analyzed crown proportions as a ratio of mesiodistal to buccolingual tooth structure (MD/BL ratio). The authors found a significantly greater overall mesiodistal 
Table 2-3. Comparison of mesiodistal tooth widths between normal occlusion and malocclusion (sexes pooled) in the upper jaw. ${ }^{1}$

\begin{tabular}{|c|c|c|c|c|c|c|c|c|}
\hline \multirow[b]{2}{*}{ Tooth } & \multicolumn{3}{|c|}{$\underline{\text { Normal Occlusion }}$} & \multicolumn{3}{|c|}{ Malocclusion } & \multirow[b]{2}{*}{$\mathrm{t}$} & \multirow[b]{2}{*}{$\mathrm{P}$} \\
\hline & $\mathrm{n}$ & $\bar{x}$ & $\mathrm{sd}$ & $\mathrm{n}$ & $\bar{x}$ & $\mathrm{sd}$ & & \\
\hline \multicolumn{9}{|c|}{ Right Side } \\
\hline 1 & 30 & 8.44 & 0.56 & 90 & 8.78 & 0.54 & 2.96 & $\underline{0.003}$ \\
\hline 2 & 30 & 6.60 & 0.51 & 90 & 6.79 & 0.55 & 1.70 & 0.091 \\
\hline 3 & 30 & 7.79 & 0.43 & 90 & 7.74 & 0.52 & -0.47 & 0.640 \\
\hline 4 & 30 & 6.93 & 0.48 & 90 & 6.92 & 0.37 & -0.07 & 0.945 \\
\hline 5 & 30 & 6.49 & 0.41 & 90 & 6.43 & 0.45 & -0.70 & 0.488 \\
\hline 6 & 30 & 10.16 & 0.53 & 90 & 10.09 & 0.62 & -0.52 & 0.601 \\
\hline \multicolumn{9}{|c|}{ Left Side } \\
\hline 1 & 30 & 8.35 & 0.51 & 90 & 8.79 & 0.53 & 3.99 & $\underline{0.000}$ \\
\hline 2 & 30 & 6.54 & 0.43 & 90 & 6.78 & 0.62 & 1.97 & 0.051 \\
\hline 3 & 30 & 7.68 & 0.44 & 90 & 7.71 & 0.57 & 0.26 & 0.797 \\
\hline 4 & 30 & 6.92 & 0.46 & 90 & 6.95 & 0.43 & 0.35 & 0.730 \\
\hline 5 & 30 & 6.43 & 0.46 & 90 & 6.46 & 0.43 & 0.31 & 0.756 \\
\hline 6 & 30 & 10.12 & 0.60 & 90 & 10.07 & 0.60 & -0.40 & 0.687 \\
\hline
\end{tabular}

1Tooth codes: 6 indicates the first molar; 5 , the second premolar; 4 , the first premolar; 3 , the canine; 2 , the lateral incisor; and 1, the central incisor.

Source: Hashim HA, Al-Ghamdi S. Tooth width and arch dimensions in normal and malocclusion samples: an odontometric study. J Contemp Dent Pract 2005;6:36-51. 
Table 2-4. Comparison of mesiodistal tooth widths between normal occlusion and malocclusion (sexes pooled) in the lower jaw.

\begin{tabular}{|c|c|c|c|c|c|c|c|c|}
\hline \multirow[b]{2}{*}{ Tooth } & \multicolumn{3}{|c|}{ Normal Occlusion } & \multicolumn{3}{|c|}{ Malocclusion } & \multirow[b]{2}{*}{$\mathrm{t}$} & \multirow[b]{2}{*}{$\mathrm{P}$} \\
\hline & $\mathrm{n}$ & $\overline{\mathrm{x}}$ & $\mathrm{sd}$ & $\mathrm{n}$ & $\bar{x}$ & $\mathrm{sd}$ & & \\
\hline \multicolumn{9}{|c|}{ Right Side } \\
\hline 1 & 30 & 5.21 & 0.31 & 90 & 5.46 & 0.37 & 3.32 & $\underline{0.001}$ \\
\hline 2 & 30 & 5.77 & 0.42 & 90 & 5.91 & 0.42 & 1.62 & 0.109 \\
\hline 3 & 30 & 6.68 & 0.44 & 90 & 6.71 & 0.51 & 0.32 & 0.749 \\
\hline 4 & 30 & 6.86 & 0.43 & 90 & 7.01 & 0.43 & 1.67 & 0.119 \\
\hline 5 & 30 & 6.84 & 0.56 & 90 & 6.93 & 0.59 & 0.76 & 0.452 \\
\hline 6 & 30 & 10.67 & 0.57 & 90 & 10.97 & 0.66 & 2.29 & $\underline{0.024}$ \\
\hline \multicolumn{9}{|c|}{ Left Side } \\
\hline 1 & 30 & 5.21 & 0.33 & 90 & 5.45 & 0.33 & 3.59 & $\underline{0.000}$ \\
\hline 2 & 30 & 5.76 & 0.41 & 90 & 5.96 & 0.42 & 2.28 & $\underline{0.025}$ \\
\hline 3 & 30 & 6.78 & 0.48 & 90 & 6.77 & 0.47 & -0.13 & 0.896 \\
\hline 4 & 30 & 6.91 & 0.43 & 90 & 7.05 & 0.45 & 1.46 & 0.147 \\
\hline 5 & 30 & 7.00 & 0.45 & 90 & 6.90 & 0.68 & -0.90 & 0.373 \\
\hline 6 & 30 & 10.79 & 0.56 & 90 & 11.12 & 0.64 & 2.55 & $\underline{0.012}$ \\
\hline
\end{tabular}

Source: Hashim HA, Al-Ghamdi S. Tooth width and arch dimensions in normal and malocclusion samples: an odontometric study. J Contemp Dent Pract 2005;6:36-51. 


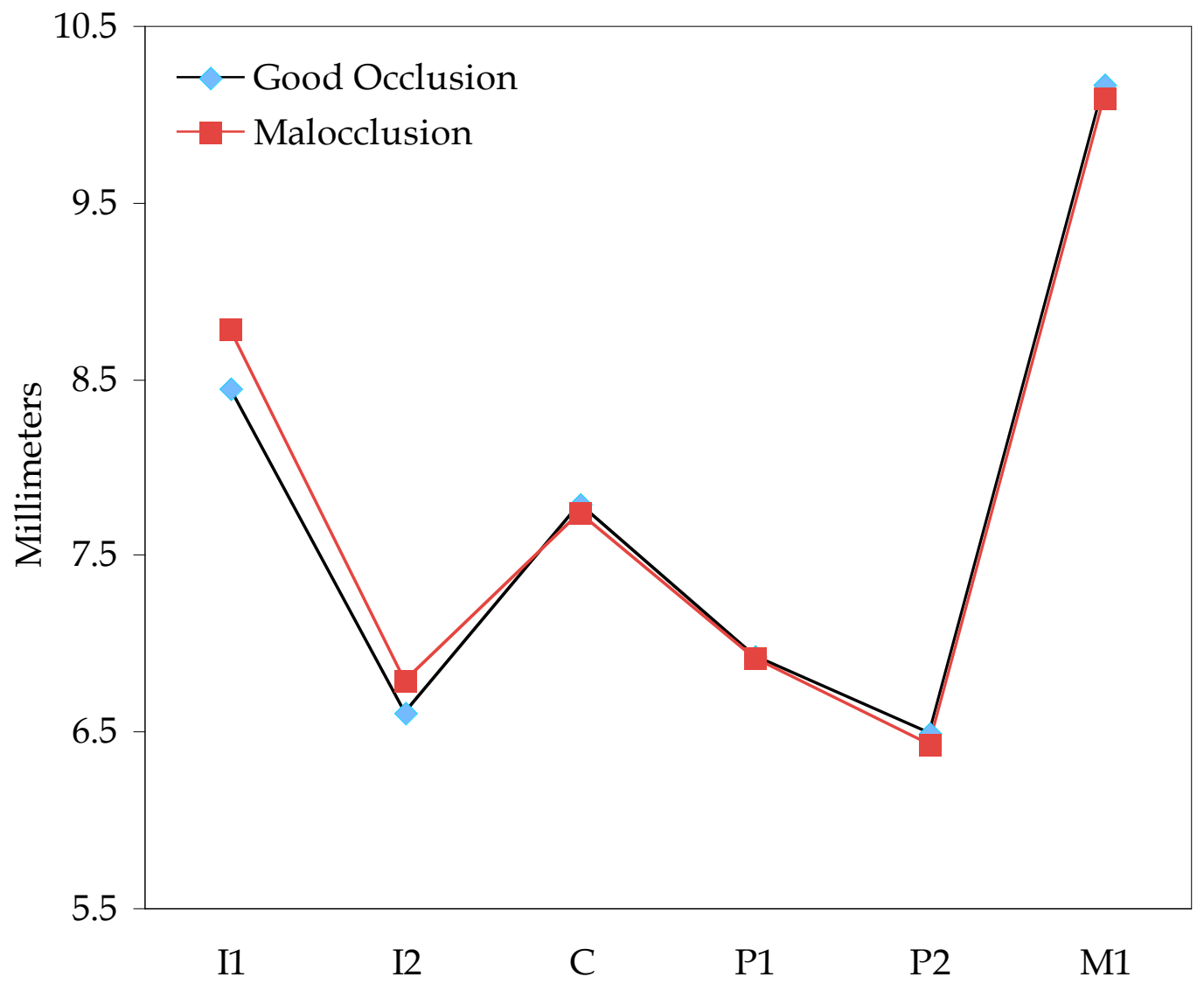

Fig. 2-8. Mean crown diameters (maxilla) in samples with good occlusion and with malocclusion. Samples are composites of males and females.

Source: Hashim HA, Al-Ghamdi S. Tooth width and arch dimensions in normal and malocclusion samples: an odontometric study. J Contemp Dent Pract 2005;6:36-51. 


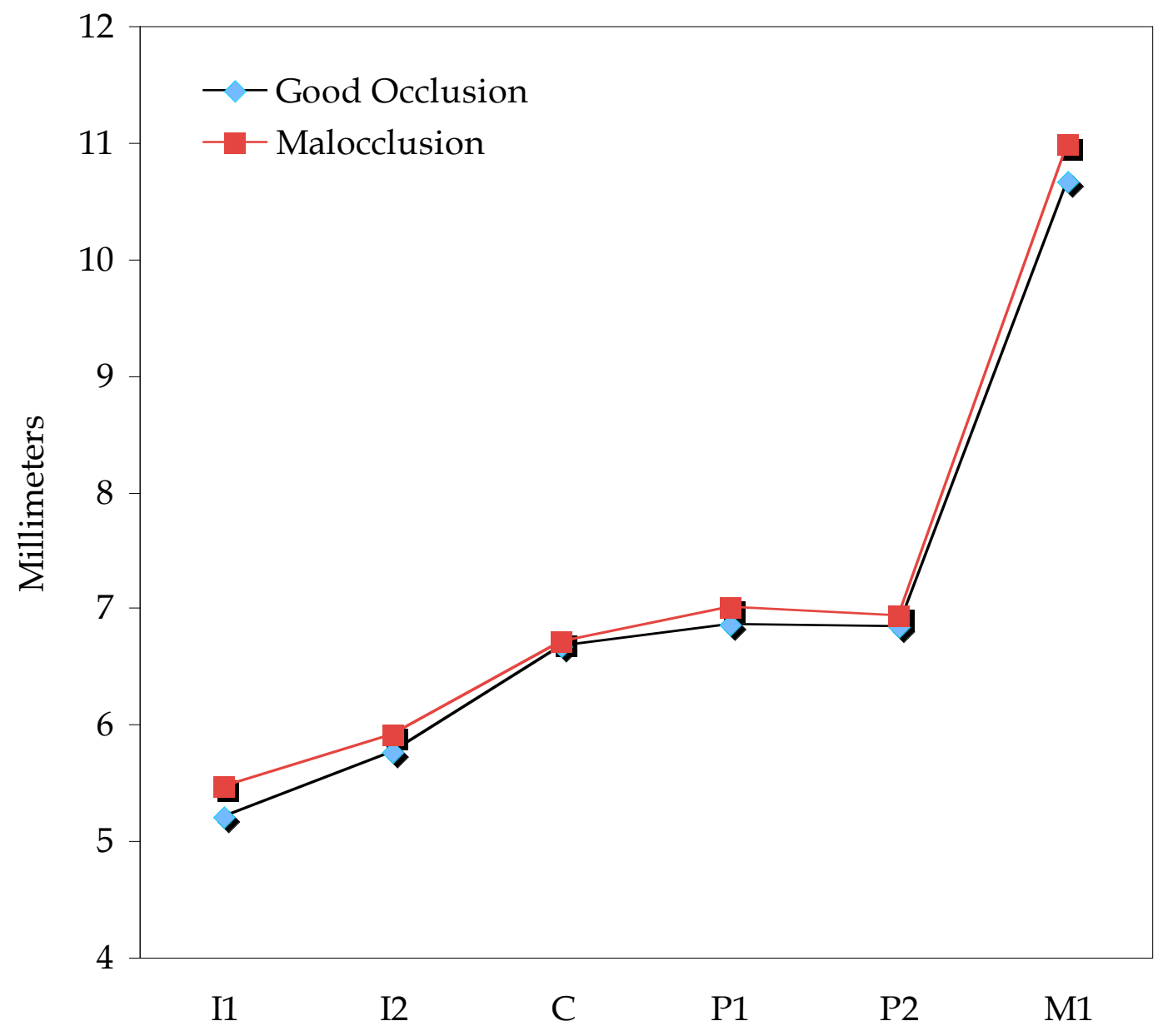

Fig. 2-9. Mean crown diameters (mandible) in samples with good occlusion and with malocclusion. Samples are composites of males and females.

Source: Hashim HA, Al-Ghamdi S. Tooth width and arch dimensions in normal and malocclusion samples: an odontometric study. J Contemp Dent Pract 2005;6:36-51. 
Table 2-5. Statistical comparison for arch dimensions between normal occlusion and malocclusion (sexes pooled).

\begin{tabular}{|c|c|c|c|c|c|c|c|c|}
\hline \multirow[b]{2}{*}{ Tooth } & \multicolumn{3}{|c|}{ Normal Occlusion } & \multicolumn{3}{|c|}{ Malocclusion } & \multirow[b]{2}{*}{$\mathrm{t}$} & \multirow[b]{2}{*}{$\mathrm{P}$} \\
\hline & $\mathrm{n}$ & $\overline{\mathrm{x}}$ & $\mathrm{sd}$ & $\mathrm{n}$ & $\bar{x}$ & $\overline{\mathrm{sd}}$ & & \\
\hline \multicolumn{9}{|c|}{ Maxilla } \\
\hline Intercanine width & 30 & 33.91 & 2.08 & 90 & 33.02 & 2.62 & -1.69 & 0.094 \\
\hline Intermolar width & 30 & 46.16 & 2.53 & 90 & 45.06 & 3.46 & -1.86 & 0.067 \\
\hline Arch length & 30 & 73.32 & 3.49 & 90 & 73.14 & 4.20 & -0.20 & 0.839 \\
\hline \multicolumn{9}{|c|}{ Mandible } \\
\hline Intercanine width & 30 & 26.1 & 1.84 & 90 & 25.22 & 2.33 & -1.90 & 0.061 \\
\hline Intermolar width & 30 & 40.27 & 2.49 & 90 & 40.32 & 3.08 & 0.08 & 0.938 \\
\hline Arch length & 30 & 63.81 & 3.55 & 90 & 63.69 & 3.11 & -0.19 & 0.850 \\
\hline
\end{tabular}

Source: Hashim HA, Al-Ghamdi S. Tooth width and arch dimensions in normal and malocclusion samples: an odontometric study. J Contemp Dent Pract 2005;6:36-51. 
tooth size (summing the mesiodistal widths of six teeth from central incisor to first molar) in the dental arches with more crowding. Interestingly, no difference was reported for the buccolingual crown dimensions. Since the buccolingual dimension showed no difference between crowded and noncrowded dentitions, it is not surprising that they found the maxillary canine, lateral incisor, second premolar, and the mandibular canine to be significantly wider (in terms of the $\mathrm{MD} / \mathrm{BL}$ ratio) as crowding increased.

\section{Tooth Size Independent of Dental Crowding}

In contrast to the findings reviewed in the prior section, the opposite results have been reported in several other studies. Gilmore and Little (1984) tested the relationship between mandibular arch alignment and mandibular incisor dimensions. Their sample consisted of 164 patients from the orthodontic department at the University of Washington, Seattle, 134 of whom had been orthodontically treated and were a minimum of 10 years postretention. The 30 remaining cases had been treated with four premolar extractions without orthodontic treatment. All cases were selected without regard for pretreatment or long-term incisor alignment. They measured buccolingual and mesiodistal crown diameters of the mandibular four incisors and compared these individually and also as a composite $\mathrm{MD} / \mathrm{BL}$ ratio in crowded versus noncrowded dentitions (methods similar to the study by Bernabé and Flores- 
Mir). They found a statistically but not clinically significant association $(r=0.30)$ between the mesiodistal width of mandibular incisors and the degree of longterm crowding. That is, only $9 \%$ of the variation in incisor irregularity could be explained by the mesiodistal incisor dimension. Looking at the MD/BL ratio, the correlation was even less $(r=0.24)$. No buccolingual dimension was significantly associated with crowding. Again, all but 30 of the subjects in this study were orthodontic patients.

Radnzic (1988) tested the relationship between mesiodistal crown width, arch dimension, and the degree of crowding. His randomly selected subjects consisted of 30 British boys and 30 Pakistani boys living in Rochdale, England, who ranged in age from 13 to 16 years. All permanent teeth were present with the exception of second and third molars, and no subject had a history of orthodontic treatment. Mesiodistal crown width (summed from first molar to first molar), arch width, and arch length were measured from dental casts. Arch perimeter was calculated by the formula:

$$
\text { Arch perimeter }=2 \sqrt{y^{2}+\left(4 x^{2} / 3\right)}
$$

where $\mathrm{x}=$ arch length and $\mathrm{y}=$ mean intermolar width divided by two.

Arch width was measured from the distal surfaces of the lateral incisors as well as between first molars. Arch length was measured in chords from the central incisor contact point to a line joining the distal surfaces of the first permanent molars. The two ethnic groups were further divided into two groups based on 
the presence or absence of dental crowding. In both groups, Radnzic found that decreases in arch length and arch perimeter were significantly related to dental crowding $(\mathrm{P}<0.001)$. In contrast, he did not find a significant association between mesiodistal tooth dimensions and dental crowding (Figs. 2-10 and 2-11).

Corruccini (1990) conducted a longitudinal study of 50 sets of Australian aboriginal dentitions (25 male) to see what role attrition played in tooth-arch discrepancies and to investigate Begg's theory (Begg 1954). Corruccini studied a tribe of contemporary aboriginals (the Yuendumu) who were provisioned by the government with rations consisting mostly of flour and sugar, and consequently did not show the advanced attrition of previous aboriginal groups. Dental casts were available from the mixed and permanent dentitions allowing longitudinal comparisons to be made. Corruccini found that absolutely or relatively bigger teeth did not relate to crowding in general or to crowding during developmental stages. He was unable to reproduce many of the major findings of the model proposed by Begg (1954). In fact, he suggested that Begg likely selected cases of unusually large unworn teeth and unusually small worn teeth. Corruccini concluded that small jaws rather than large teeth were more likely responsible for dental crowding.

Seipel (1946) investigated changes that accompanied development of the dentition and growth of the jaws in the deciduous and permanent dentitions. 


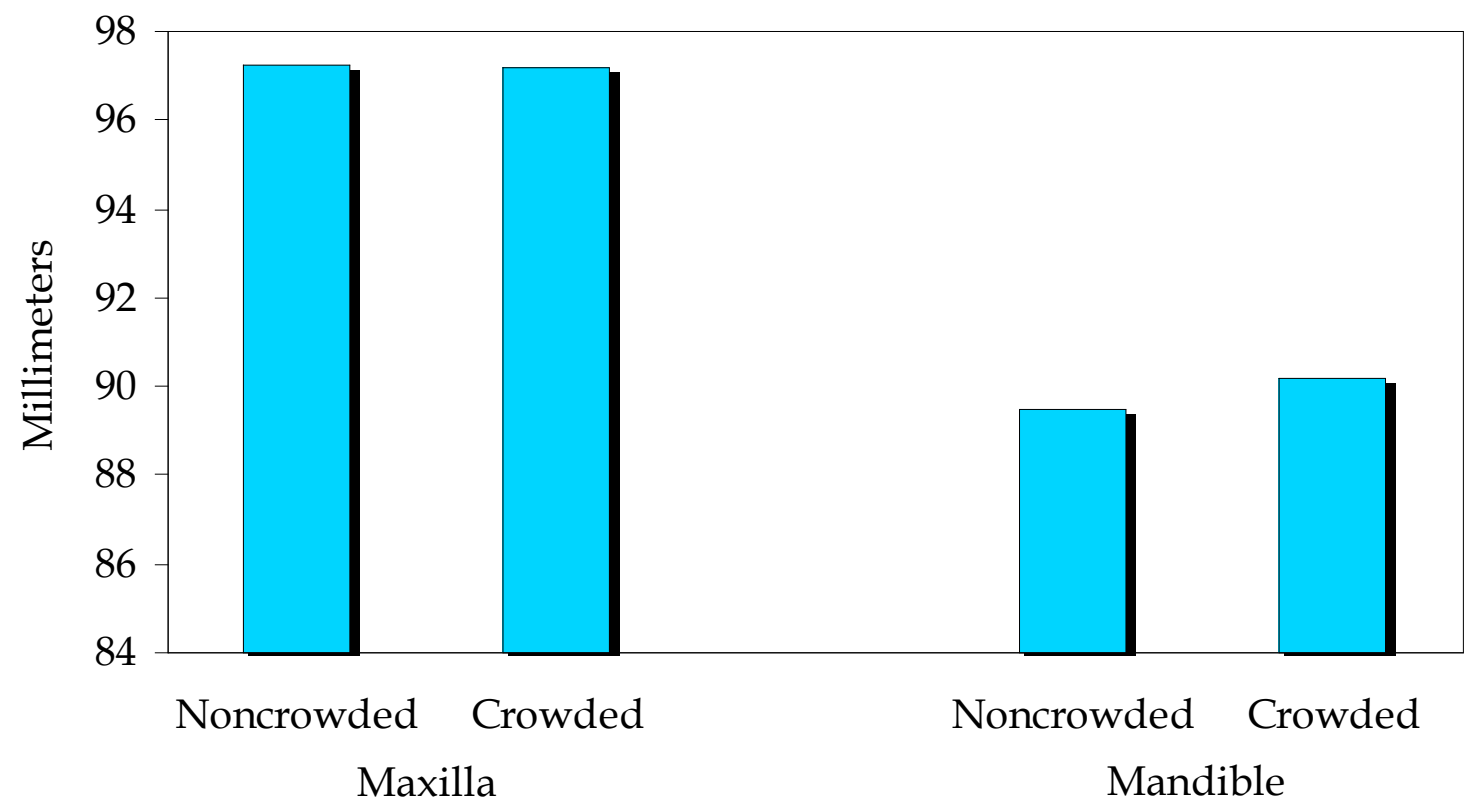

Fig. 2-10. Summation of the 12 mesiodistal crown diameters in the maxilla (M1 through M1) in British white boys depending on whether the person exhibited "noncrowding" or crowding. Differences between groups were not significant statistically.

Source: Radnzic D. Dental crowding and its relationship to mesiodistal crown diameters and arch dimensions. Am J Orthod Dentofacial Orthop 1988;94:50-6. 


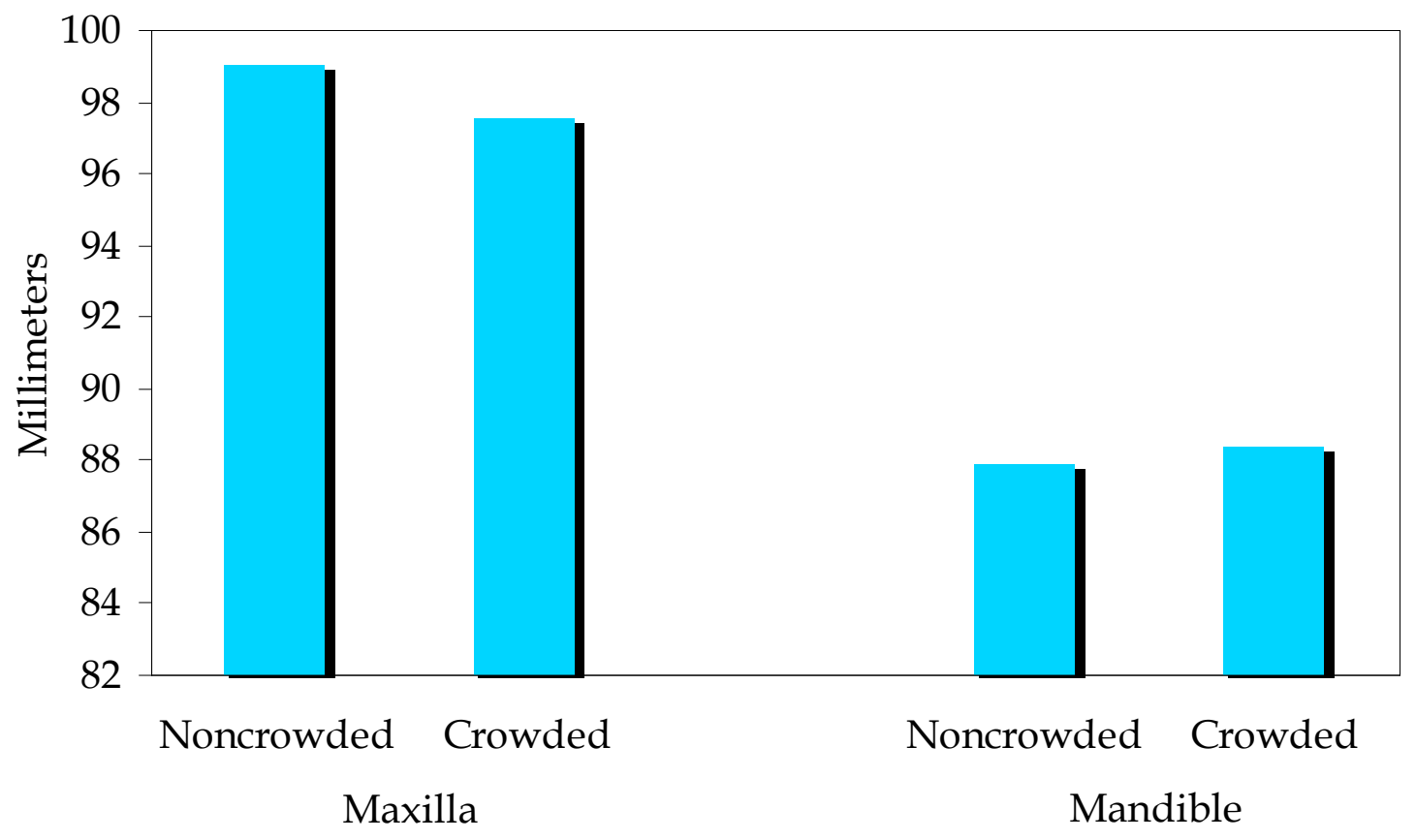

Fig. 2-11. Summation of the 12 mesiodistal crown diameters in the maxilla (M1 through M1) in Pakistani boys living in Britain depending on whether the person exhibited "noncrowding" or crowding. Differences between groups were not significant statistically.

Source: Radnzic D. Dental crowding and its relationship to mesiodistal crown diameters and arch dimensions. Am J Orthod Dentofacial Orthop 1988;94:50-6. 
His sample included 1,500 subjects from Stockholm, Sweden. Data were collected cross-sectionally from individuals at 4, 13, and 21 years of age (500 subjects in each age group, with nearly equal distribution of males and females). The 4 year-old subjects consisted of children from the Eastman Institute in Stockholm who had been treated for dental caries but had not received orthodontic treatment. They were selected to demonstrate the position of the teeth in the deciduous dentition. Subjects in the 13 year-old group were examined at municipal schools in Stockholm and were selected with regard to the positional conditions of the teeth during development of the permanent bite. In essence, the deciduous teeth had been replaced by permanent ones, but the jaws were not fully developed. As such, it could be inferred whether the position of the teeth changed during continued development of the jaws. Five males and three females in this group had received limited orthodontic treatment. The 21 year-old group was chosen to represent the fully-developed permanent dentition. The males in this group were conscripts of the navy, while the females were selected from a population of post office employees, nurses, and students. Six females in this group had a history of orthodontic treatment. Seipel made about 50 measurements on each case including measurements related to tooth size, tooth position, transverse dimensions of the dental arch, arch length, interarch relations, and cephalometric measurements. Although his findings were extensive, our focus is specifically directed to his findings 
regarding the relationship between the position of the teeth and the size of the teeth and jaws. Looking at the effect of tooth width on the position of the teeth, Seipel compared the mesiodistal widths of deciduous and permanent mandibular incisors. He found that (between the ages of 4 and 13) the combined mesiodistal width of the incisors increased by $30 \%$, the degree of spacing decreased by over $50 \%$, and the frequency of lower anterior crowding increased by $37 \%$. He stated, however, that the difference in the size of the incisor teeth was only one of the changes that distinguished the deciduous from the permanent dentition. He also found that, while the total tooth material increased by $65 \%$, the jaw size increased by only $20 \%$ from 4 to 13 years and by $30 \%$ from 4 to 21 years. He stated that the difference in the dimensional changes between the tooth and jaw materials is of considerable importance in the positional changes of the teeth. Interestingly, comparing the mesiodistal widths of incisors, he found that the association between large teeth and crowding was weaker than the association between small teeth and spacing. In contrast, in subjects with crowding, he found that $53 \%$ had incisors with mesiodistal widths greater than the mean value, while $47 \%$ had widths below the mean. Whereas, in subjects with spacing, $72 \%$ had incisors with mesiodistal widths less than the mean value and $28 \%$ had widths greater than the mean. A comparison of cephalometric measures (porion to infraorbital point) disclosed that the jaw size is at the same time considerably smaller in cases with crowding. For instance, in 13 year-old 
males, the distance from porion to infraorbital point measured $75.0 \mathrm{~mm}$ in crowded subjects as opposed to $77.4 \mathrm{~mm}$ in subjects with spacing. Unfortunately, Seipel did not say if this finding was statistically significant. Seipel concluded that the divergence between tooth size and jaw size was encountered more extensively in cases of spacing and crowding than in cases with normal alignment of the incisors.

Shah et al. (2003) tested whether mandibular incisor crown shape was correlated with dental crowding, as suggested by Peck and Peck (1972a). Their sample consisted of 50 white subjects ( 25 males, 25 females) with comparable age among males and females (range from 17 to 29 years). All permanent teeth were present except third molars, and no subject had a history of orthodontic treatment. Subjects were dental students or staff members of the orthodontic department of the Charles Clifford Dental Hospital in Sheffield, United Kingdom. Using a fine metal file, the authors reduced the mandibular dental casts perpendicular to the long axes of the teeth down to the incisal-most proximal contact points, and subsequently reduced the casts down to their coronal midpoints. The dental casts were imaged with a digital camera, and measurements were made from these images. In this way, the mesiodistal crown diameters of the mandibular central and lateral incisors could be measured from the most incisal contact points as well as from the midpoint of the clinical crowns. Mandibular crowding was measured using Little's irregularity index 
and anterior tooth-size arch-size discrepancy (TSASD). They found that males exhibited greater incisor irregularity than females (mean of $5.8 \mathrm{~mm}$ compared to $4.2 \mathrm{~mm})$; however, this difference was not significant $(P=0.07)$. Likewise, the anterior TSASD was also greater in males than in females $(P=0.06)$. Incisor crown shape (MD/BL) was not significantly related to the crowding index in males. In females, the anterior TSASD was significantly related to the incisor $\mathrm{MD} / \mathrm{BL}$ ratio $(\mathrm{r}=0.55)$; however, the irregularity index was not significantly associated with the incisor $\mathrm{MD} / \mathrm{BL}$ ratio. The authors concluded that no predictor of lower incisor crowding could be established from mandibular incisor mesiodistal or buccolingual crown dimensions.

Tsai (2003) compared dental arch size, mesiodistal and buccolingual crown diameters, and crown shape (i.e., mesiodistal crown width divided by buccolingual crown width) in two groups of Taiwanese children in the primary dentition. Children with anterior crowding in both dental arches $(n=27)$ were compared with 34 children with spacing in both arches. Ages of all subjects ranged from 4 to 5 years. Arch measurements were made from photographs of the occlusal surfaces of dental casts. They found that the crowded upper and lower dentitions had significantly narrower arch widths than dentitions with spacing. Additionally, they found that the mesiodistal and buccolingual crown widths of all maxillary teeth were consistently larger in the sample of crowded dentitions; however, only the buccolingual width of the upper second primary 
molar was found to be significantly different statistically. Mesiodistal crown width, arch length and crown shape were not significantly different in the crowded versus spaced dentitions. They concluded that inadequate arch width contributes most to crowding in the primary dentition.

Mills (1964) also found smaller arch widths associated with dental crowding. He conducted a study of 230 midshipmen at the United States Naval Academy in Annapolis, Maryland, to determine if well-aligned dental arches differed from crowded dental arches in arch width, arch length, or tooth crown size. All subjects were males between the ages of 17 and 21 years without orthodontic treatment, crossbite, openbite, or missing teeth mesial to the second molars. The mesiodistal widths of the right maxillary central and lateral incisors were measured with a Boley gauge and considered to be representative of dental size in general. Arch length was measured by chord from the mesial aspect of the central incisor to the mesiolingual angle of the first molar. Arch widths were measured between canines, first premolars, and second premolars. Malalignment was measured from first molar to first molar and defined as the "degree of displacement from the general configuration of the dental arches." Mills found a significant association between malalignment of teeth and arch width. Specifically, the average width of both the maxillary and mandibular arches across the second premolar region steadily decreased in size as malalignment increased in severity. The correlation between arch length and 
malalignment was not significant $(\mathrm{r}=0)$. Likewise, there was no significant difference in the mean mesiodistal crown widths in the presence of varying degrees of crowding as compared to no crowding.

\section{Masticatory Stress During Development and Jaw Size}

Some studies have attributed environmental factors, such as decreased masticatory stress during development, to the etiology of dental crowding. Watt and Williams (1951) were among the first to investigate the influence of environmental factors such as dietary consistency and muscle activity on jaw size. They tested the relative effects of masticatory function on the growth and development of the mandible and maxilla of the rat. By extension, Watt and Williams inferred that the results of their study on rats may be applied to humans. They wanted to determine if the broad, well-developed arches of primitive races of humans were the result of increased function or hereditary background. Their sample included two groups of rats: one group consisted of 60 weanlings with an average weight of 51 grams, while the second group included 40 adults with an average weight of 433 grams. In order to compare similar animals under different dietary influences, each group was further divided into two subgroups that were comparable in age and weight. In the first group, one subgroup was given a hard diet while the other was given a soft diet. The same procedure was done for the second group. After four months, all the 
rats were sacrificed and their skulls, mandibles and maxillae were examined. The authors looked at the wear of teeth, radiographic density of bone, width of the maxillae, and the thickness, weight, volume and density of the mandibles. They found that the two hard diet subgroups exhibited larger, heavier jaws and greater wear of teeth (especially the earlier-erupting first molars). Bone density, however, was not significantly different by their measurements. They concluded that function, as influenced by differences in the physical consistency of food, was an important factor in the growth and development of the jaws of the rat. More recently, Beecher and Corruccini (1981) tested the effect of dietary hardness on the craniofacial and occlusal development in the rat. Their subjects consisted of ninety 21-day-old Sprague-Dawley rats divided into 3 groups based on physical dietary consistency: hard diet (pelletted rat chow), soft diet (gruellike porridge consisting of ground chow moistened with water), and a medium diet (soft diet for six days and dry pellets provided every 7th day). After 4 months, the animals were sacrificed and the following data were collected: body mass, fresh mass of the entire masseter, maxillary arch length (incisor to distal edge of the last molar), maxillary arch width (across buccal points of the first molars), mandibular length (incisor to first molar), and anteroposterior length of the condylar articular surface. They found that the hard diet sample was larger in all dimensions. In particular, the maxillary width was markedly increased in the hard diet group as compared to the soft diet group (means of $9.64 \mathrm{~mm}$ versus 
$9.39 \mathrm{~mm})$. Beecher and Corruccini concluded that muscular stimulation mediated through occlusal function played a significant role in the development of facial structures.

Maki et al. (2002) also tested the effects of physical food consistency on the mandible of growing rats. Their subjects consisted of thirty 3-week-old Wistar rats divided into a hard diet control group, a kneaded diet (medium consistency) group and a powdered diet group. After 6 weeks of growth, the animals were sacrificed and the mandibles were removed and prepared by fixing in 10\% neutral formalin. Bone morphology of the three groups was compared by measuring 15 selected points on the mandible using a lateral cephalometric analysis. The mandible was superimposed on an X-Y coordinate system (with the mental foramen at the intersection of the X-and Y-axes) in order to document dimensional changes in mandibular morphology based on dietary consistency. Maki et al. found significant differences in the means and standard deviations of points on the mandible between the hard and soft diet groups. In the powdered diet group, Gonion (a measure of depth along the X-axis) was significantly smaller as compared to the hard and medium groups. Similarly, values measured relative to the $\mathrm{Y}$-axis showed that the coronoid process, condylar process, and gonion (measurements of height to the Y-axis) were significantly smaller in the powdered diet group. Differences between the kneaded group and the control group were small and not significant. Additionally, bone 
mineral content was quantified using computed radiographic densitometry. The only significant difference in bone mineral content was a decreased level in the powdered diet group compared to the hard diet group in the mandibular angular process and coronoid process.

Mavropoulos et al. (2005) found similar results to Watt and Williams (1951) and Maki et al. (2002). They tested the structural adaptation of the mandibular bone when subjected to different masticatory functional and mechanical demands during growth. Their subjects consisted of 52 male albino rats divided into two equal groups which were fed either a hard or soft diet. After 4 weeks, the animals were sacrificed, and the mandibles were scanned with a pencil-beam bone densitometer and bone mineral density (BMD) was quantified for each group. They found a significant decrease in BMD in the soft diet group in all regions under study, which they attributed to reduced forces exerted during mastication.

Corruccini (1984) tested the role of environmental factors (i.e., dietary consistency) on occlusal development and the incidence of crowding. His study situations varied but always involved at least two populational components, of which one was industrially modernized while another was sociotechnologically preindustrial. His study materials varied from stone casts from living subjects to skeletal remains to wax-bite impressions and visual assessment of centric occlusion in the field. The overall age distribution of his subjects was 
concentrated between 12 and 35 years of age. Because significant sex differences in occlusion were found in less than $5 \%$ of subjects, males and females were combined. Seven different samples were presented, and the findings appeared to be consistent among samples.

In his Chinese sample, Corruccini compared dental casts of 74 adults reared in China (predominantly of rural Cantonese origin) with 78 offspring reared in Liverpool, Great Britain, after the parents' immigration. He found that occlusal variation (i.e., malocclusion) in the urban-environment offspring was about twice that of the rural-origin parents. Change in dietary consistency was posited as the relevant agent, and he stated that no interproximal caries or attrition was visible.

In a Punjabi (Northwest Indian) sample, Corruccini compared occlusion by the use of a wax-bite impression and oral examination of 590 youths (12 to 16 years of age). His "cross-cultural" sampling compared students from rural schools (considered less industrialized) with those from urban schools. He found more than three times as many urban youths had a posterior crossbite with 1.5 times as many crowded and displaced teeth compared to the rural youths. Again, dietary coarseness was considered the controlling agent. Corruccini stated that various genetic factors, periodontal disease, caries, interproximal attrition, and oral breathing could be excluded based upon his study. 
Corruccini (1984) noted similar findings in cross-cultural samples of Melanesians, Kentuckians, American Indians, American whites and blacks, and nonhuman primates (squirrel monkeys and chimpanzees). He concluded that cross-cultural data demonstrate that considerable occlusal variation (i.e., malocclusion) was not inevitable or normal; rather, it was a consequence or "aberrancy" of modern urbanized populations. Urbanized populations are subjected to respiratory allergens, softer diets, and premature deciduous tooth loss. Because the transition from predominantly good to predominantly poor occlusion repeatedly occurred within one to two generations, the suggestion of a genetic etiology was not tenable.

\section{Arch Length and Dental Crowding}

Numerous reports have found an association between arch length and dental crowding. Bernabé et al. (2005) investigated intra-arch occlusal indicators of crowding. Their sample consisted of 150 sets of dental casts from 12 to 16 year-old Peruvian school students divided into three groups based on the degree of crowding or spacing. They examined arch length, intercanine and intermolar arch width, mesiodistal and buccolingual crown size, and crowding. Crowding was calculated in each arch as the numerical difference between arch perimeter (Lundström 1949) and the mesiodistal tooth size sum. They did not state how arch length or arch perimeter were measured. Although increased mesiodistal 
crown size was associated with crowding, they found that arch length was a more consistent indicator of crowding. When arch length was eliminated from a stepwise multiple discriminant analysis, the explanatory capability from the variability on the dental arch discrepancies dropped from $51 \%$ to $14 \%$.

Howe et al. (1983) tested for differences in tooth size between a group with major crowding and a second group with little or no crowding (Figs. 2-12 and 213). The total sample consisted of 104 subjects, of which 50 exhibited gross crowding while the remainder had little or no crowding. All individuals were either part of the University of Michigan Elementary and Secondary School Growth Study or from the private practices of three orthodontists. The crowded group consisted of 32 females and 18 males with a mean age of 19.6 years, whereas the noncrowded group consisted of 30 females and 24 males with a mean age of 15.6 years. Mesiodistal tooth width and arch width were measured directly on the dental casts. Arch perimeter measurements were obtained by first placing a rigid acetate directly over the occlusal surface of each cast. A line was then traced from the buccolingual center of the distal surface of the first permanent molar along the dental arch through the buccolingual centers of the posterior teeth and over the incisal edges of the anterior teeth. This was then digitized and analyzed. The authors found that the mean value of the difference in maxillary mesiodistal tooth width between the crowded and noncrowded groups for males and for females was $0.7 \mathrm{~mm}$, while the differences for the 


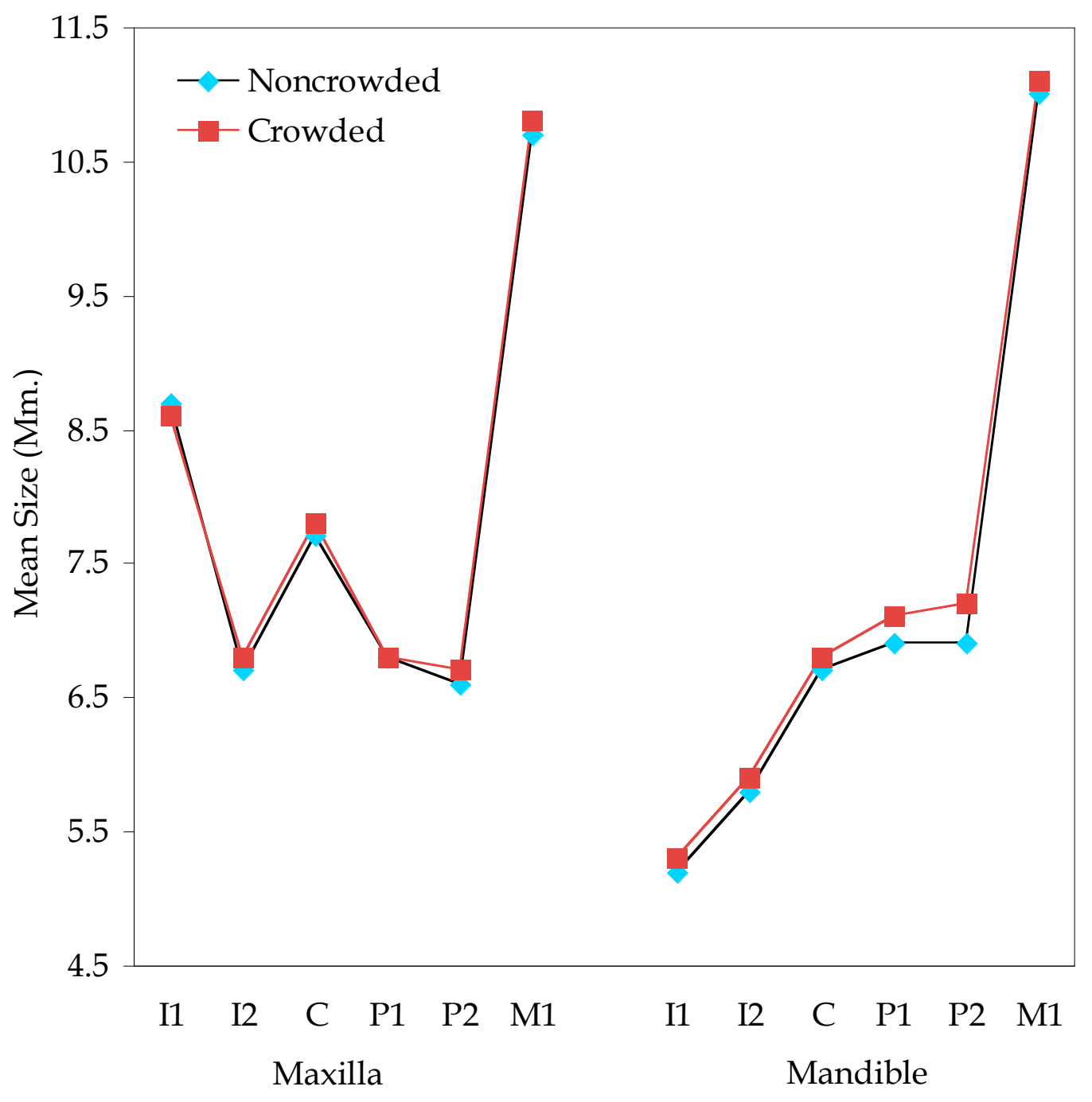

Fig. 2-12. Results published by Howe et al. (1983) for boys. There was no statistically significant difference in size between the crowded and noncrowded samples.

Source: Howe RP, McNamara JA Jr, O'Connor KA. An examination of dental crowding and its relationship to tooth size and arch dimension. Am J Orthod 1983;83:363-73. 


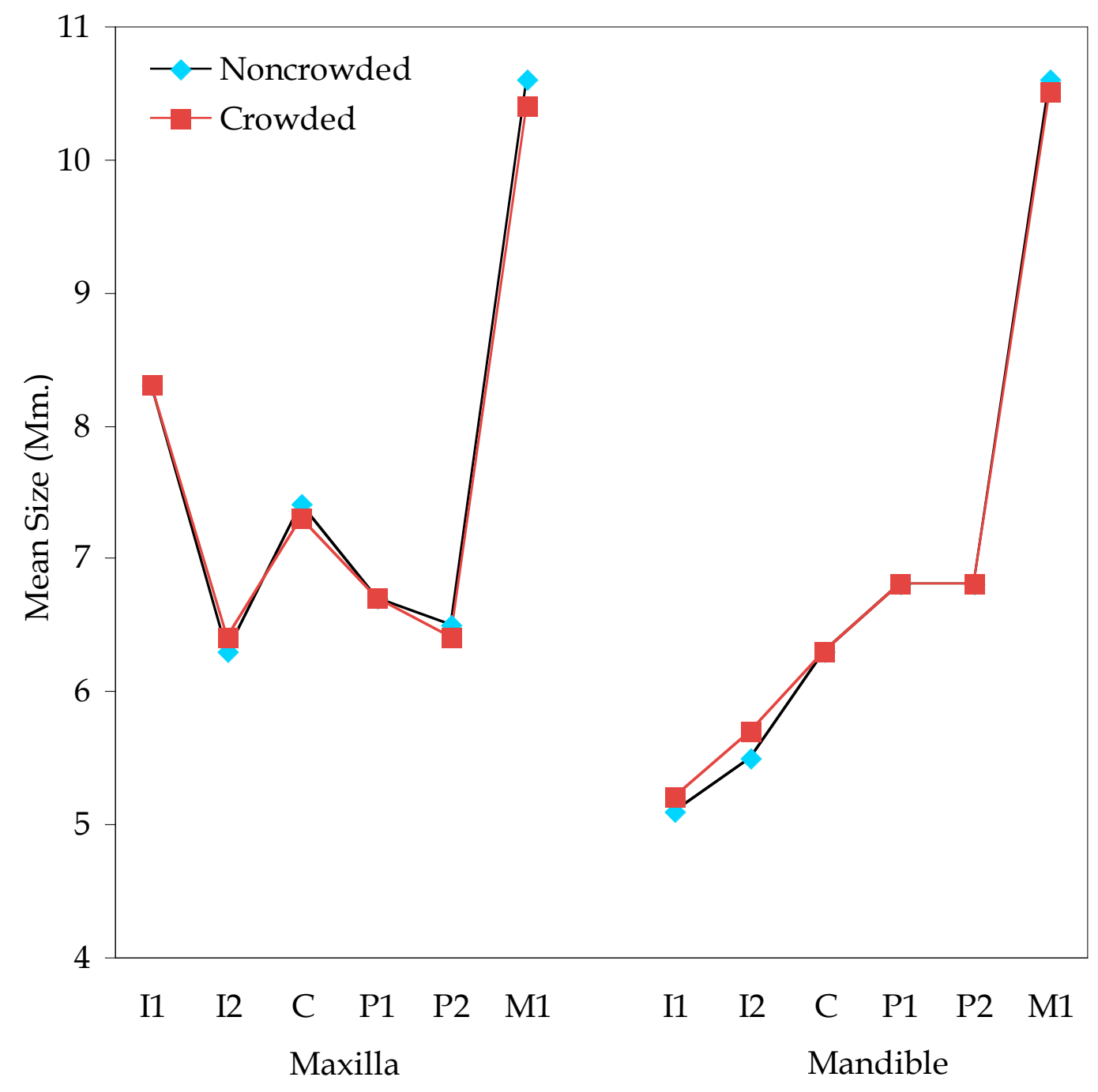

Fig. 2-13. Results published by Howe et al. (1983) for girls. There was no statistically significant difference in size between the crowded and noncrowded samples.

Source: Howe RP, McNamara JA Jr, O'Connor KA. An examination of dental crowding and its relationship to tooth size and arch dimension. Am J Orthod 1983;83:363-73. 
mandibular arch were $0.7 \mathrm{~mm}$ and $0.5 \mathrm{~mm}$, respectively. None of these differences was statistically significant. Conversely, noncrowded arches were statistically significantly wider. Arch width at the first molar site in females was $5.4 \mathrm{~mm}$ greater in the noncrowded group compared to the crowded group; whereas, in males the difference was $6.1 \mathrm{~mm}$. Also, at least some individuals in their sample had presented for treatment at one of three private orthodontic practices, so their tests may be confounded.

Bishara et al. (1995) assessed changes in maxillary and mandibular crowding after complete eruption of the deciduous dentition to the time of eruption of the second permanent molars. They attempted to predict crowding in the permanent dentition based on observations of the deciduous dentition. Their sample consisted of 35 males and 27 females from the Iowa Longitudinal Growth Study. Each subject had a flush terminal plane or a mesial step relationship in the second deciduous molars, 0 to $50 \%$ overbite, and 0 to $3 \mathrm{~mm}$ of overjet. Arch length, arch width, and mesiodistal widths of the maxillary and mandibular deciduous and permanent teeth were measured. With the exception of the maxillary second molars, all deciduous teeth were significantly correlated (nearly all correlation coefficients less than 0.7 ) to their permanent successors. In other words, the mesiodistal widths of the deciduous teeth were, for the most part, predictive of the mesiodistal widths of the permanent successors. They found that crowding was mainly due to a decrease in arch length in both arches. 
No comments were made in the results regarding arch widths. They were unable to predict crowding in the permanent dentition from dental measurements in the deciduous dentition.

Warren and Bishara (2001) investigated secular changes that may have occurred in dental arch dimensions by comparing a sample of contemporary North American white children with an historical sample. Boys $(n=54)$ and girls $(\mathrm{n}=58)$ who were part of the Iowa Fluoride Study and born between 1992 and 1995 (mean age 4.8 years) were compared with 89 boys and 86 girls who were part of the Iowa Growth Study and were born between 1946 and 1948 (mean age 4.9 years). All subjects had intact deciduous dentitions. Arch width, arch length, overjet, and overbite were measured directly from the dental casts. Arch length was measured from segments on the right and left sides of each arch that were summed to determine total arch length. For the anterior segment, measurements were made from the contact area of the central incisors to the contact area between the canine and first primary molar. For the posterior segment, measurements were made from the contact between the canine and first primary molar to the most distal point of the primary second molar. Warren and Bishara found that average arch lengths were significantly smaller in the contemporary children of both sexes, while arch widths were smaller in the contemporary males (not females). 


\section{$\underline{\text { TSASD as a Measure of Crowding }}$}

A useful way to measure anterior dental crowding was established by Little (1975). After reviewing the literature for a numerical index to assess incisor crowding, Little was unsatisfied and developed the "irregularity index" (Fig. 214). He reasoned that, because the status of the six mandibular anterior teeth was often the limiting factor in treatment and stability, a diagnostic index should accurately reflect their condition. He had seven orthodontists with varying levels of experience apply the "irregularity index" to a set of 50 casts. The technique involved measuring the linear distance from anatomic contact point to adjacent anatomic contact point from the right mandibular canine to the left mandibular canine and summing the measurements. In concept, a value of zero would indicate perfect alignment or, conversely, no crowding. As recognized by Little, the irregularity index is not sensitive to incisors with torsiversion while the contacts remain approximated. So, in the vernacular, when the incisors are "accordianed," irregularity is underestimated. In addition, interdental spacing is combined with irregularity with Little's method, though, spacing often is etiologically different from crowding.

Normative Increases in Dental Crowding with Age

Some studies have attributed dental crowding to causes distinctly different from the paradigm of relatively large teeth simply erupting into relatively small 


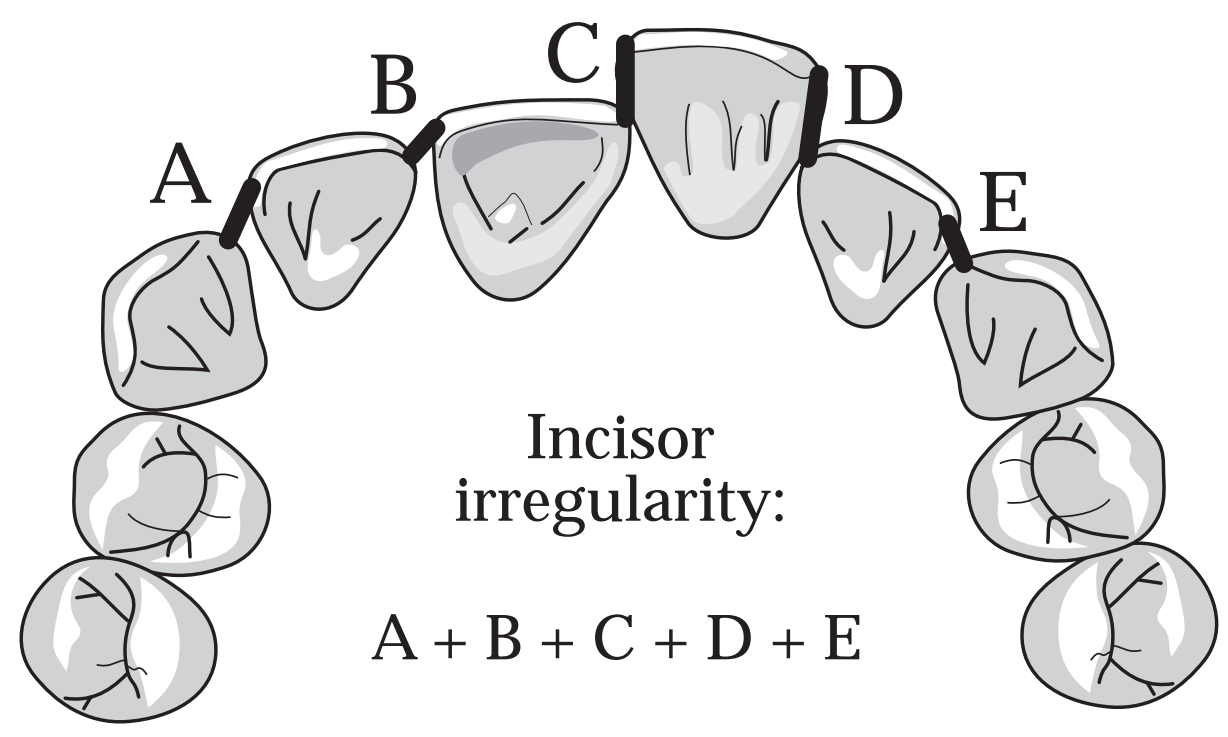

Fig. 2-14. Schematic representation of the incisor "irregularity index" developed by Little (1975).

Source: Little RM. The irregularity index: a quantitative score of mandibular anterior alignment. Am J Orthod 1975;68:55463. 
dental arches. Indeed, researchers have found that dental crowding increases in the absence of malocclusion simply as a function of age. Little et al. (1988) conducted a 20-year follow-up study to determine whether there was an age of "final dental alignment stability." Dental casts of 31 cases with 4 sets of complete records (pretreatment, end of active treatment, a minimum of 10 years postretention, and a minimum of 20 years postretention) were evaluated with Little's irregularity index. They found mean incisor irregularity values of $7.4 \mathrm{~mm}$ for pretreatment, $1.7 \mathrm{~mm}$ for posttreatment, $5.2 \mathrm{~mm}$ for 10 years postretention, and $6.0 \mathrm{~mm}$ for 20 years postretention. Indeed, only $10 \%$ of the cases had clinically acceptable mandibular alignment at the 20-year stage of records. Moreover, they found that crowding continued to increase during the 10-year to 20-year postretention phase but at a slower rate. They argue that the only way to ensure posttreatment alignment is by the use of fixed or removable retention for life.

Driscoll-Gilliland et al. (2001) evaluated the relationship between skeletal changes and mandibular incisor crowding. They conducted a longitudinal retrospective study comparing skeletal and dental changes in orthodontically treated versus untreated individuals. Two time points were evaluated, (1) at the completion of orthodontic treatment or at an age "typical" for completion of treatment and (2) between 20 and 44 years. Their sample consisted of 44 untreated subjects with an average age of 14 years at the initial time point and 23 
years at the second time point. The treated group consisted of 43 patients (21 males, 22 females) with an initial average age of 15 years and a final age of 29 years. Cephalometric superimpositions and dental cast analyses were obtained. They found that, in both groups, significant growth occurred beyond the age when orthodontic treatment is typically completed. Comparing the two groups at the initial time point, the mean anterior facial height (nasion to menton) was 6 $\mathrm{mm}$ shorter in the untreated group, while SNA and SNB angles were 3 to $4^{\circ}$ smaller in the treated group. At the second time point, with the exception of SNA, all skeletal dimensions changed significantly in both groups. The anterior and posterior facial heights increased approximately 4 to $5 \mathrm{~mm}$. The largest dental change observed in both groups was a 4 to $5 \mathrm{~mm}$ inferior displacement of the lower incisor attributed to growth. They also found that lower incisor irregularity increased in both treated and untreated subjects (mean increase of 1.0 to $1.5 \mathrm{~mm}$ ), although the increase was greater in untreated subjects.

\section{Facial Type and Dental Crowding}

Two studies investigated facial type and dental crowding. Keene and Engel (1979) sought to identify cases with a high potential for relapse based on cephalometric analysis of the cases prior to orthodontic treatment. Their sample consisted of 50 untreated adults over 18 years of age, all of whom had "ideal" occlusions and "perfect" lower incisor alignment. This group represented the 
goal for postretention incisor alignment in orthodontically treated cases. Mesiodistal and buccolingual tooth crown measurements were taken on dental casts, and lateral and frontal radiographic tracings were used to test for statistical associations between facial features and mesiodistal tooth sizes which were associated with ideal alignment of incisors. They found that greater values for corpus length and mandibular arc, and smaller mandibular plane angles accommodated wider incisors. These facial types were characteristically short and wide, or brachycephalic. On the other hand, long and narrow faces, dolichocephalic, seemed to require narrower incisors to achieve ideal incisor alignment. As such, they stated that the facial pattern is critical in identifying potential for relapse. From this, they concluded that, when lower incisor width exceeds the predicted value by more than $1.2 \mathrm{~mm}$ in borderline extraction cases, interproximal stripping should be applied.

In addition to the 50 untreated cases, Keene and Engel also studied 35 treated cases (18 males, 17 females). The patients in the treated group were from a collection of long and short-term retention cases treated by Ricketts, although the actual retention periods were not provided. These cases were divided into two groups, (1) twenty-five without relapse ( $0.0 \mathrm{~mm}$ overlap of the lower incisors and canines) and (2) ten with greater than $2 \mathrm{~mm}$ of overlap. Peck and Peck (MD/BL) ratios were measured for each of the 35 treated cases. Using a t-test, the authors found no significant difference between the average ratios of the 
relapse and non-relapse groups. They concluded that the Peck and Peck incisor ratio was not a practical discriminator between the two populations.

Bishara et al. (1994) conducted a longitudinal study of 30 adults who had been part of the Iowa Facial Growth Study. Cephalometric and dental cast analyses were used to measure dentofacial changes occurring with age in 30 adults (15 male) between 25 and 46 years of age. All individuals were orthodontically untreated. Angular and linear measurements of the skull, maxilla, mandible, incisor position, soft tissue profile, and the dental arches were evaluated. Data were assessed separately for males and females. In males, they found that all skeletal linear dimensions increased with age as did facial convexity as a result of increased maxillary prominence. Upper and lower lips became more retruded in relation to the nose and chin. In the females, similar skeletal and profile changes were observed; however, increased facial convexity was attributed to posterior rotation of the mandible. Both sexes displayed increased dental crowding in both dental arches, although to a greater degree in the mandible. They concluded that these changes are part of the normal maturational process and should be appreciated by orthodontists when planning treatment and considering retention options for adult patients. 


\section{Dental Proportionality and the Bolton Index}

There is a different aspect of the general topic of tooth size and malocclusion: Perhaps tooth size in itself is not a risk factor. Instead, it may be the relative sizes of the teeth. Teeth of disproportionate mesiodistal sizes will not couple well, leading to TSASD. Bolton (1958) was among the first to investigate this question in depth (Lundström 1955). He suggested that well-interdigitated, good occlusions possessed teeth within a fairly narrow band of proportions. He analyzed 55 sets of dental casts carefully selected and judged to have excellent occlusions, 44 of which were from orthodontically treated nonextraction cases and 11 were from untreated subjects. He measured the degree of overbite and overjet, the angle between the maxillary and mandibular central incisors, and the mesiodistal widths of teeth from first molar through first molar in both arches. Bolton came up with two tooth size ratios: an overall ratio consisting of the 12 teeth from first molar to first molar and an anterior ratio including six teeth from canine to canine. In the overall ratio, Bolton summed the mesiodistal widths of the mandibular 12 teeth and divided it by the sum of the maxillary 12 teeth. For the anterior ratio, only the six anterior teeth were summed. His calculations produced a means of $91.3 \%(\mathrm{sd}=0.26)$ for the overall ratio and $77.2 \%(\mathrm{sd}=0.22)$ for the anterior ratio. The issue is that the mesiodistal crown diameters need to be proportionate in order for (A) the teeth to fit together within an arch with 
their anatomic contacts approximated and for (B) the teeth between the arches to be properly interdigitated.

The importance of size proportions is not obvious from the literature. Crosby and Alexander (1989) and Freeman et al. (1996) both reported that Bolton tooth-size discrepancies were important to consider when managing orthodontic cases (also see Sperry et al. 1977). Crosby and Alexander calculated the frequency of tooth-size discrepancies among different malocclusion groups and compared their findings to Bolton's published norms. Their sample consisted of 109 orthodontically treated individuals grouped by type of malocclusion (30 Class I, 30 Class II division 1, 29 Class II division 2, and 20 Class II surgical cases). No extractions or interproximal stripping had been performed and all permanent teeth were erupted and present from first molar to first molar. The anterior and total ratios in the malocclusion groups were analyzed and compared with Bolton's means and standard deviations. Although the mean ratios did not differ significantly from Bolton's, the range of values above and below the mean was significantly greater than that demonstrated by Bolton. Indeed, $23 \%$ of patients had an anterior ratio beyond two standard deviations of Bolton's mean. They concluded that a Bolton's analysis would be beneficial prior to orthodontic treatment.

Freeman et al. (1996) conducted a study of orthodontic patients in a military orthodontic training program who had a clinically significant interarch 
tooth-size discrepancy. Their sample consisted of 157 records containing Bolton tooth-size analyses conducted by 24 different orthodontic residents at the Fort Meade Residency Program in Maryland. They found a greater percentage of patients with Bolton discrepancies greater than 2 standard deviations from the norm ( $31 \%$ as compared to $23 \%$ found by Crosby and Alexander). They suggested that the larger discrepancy could be due to potentially more severe malocclusions encountered in a military residency as opposed to a private practice. In this vein, the authors noted that due to limited resources in the military, patients are selected based upon the severity of their malocclusion. Although an individual might decidedly benefit from orthodontic treatment, if their malocclusion was not severe, they were unlikely to receive treatment. Like Crosby and Alexander, Freeman and coworkers concluded that a Bolton analysis is useful prior to orthodontic treatment.

Sperry et al. (1977) used the Bolton analysis to test the frequency and magnitude of excess tooth structure in mandibular prognathism. Their sample consisted of 78 cases of Angle Class II malocclusions with varying degrees of severity. Of these, 38 subjects were treated with orthodontic therapy alone, 20 with mandibular subapical osteotomy, and 20 with bilateral vertical ramus osteotomy. Two control groups consisted of 26 patients with Angle Class I malocclusions and 26 with Angle Class II malocclusions. The total and anterior Bolton ratios were calculated for the three groups using pretreatment dental 
casts. The Angle Class III subjects had a significantly higher frequency and magnitude of mandibular tooth-size excess for the overall Bolton ratio but not for the anterior ratio compared to the other malocclusion groups. They concluded that a tooth-size analysis should be included in diagnostic records for mandibular prognathism.

Basaran et al. (2006) tested for an association between tooth-size discrepancies and different malocclusion groups among Turkish youths (ages 13 to 19 years). Their sample consisted of 60 normal subjects (ideal Class I occlusion) and 300 subjects divided into 5 malocclusion groups: Class I, Class II, Class II division 1, Class II division 2, and Class III ). Bolton's anterior and overall ratios were calculated from dental cast measurements. No sexual dimorphism was found in the ratios for the 5 groups, so the sexes were pooled. Also, no difference was found among the Class I or Class II subgroups, so these also were combined, yielding three groups: Class I, Class II and Class III. Like Akyalçin et al. (2006), they found no significant difference for the ratios between the groups. They concluded that tooth size discrepancies were independent of Angle classification.

Al-Khateeb and Abu Alhaija (2006) conducted a similar test in a Jordanian sample and found different results. Their subjects consisted of 140 students (age 13 to 15 years). They divided the youths into groups based on sex and malocclusion: 34 Class I, 33 Class II division 1, 37 Class II division 2, and 36 
Class III. In addition to mesiodistal tooth width, they measured arch length and arch width. They found that males had larger teeth than females, and subjects with Class III malocclusion exhibited significantly larger teeth than the other malocclusions. Interestingly, they found that there were differences in tooth size between right and left sides, confirming the presence of asymmetry. No significant difference was found in anterior or overall Bolton ratios between the groups. In terms of arch dimensions, subjects with Class II division 1 exhibited the narrowest maxillary arch width, while the mandibular intercanine width was significantly larger in the Class III group compared to both of the Class II groups. Comparing arch length, they found that while the maxillary arch was significantly longer in the Class II division 1 than in the Class II division 2, the mandibular arch of Class III subjects was significantly longer than both of the Class II subgroups. Oddly, comparing males and females, the only significant difference in arch dimensions was a decreased maxillary intercanine width observed in females. Although there was a tendency toward shorter maxillary and mandibular arches in females, the differences were not significant. They concluded that tooth-size differences were found between sexes and between malocclusions; however, arch dimensions differed for the most part only among categories of malocclusions.

Paredes et al. (2006) tested Bolton ratios in Spanish subjects. Their sample consisted of 30 females and 70 males presenting for treatment in the orthodontic 
department at the University of Valencia, Spain. The subjects ranged in age from 11 to 23 years (mean age 15 years) and exhibited an Angle Class I relationship with no arch discrepancy. They did not find a significant difference in the anterior or overall Bolton ratios between males and females, so sexes were pooled. They found an anterior ratio of $78.3 \%(\mathrm{sd}=2.5)$ and an overall ratio of 92.0\% (sd $=2.0)$ for the Spanish subjects, which were both significantly greater than Bolton's ratios. Surprisingly, they found that $21 \%$ of their subjects were at least two standard deviations from the anterior Bolton mean and that $5 \%$ were at least two standard deviations from the overall Bolton mean. They concluded that the relationship between the sizes of the mandibular and maxillary teeth depends on the population, and that specific standards should be established for the Spanish population.

Alkofide and Hashim (2002) divided a sample of orthodontic cases by type of malocclusion and found no difference in the frequency of Bolton discrepancies. Their sample consisted of 240 pretreatment casts of 13 to 20 yearold Saudis attending the orthodontic clinic at the Dental College of King Saud University. Their sample was divided equally into four groups consisting of Class I occlusion and Class I, Class II and Class III malocclusions. An equal number of males and females were assigned to each group. They measured the maximum mesiodistal widths of 12 maxillary and mandibular teeth from first molar through first molar and calculated the overall and anterior Bolton ratios. 
For all classes combined, they found that an average overall ratio of $92.6 \%$ and an anterior ratio of $78.9 \%$. Both differed significantly from Bolton's values (91.3\%; $\mathrm{sd}=0.3$ and $77.2 \% ; \mathrm{sd}=0.2$, respectively). They found no significant difference in the frequency of tooth-size discrepancies for the overall or anterior ratios between malocclusion groups.

In a similar study, Laino et al. (2003) also found no relationship across three categories of Angle malocclusions. Their sample consisted of 94 orthodontic patients from the Campania region of Italy who were divided into three groups based on Angle molar classification and the cephalometric ANB value. The first group consisted of 57 subjects ( 26 males and 31 females) with a Class I molar relationship and an ANB angle between 0 and $5^{\circ}$. The second group consisted of 24 subjects (6 males and 18 females) with a Class II molar relationship and an ANB angle greater than $5^{\circ}$. Finally, a third group was composed of 13 subjects ( 7 males and 6 females) with a Class III molar relationship and an ANB angle less than $0^{\circ}$. Mesiodistal crown diameters were measured from first molar through first molar on dental casts. Through discriminant analysis, they found no association between tooth size and any of the malocclusion groups. The problem with both of these studies is that they may have been asking the wrong question since all of the individuals in their samples had malocclusions. 
CHAPTER 3

\section{MATERIALS AND METHODS}

\section{Data Collection}

Our data collection design was based on the simple dichotomous question of whether an individual had been treated orthodontically. Unfortunately, this obscures the broad range of severity of malocclusion. Notably, these generally well-off subjects had ready access to treatment; indeed, their enrollment in dental school implied a conscious awareness of dental health and dental esthetics. There is the likelihood, then, that more of these people with minor malocclusions would have sought treatment than would be the case in the general population.

The subjects used in the present study consisted of 111 American white male dental students at The University of Tennessee Health Science Center, augmented with 21 American white male patients previously treated in the graduate orthodontic clinic at The University of Tennessee Health Science Center. The subjects were divided into two groups based on whether or not they had had orthodontic therapy. Forty-two of the subjects had not received previous orthodontic treatment (excluding limited treatment in the mixed dentition such as correcting a tooth in anterior crossbite) and were considered to have naturally-occurring good occlusions. The remaining 90 subjects had 
undergone comprehensive orthodontic treatment to correct a range of malocclusions.

\section{Study Design}

A few words will be helpful to clarify the rationale for our particular study design. It is difficult, in an orthodontic setting, to collect records on people with naturally-occurring good occlusions because these people have no need of the specialist's services. It seemed, then, that dental students, who are required to make dental casts on one another as one of their orthodontic exercises, provide an excellent resource from which we could collect the two samples, namely (1) those with naturally-occurring good occlusions and (2) those who had been treated orthodontically.

With many women in the dental classes (ca. 50\%), the expectation was that we could collect roughly equal sample sizes of males and females. In fact, though, almost every woman in the dental classes had been treated orthodontically. We surmise that two prevailing trends may have thwarted an effort to include women in the present study. Principally, it seems that women's esthetic "threshold" motivating them to seek treatment is appreciably lower than for males. Additionally, these women—pursuing dental careers—presumably possess a higher "dental IQ" as compared to women in general. That is to say, women entering dental school could be expected to have a heightened concern 
for their oral health. Consequently, we omitted women from the study because we could not obtain a practical-size sample of women with naturally-occurring good occlusions.

\section{Selection Criteria}

Dental casts ( $n=132$ pairs) of the subjects above were selected from 240 available pairs. The selection criteria were as follows:

1. Females were excluded from the study due to an inadequate sample size of orthodontically untreated females. The statistical analysis, therefore, was performed controlling for sexual dimorphism in tooth size (Seipel 1946; Garn et al. 1967; Smith et al. 1982).

2. Because of ethnic differences in tooth size (e.g., Kieser 1990); only cases of American whites were included.

3. Because hypodontia likely affects the size of the remaining teeth (e.g., Garn $e t$ al. 1964, 1965), cases with hypodontia (excluding third molars) were excluded.

4. Cases with naturally-occurring good occlusions exhibited bilateral Class I sagittal molar and canine relationships, less than 3 millimeters of mandibular incisor irregularity (Little 1975), overjet and overbite within normal limits (Kelly and Harvey 1977) and no dental midline deviation.

5. Orthodontic cases treated with orthognathic surgery were excluded. 
6. Because we were investigating differences in mesiodistal tooth width, individuals who remembered having interproximal reduction (IPR) were excluded.

\section{$\underline{\text { Tooth Codes }}$}

Various naming, lettering, and coding systems have been used to refer to specific tooth types (reviewed by Peck and Peck 1993). A combination of letters and numbers is used in the present study. The system in the present study is to refer to the four tooth types by their initials, namely incisor (I), canine (C), premolar $(\mathrm{P})$, and molar $(\mathrm{M})$, and to code a tooth's location within each morphogenetic complex by its position, mesial to distal (e.g., Dahlberg 1945, 1951). Arcade and side of the body, where applicable, are written-out for clarity.

\section{$\underline{\text { Odontometrics }}$}

The maximum mesiodistal and buccolingual tooth crown diameters were measured using a conventional, systematic approach (Moorrees 1957) with digital-readout, sliding calipers. The beaks of the calipers were machined to fit well into the embrasures, and Dr. Harris oversaw training and data collection. The mesiodistal and buccolingual crown diameter of (1) the central incisor, (2) the lateral incisor, (3) the canine, (4) the first premolar, (5) the second premolar and (6) the first molar were measured in each dental arch, with exception to the 
orthodontic treatment group which in some cases was limited to one set of premolars, and hence only five teeth were measured in each arch. As such, all tooth types were measured except second and third molars, allowing for the anterior and overall Bolton ratios to be assessed (Bolton 1958). The anterior Bolton's ratio is the ratio of the sum of the anterior 6 mandibular mesiodistal dimensions (4 incisors and 2 canines) divided by the sum of the maxillary 6 dimensions:

\section{Anterior ratio $=$ Sum Md $6 /$ Sum Mx 6}

Bolton (1958) reported that the mean of the anterior ratio should be $77.2 \%$ with a standard deviation of $1.55 \%$. The overall Bolton's ratio is the ratio of the sum of 12 mandibular mesiodistal dimensions (4 incisors, 2 canines, 4 premolars, and 2 first molars) divided by the sum of the maxillary 12 dimensions:

$$
\text { Overall ratio }=\text { Sum Md } 12 / \text { Sum Mx } 12
$$

Bolton reported that the mean of the overall ratio should be $91.3 \%$ with a standard deviation of $1.91 \%$.

\section{$\underline{\text { Technical Error }}$}

Precisional accuracy of the dental crown measurements is important in order to provide reliable data and, thereby, realistic tests of the hypotheses. Measurement "error" combines issues of precision and accuracy. Accuracy is how close a measured value is to its true value (Sokal and Rohlf 1995). Precision, 
in contrast, is the closeness of repeated measurements of the same quantity. This has to do with the consistency (measurement style) within and between observers. Sokal and Rohlf noted that, "Unless there is bias in a measuring instrument, precision will lead to accuracy. We therefore mainly need to be concerned about the former" $(1995$, p. 13). Statistically, the issue is to confirm that the measurement errors in a study are random and appreciably smaller than the intergroup differences claimed to be of biological importance (e.g., Hopkins 2000; Perini et al. 2005).

Intraobserver repeatability error was calculated using the familiar Dahlberg formula (Dahlberg 1940)

$$
\text { mean error }=\sqrt{\frac{\sum d^{2}}{2 n}}
$$

where $d$ is the difference between the repeated readings and $n$ is the number of duplicates.

A total of 120 teeth (a composite of all tooth types) was measured twice several months apart, and mean repeatability error was just $0.069 \mathrm{~mm}$ (about seven hundredths of a mm), which is appreciably less than any of the statistically significant (biologically relevant) differences reported in this study.

Another informative way of presenting technical error is as a percentage of the object being measured. We used this formula 


$$
\frac{\sum_{i=1}^{n}\left(\frac{\frac{\left|A_{i}-B_{i}\right|}{A_{i}+B_{i}}}{2} \times 100\right)}{n}
$$

where $\mathrm{i}$ is the tooth being measured, A and B are the two repeated measurements of tooth $\mathrm{i}$, and $\mathrm{n}$ is the number of teeth studied. Multiplication by 100 simply expresses the technical error as a percentage.

For the 120 teeth measured and remeasured, the average percentage of crown size attributable to technical error is just less than one percent, specifically $0.991 \%$. Again, this small source of random variation, less than a percentage point, is insufficient to account for the intergroup differences encountered in this study.

\section{Missing Value Propagation}

The multivariate statistical tests performed here require complete datasets. This can create problems particularly for dental metrics because, in the present study, 24 dimensions need to be measured on each individual and some teeth may be unmeasurable due to malalignment, breakage on a cast, restorations, and other problems. The most common situation encountered here was missing premolars that had been extracted as part of orthodontic treatment. Rather than delete these cases that had just a few missing dimensions, we used multivariate linear regression analysis (e.g., Freund and Littell 1991) to estimate the missing 
values. This is particularly feasible with dental metrics since there are multiple dimensions per individual and most crown diameters are significantly intercorrelated (e.g., Harris and Bailit 1988).

An option developed in a recent version of the JMP statistical package (version 5.0.1.2) was used. The following steps were used to estimate (and substitute for) a missing value. (Just males were used here since there were too few untreated females for analysis.) At step one, all of the other (non-missing) variables were input into a stepwise multivariate analysis of variance, and the subset of significantly correlated variables (correlated with the missing variable) were identified (while accounting for statistical intercorrelations among the predictors). At step two, this subset of variables was used in multiple linear regression to estimate missing values of a dimension. That is, data from members of the sample who had all of the relevant measures were used to develop prediction equations and these equations, in turn, were used to estimate the missing values in the other cases. At step three, these predicted values were used to develop complete data sets.

\section{$\underline{\text { Statistical Methods }}$}

The study design developed in this project compared two groups, namely (1) people with naturally-occurring good occlusions and (2) people who had malocclusions warranting comprehensive orthodontic treatment. The original 
intent was to test samples of males and females in tandem (statistically accounting for sexual dimorphism in tooth crown dimensions), but it was not feasible to collect an adequate sample of untreated females. Consequently, the analysis was centered on statistical comparisons of the two samples of males.

Descriptive statistics were calculated as defined by Sokal and Rohlf (1995), namely sample size $(\mathrm{n})$, arithmetic mean $(\overline{\mathrm{x}})$, standard deviation $(\mathrm{sd})$, sample variance $\left(\mathrm{s}^{2}\right)$, standard error of the mean (se), skewness $\left(\mathrm{g}_{1}\right)$, and kurtosis $\left(\mathrm{g}_{2}\right)$. Regarding skewness and kurtosis, statistical packages commonly fail to provide inferential tests of whether $g_{1}$ or $g_{2}$ differ significantly from normality. Inspection of these raw statistics themselves is not particularly informative. Following Sokal and Rohlf (1995), the standard error for skewness is

$$
\mathrm{se}_{\mathrm{g}_{1}}=\sqrt{\frac{6 n(\mathrm{n}-1)}{(\mathrm{n}-2)(\mathrm{n}+1)(\mathrm{n}+3)}}
$$

where $\mathrm{n}$ is the sample size, and the standard error for kurtosis is

$$
\mathrm{se}_{\mathrm{g}_{2}}=\sqrt{\frac{24 n(\mathrm{n}-1)^{2}}{(\mathrm{n}-3)(\mathrm{n}-2)(\mathrm{n}+3)(\mathrm{n}+5)}}
$$

An interesting feature of the tests of whether skewness or kurtosis departs from normality is that they are each evaluated at infinite degrees of freedom regardless of the actual size of the samples. Exploratory data methods (Tukey 1977) were used to identify statistical outliers. Analysis of variance (one-way factorial) was used to assess the intergroup differences, using designs described by Winer et al. (1991). 
Tooth crown dimensions are strongly intercorrelated (e.g., Moorrees and Reed 1964), and, to account for this statistical redundancy of information, principal components analysis (PCA) was performed with varimax rotation (Kaiser 1958) using the covariance matrix (Cooley and Lohnes 1971; Harmon 1976). One-way ANOVA was used to test for group differences in the derived factor scores. Rather redundant with PCA, multivariate analysis of variance (MANOVA) also was used to test whether, comprehensively across all crown dimensions, the two groups differed statistically. Except where noted, statistics were generated using JMP version 5.0.1.2 (SAS Institute Inc., Cary, NC). Tests were two-tail, and the conventional level of statistical significance $($ alpha $=0.05)$ was used throughout.

We initially used a one-way factorial analysis of variance while testing between the sample with naturally-occurring good occlusions and those who received orthodontic treatment. This was done univariately. This was followed up by stepwise discriminant functions analysis, where the test disclosed which variables differed most between the samples. These results also suggested the composite effects of multiple tooth-size variables, which moved us beyond the univariate mind set. 


\section{CHAPTER 4}

\section{RESULTS}

\section{$\underline{\text { Descriptive Statistics }}$}

Data were tabulated as to whether (A) the crown diameters were mesiodistal or buccolingual and (B) the individuals possessed natural-occurring good occlusions or malocclusions treated orthodontically. Descriptive statistics for these four groups are listed in Tables 4-1 through 4-4 (also see Appendix). Additionally, skewness $\left(\mathrm{g}_{1}\right)$ and kurtosis $\left(\mathrm{g}_{2}\right)$ are tested for deviations from normality using formulae in Sokal and Rohlf (1995:138). A scattering of variables is significant for $\mathrm{g}_{1}$ and/or $\mathrm{g}_{2}$. The distribution of cases for these variables (and all others) was examined, and all outliers were listed and remeasured. Very few of these outliers were due to measurement or technical error. When, upon remeasurement, the values did not change, these extremes were not deleted from subsequent analysis.

\section{Univariate Analysis of Variance}

The core question in this study is whether mean tooth crown diameters differ significantly between the sample with naturally-occurring good occlusions versus the sample that warranted comprehensive orthodontic treatment. 


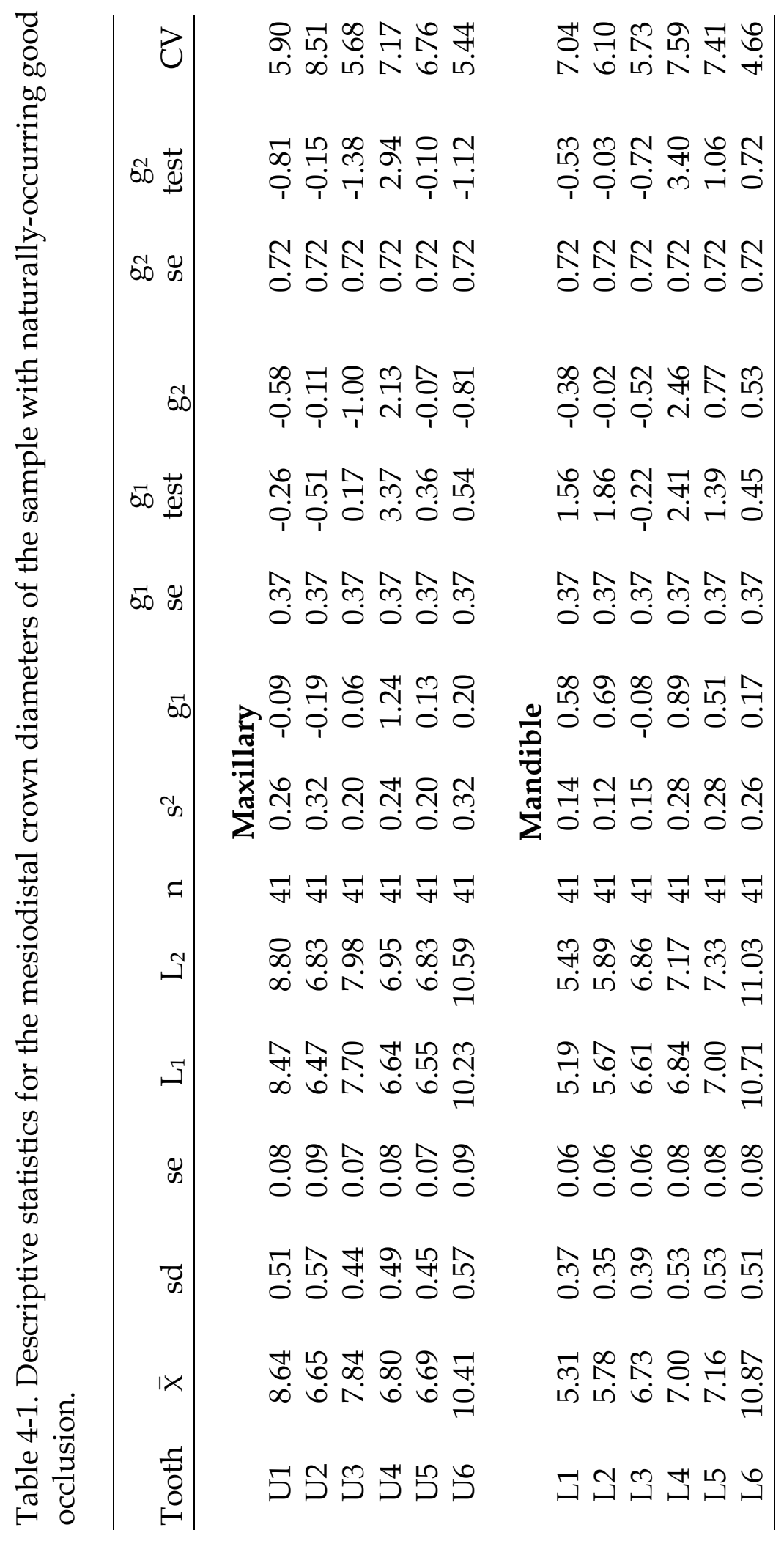




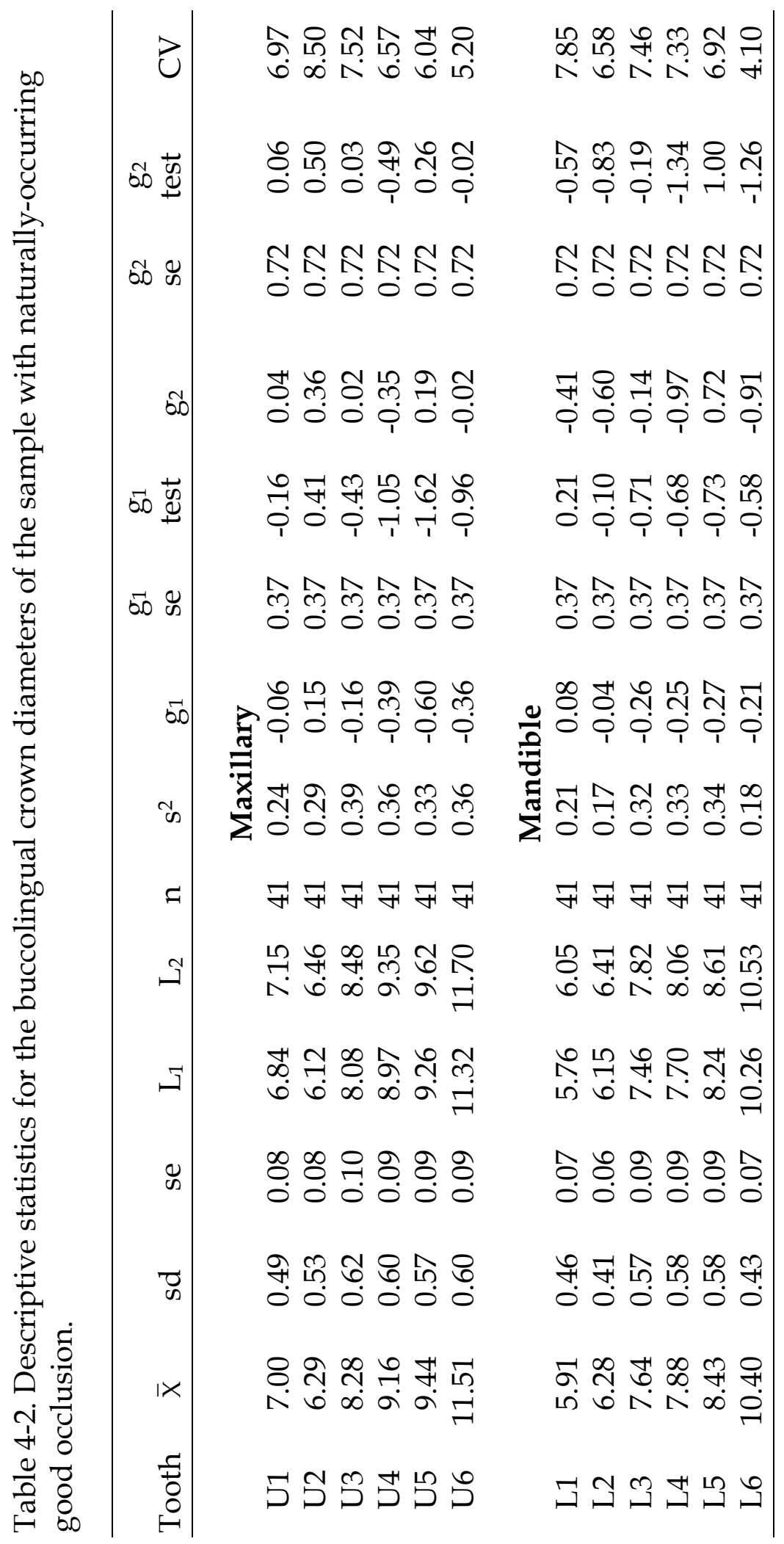




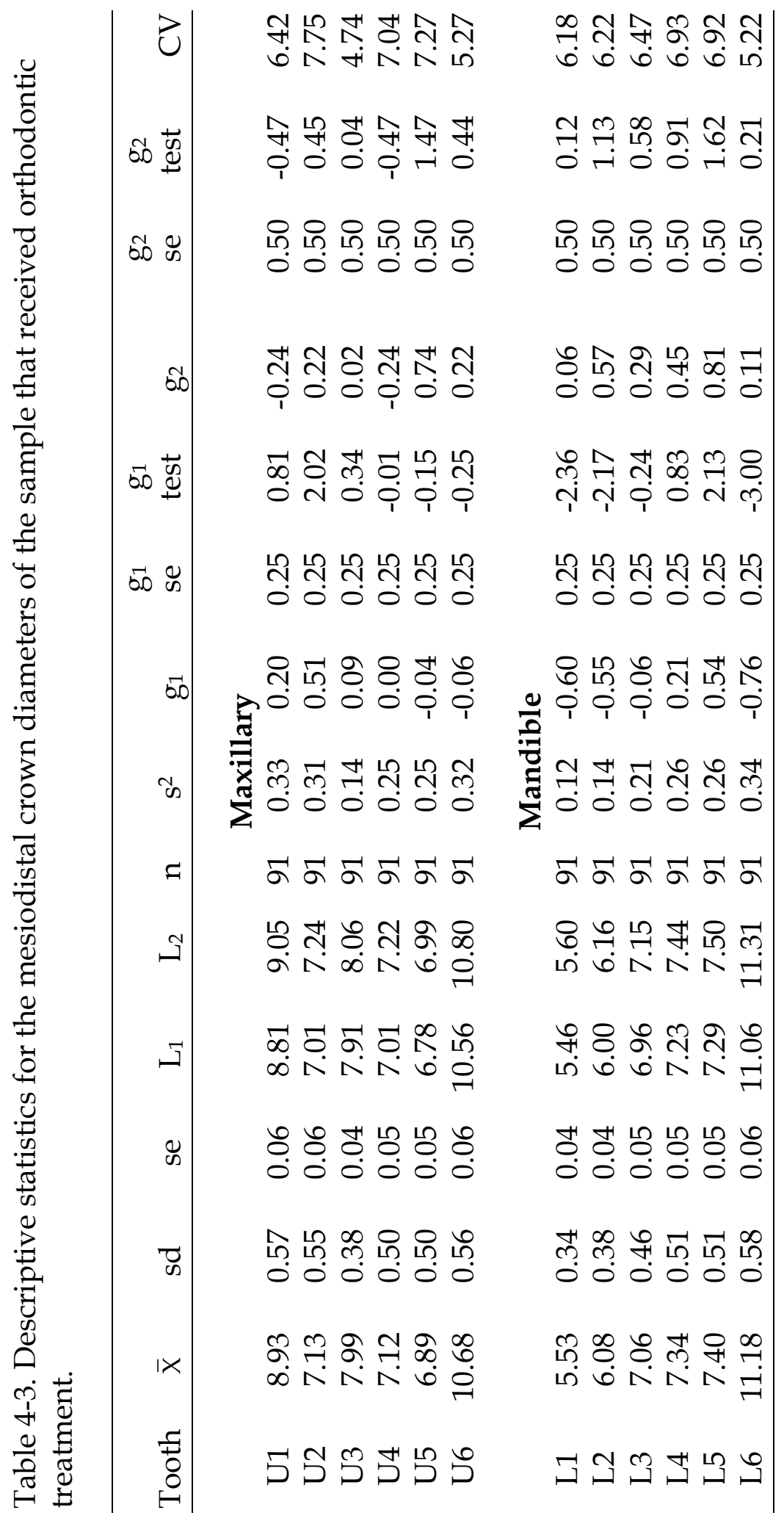




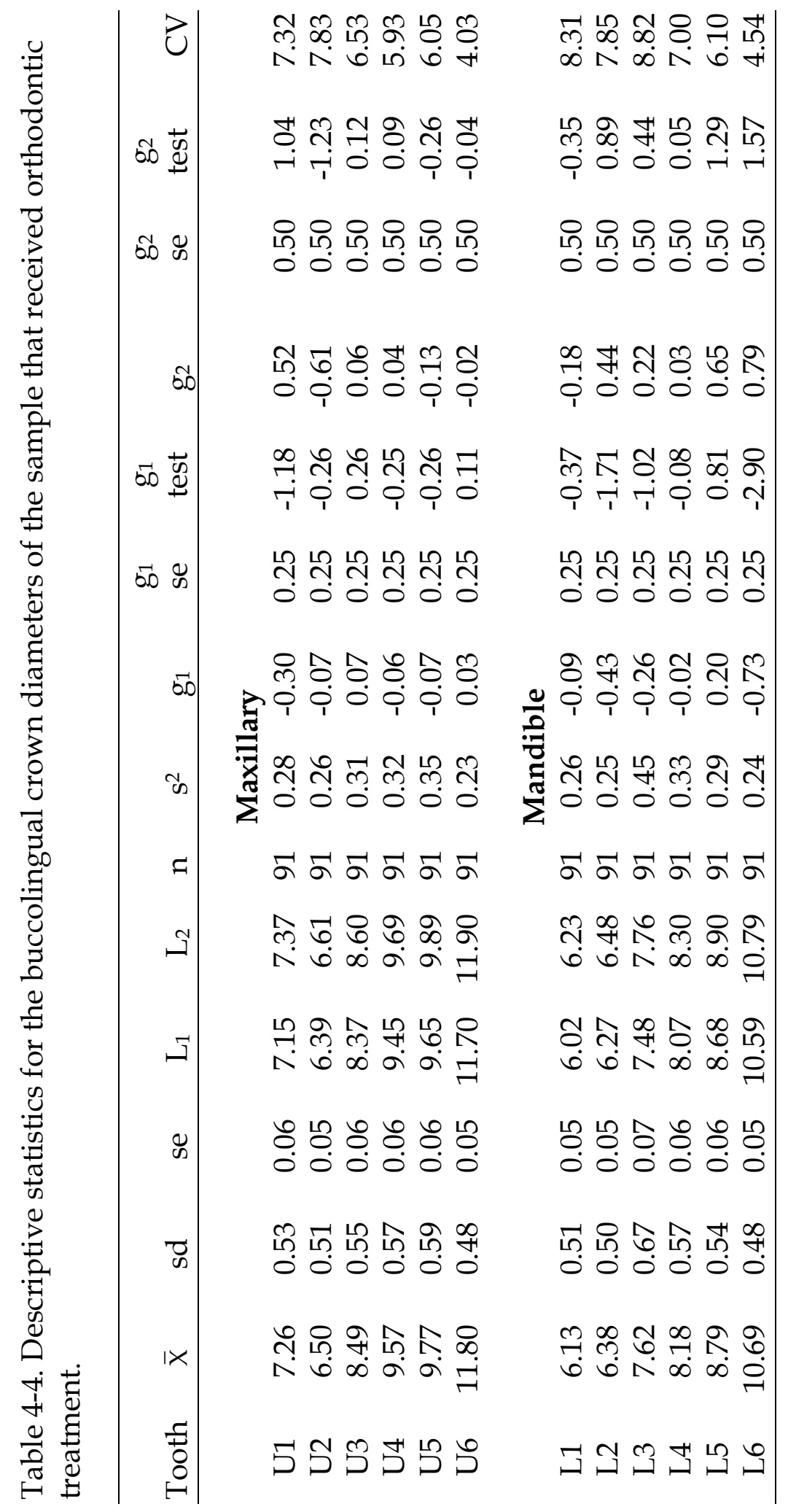


Factorial one-way analysis of variance was used to test this difference for each of the 24 tooth crown variables, and results are listed in Tables 4-5 (mesiodistal) and 4-6 (buccolingual).

Rather strikingly, 21 of these 24 tests exhibited statistically significant differences ( $\mathrm{P}<0.05$; two-tail tests), and 15 of the tests can be labeled highly significant $(\mathrm{P}<0.01)$. Group means are graphed in Figures 4-1 and 4-2.

Examination of just the sample means shows that the average tooth size is larger in the treated sample for 23 of the 24 variables, with buccolingual width of the mandibular canine being the single exception, where mean size is nonsignificantly larger in the untreated sample $(\mathrm{P}=0.87)$, but by a mere 0.02 $\mathrm{mm}$. These BL group means are graphed in Figures 4-3 and 4-4. Graphically, samples are approximately different significantly $($ alpha $=0.05)$ when these confidence limits do not overlap vertically.

Notice that the coefficient of determination $\left(\mathrm{r}^{2}\right)$ is listed for each ANOVA (Tables 4-5, 4-6). These are the percentages of variation in tooth size explained (in the statistical sense) by the grouping between those with and without orthodontic treatment. The $\mathrm{r}^{2}$ are low-below 3\%-for the three nonsignificant variables, but they range from about $5 \%$ up to a high of $14 \%$ for the others. The largest $\mathrm{r}^{2}$ are for the mesiodistal diameters of some incisors, notably the lower lateral incisor $\left(r^{2}=12.3 \%\right)$ and the upper lateral incisor $\left(r^{2}=13.9 \%\right)$. 


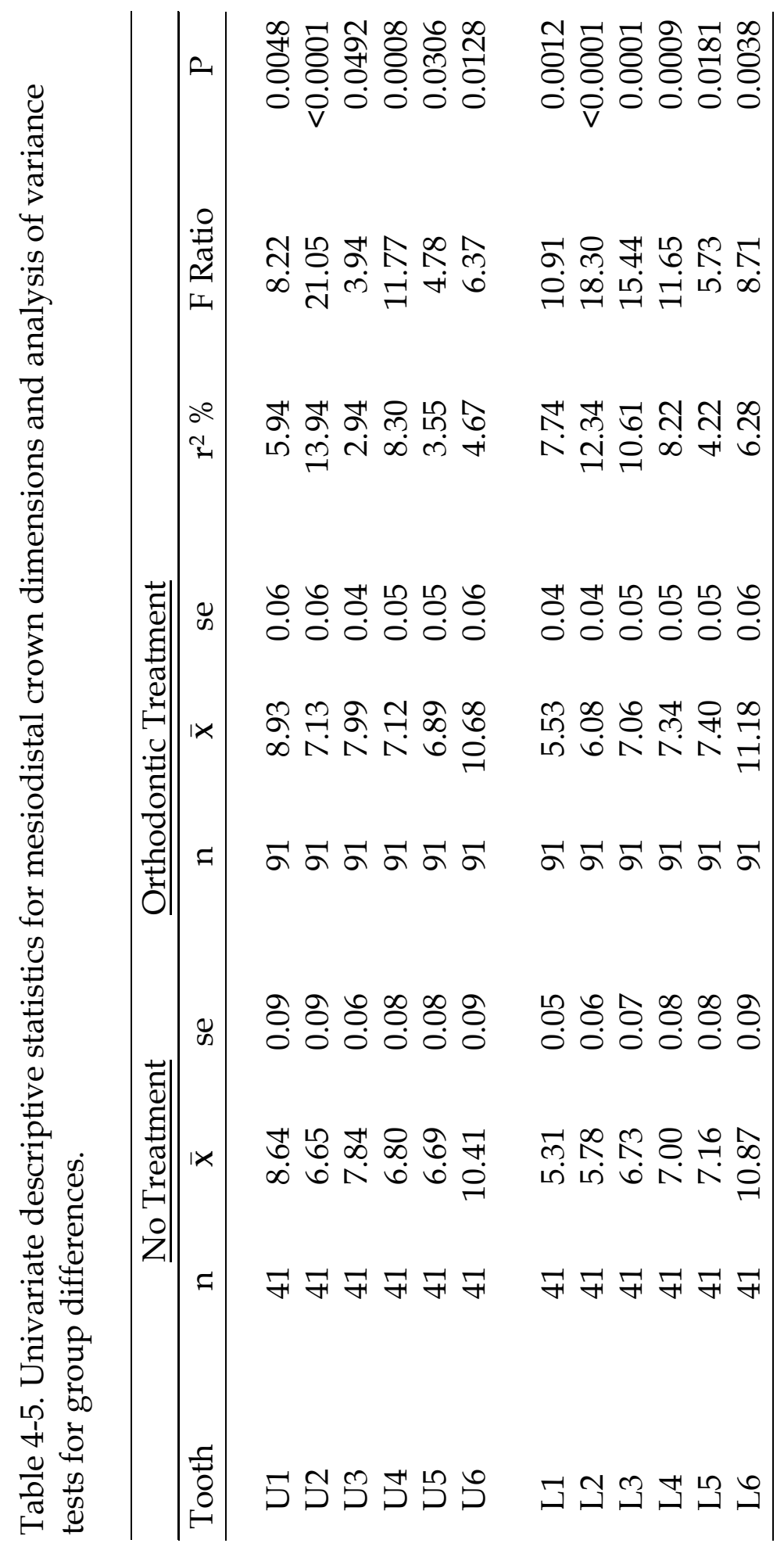




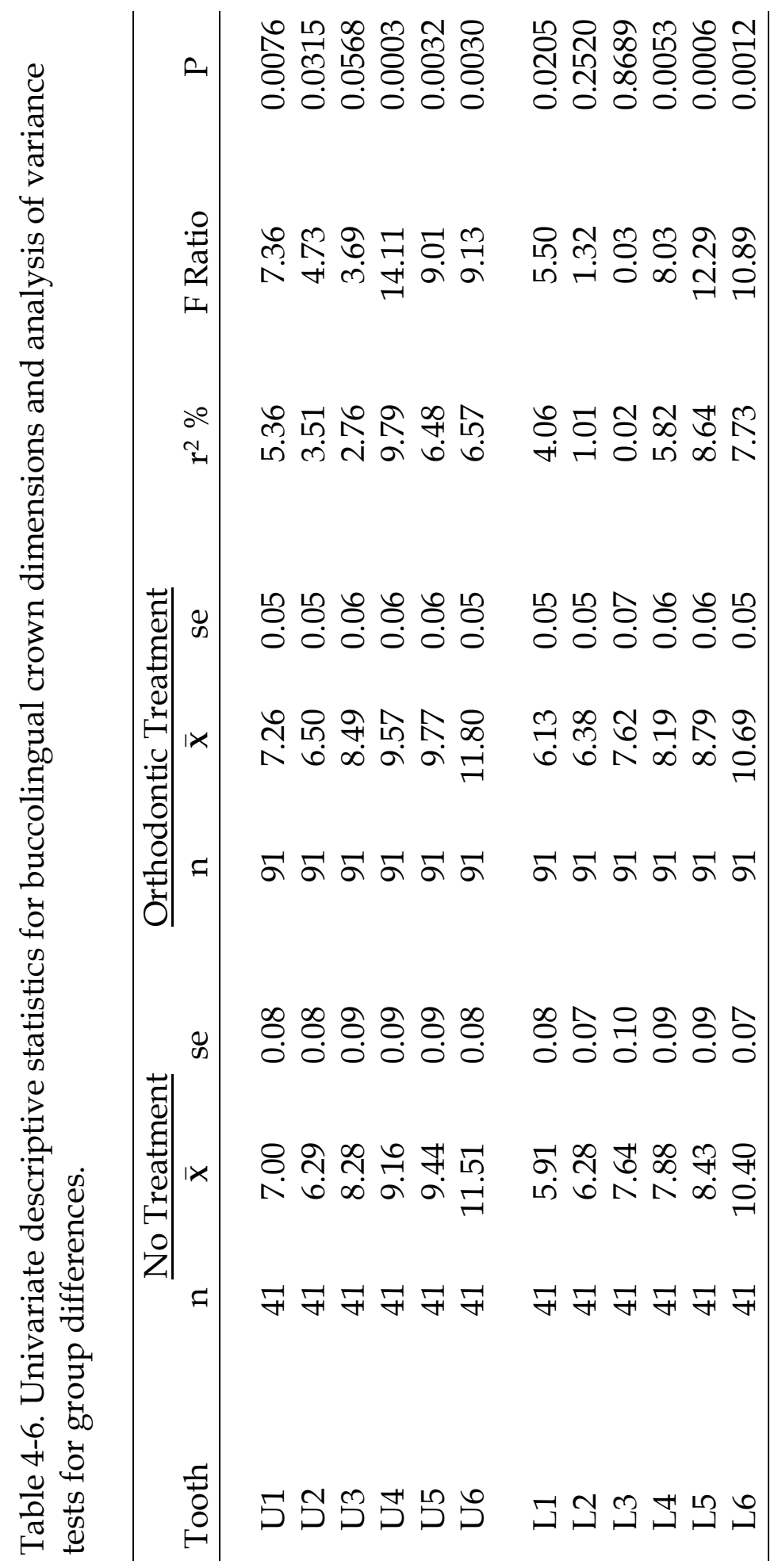




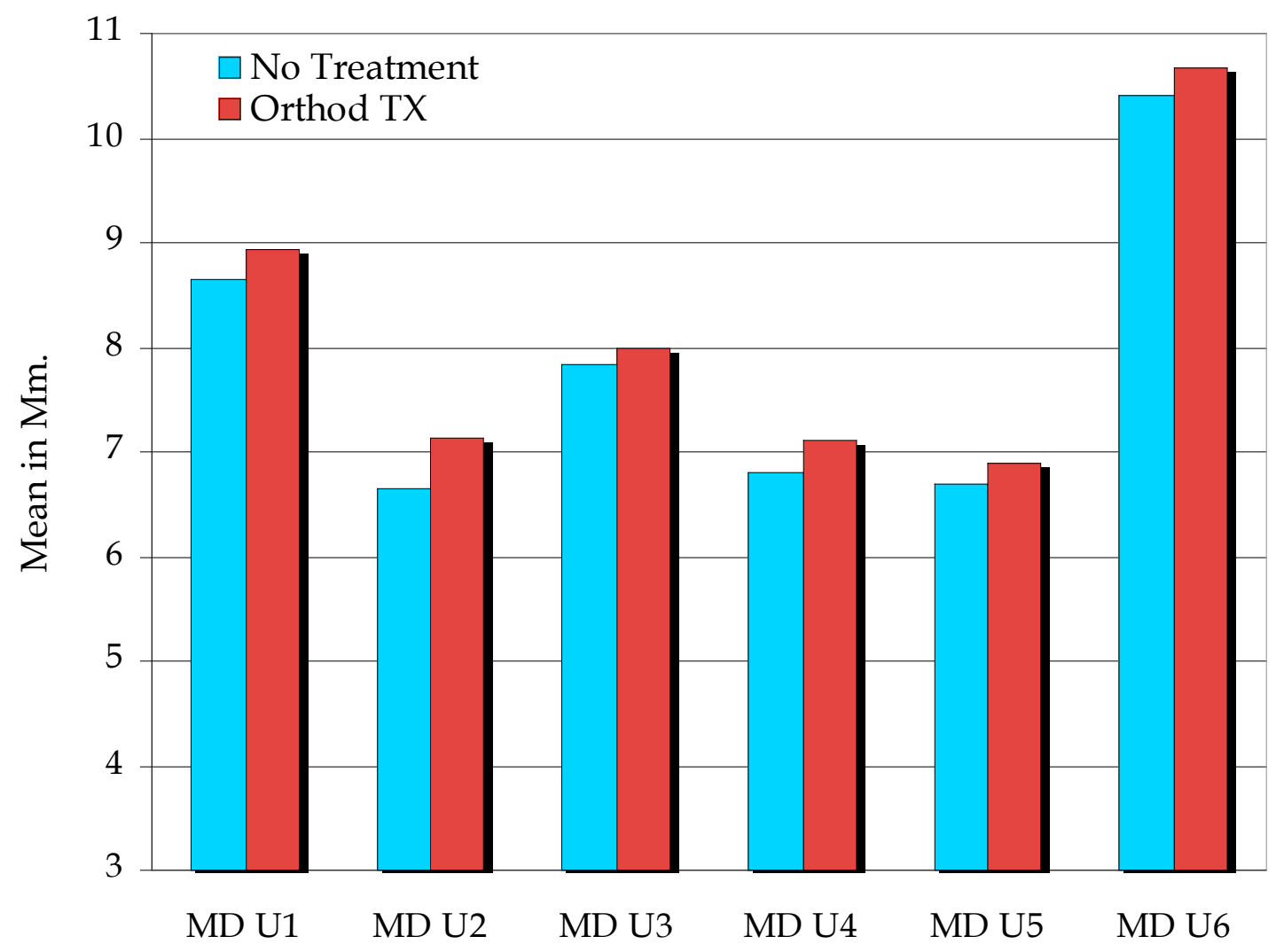

Fig. 4-1. Bar chart of mean tooth size by tooth type for the mesiodistal maxillary crown diameters. 


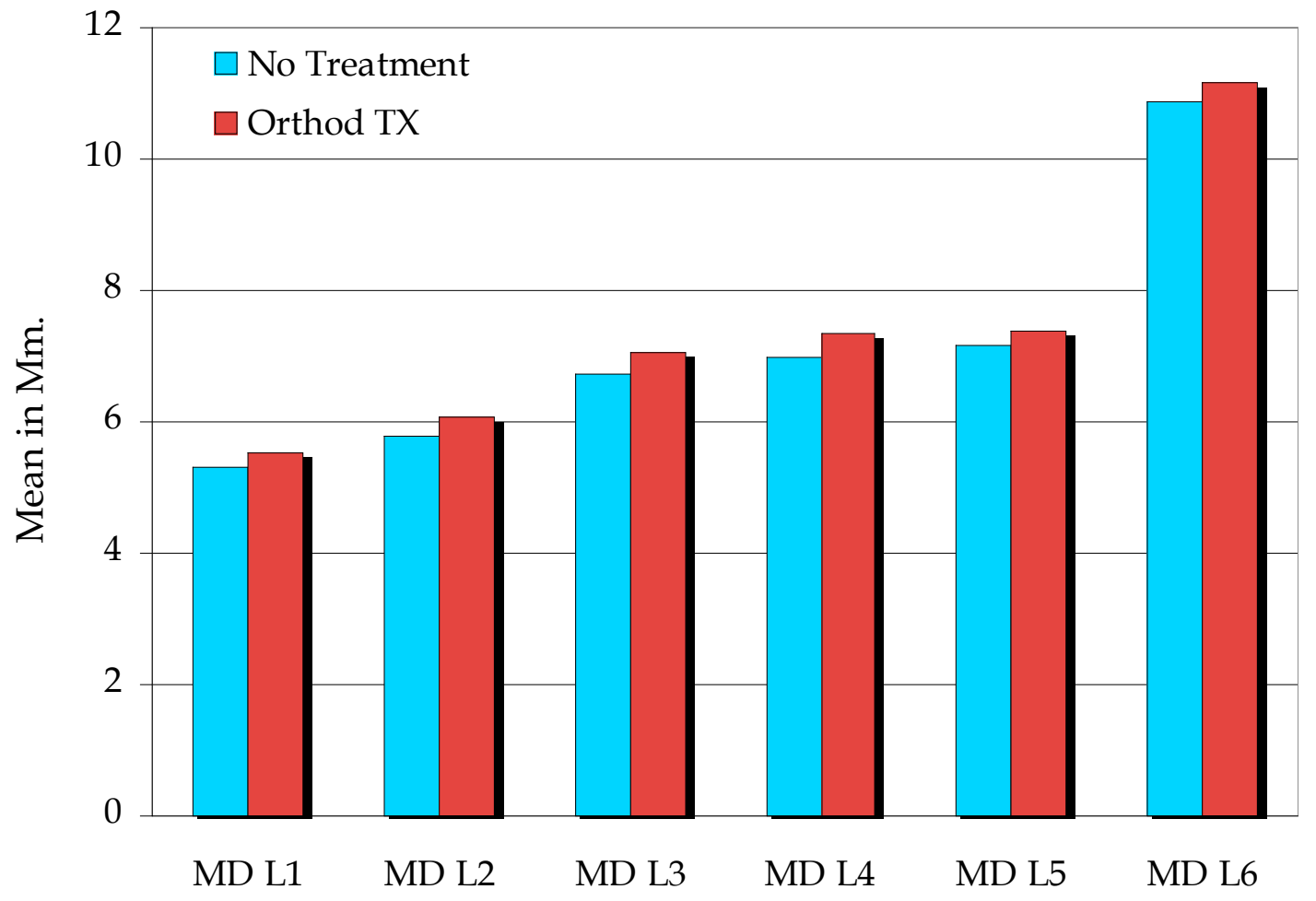

Fig. 4-2. Bar chart of mean tooth size by tooth type for the mesiodistal mandibular crown diameters. 


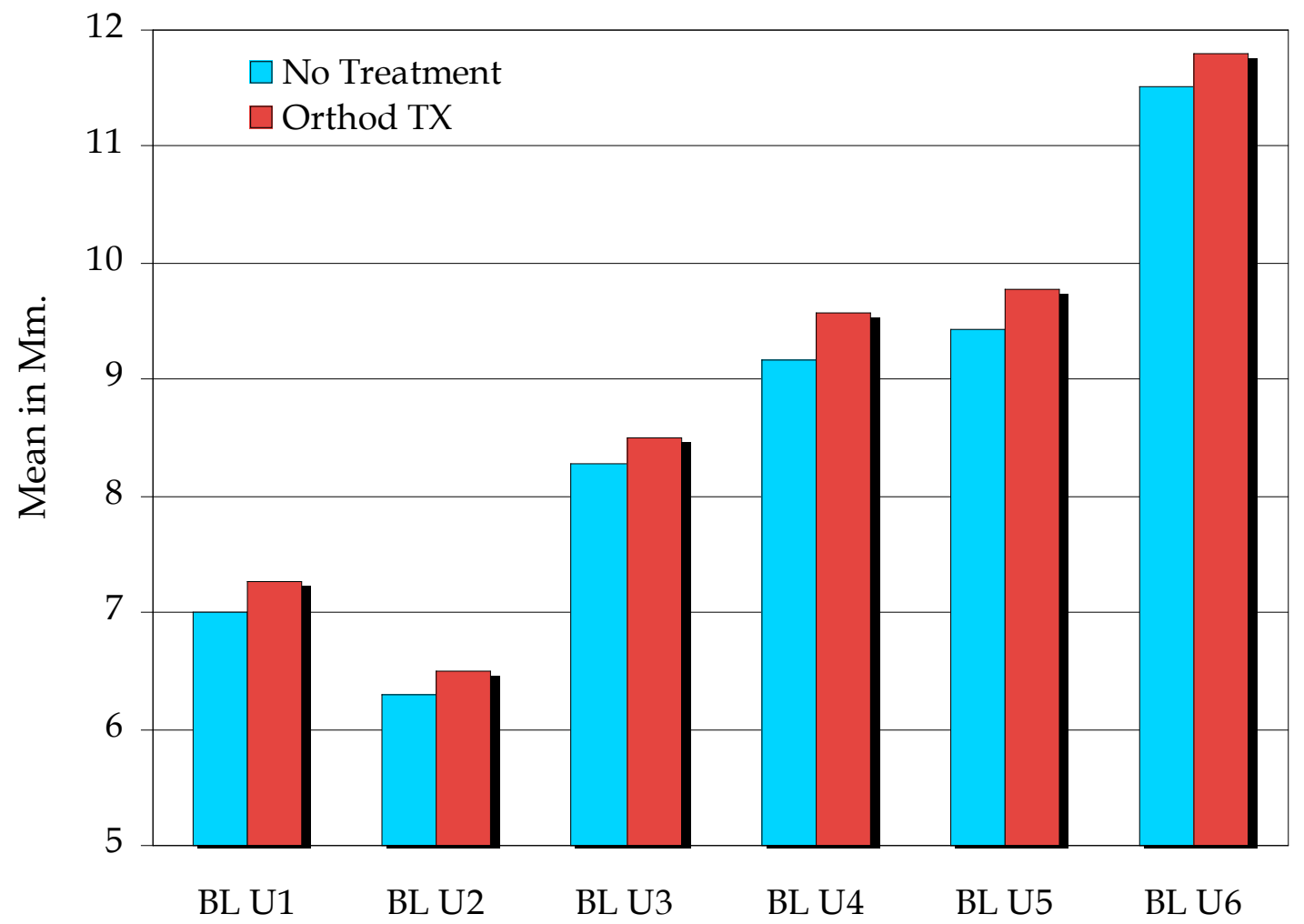

Fig. 4-3. Bar chart of mean tooth size by tooth type for the buccolingual maxillary crown diameters. 


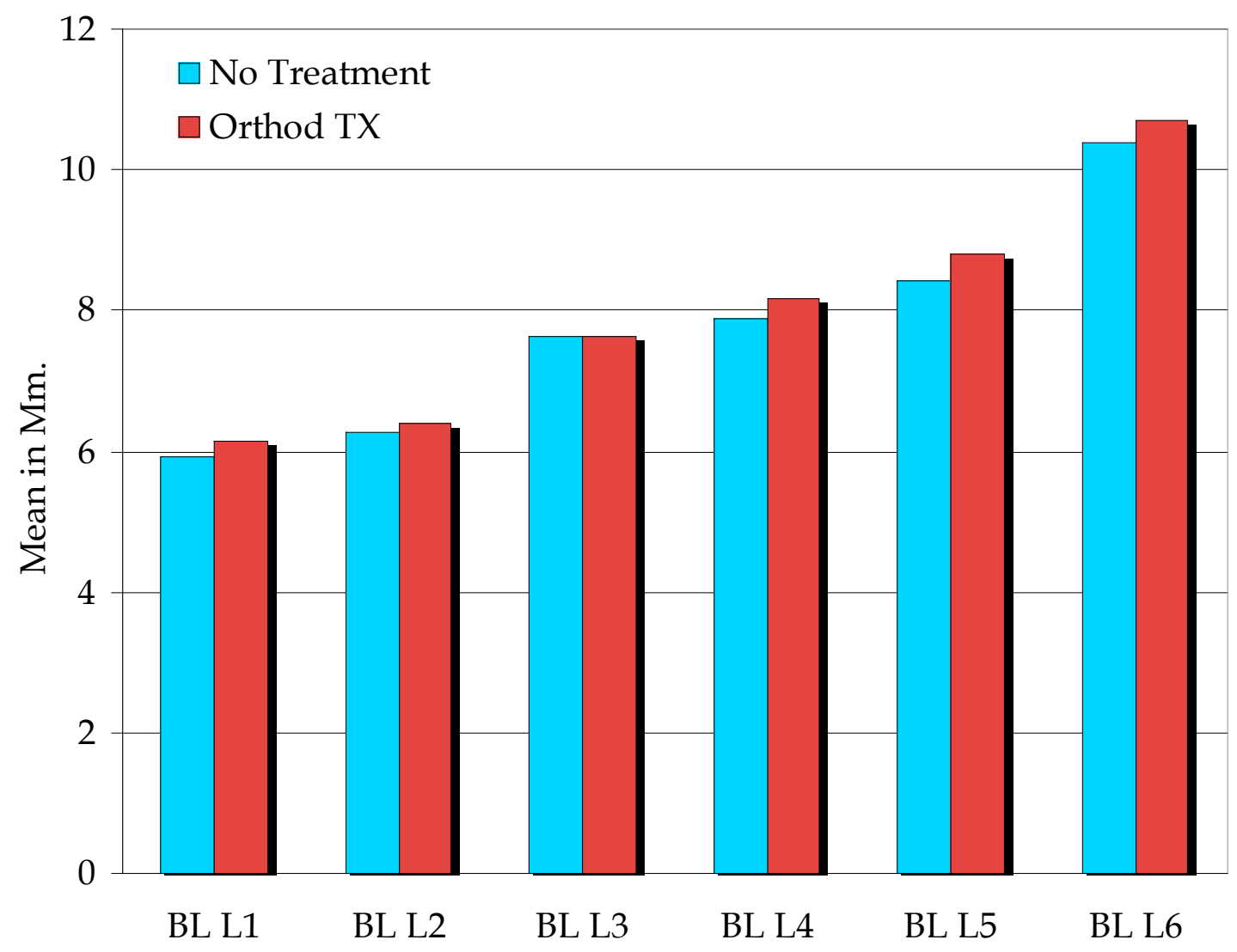

Fig. 4-4. Bar chart of mean tooth size by tooth type for the buccolingual mandibular crown diameters. 


\section{$\underline{\text { Nonparametric Tests }}$}

One concern with the prior tests is whether the data truly meet the assumptions of parametric tests. Deviation in the sample distributions can influence attainment of statistical significance. In fact, we did examine the data vis-à-vis the assumptions of analysis of variance, but here-largely for completeness - we also report on the use of a nonparametric test (the Wilcoxon test) that makes no assumption about the nature of the sample distributions (Siegel and Castellan 1988). Table 4-7 lists the results of the Wilcoxon test for the 12 mesiodistal crown dimensions and Table 4-8 lists results for the 12 buccolingual dimensions. All of the mesiodistal variables are statistically significant by this nonparametric test except the maxillary canine $(P=0.08)$, and this agrees with the results from the ANOVA tests. Curiously, while mesiodistal size of the upper canine does not differ between groups, the corresponding size of the lower canine is highly significant $(\mathrm{P}=0.0002)$, being smaller in the good occlusion sample.

Nine of the 12 buccolingual crown diameters also are significant by the Wilcoxon test (Table 4-8), exceptions being the maxillary canine $(\mathrm{P}=0.09)$, the lower lateral incisor $(\mathrm{P}=0.20)$, and the lower canine $(\mathrm{P}=0.96)$. These results are wholly in agreement with the parametric tests reviewed above. Likewise, tests for the maxillary canine and mandibular lateral incisor have small enough (but nonsignificant) P-values to suppose that these two dimensions could achieve 


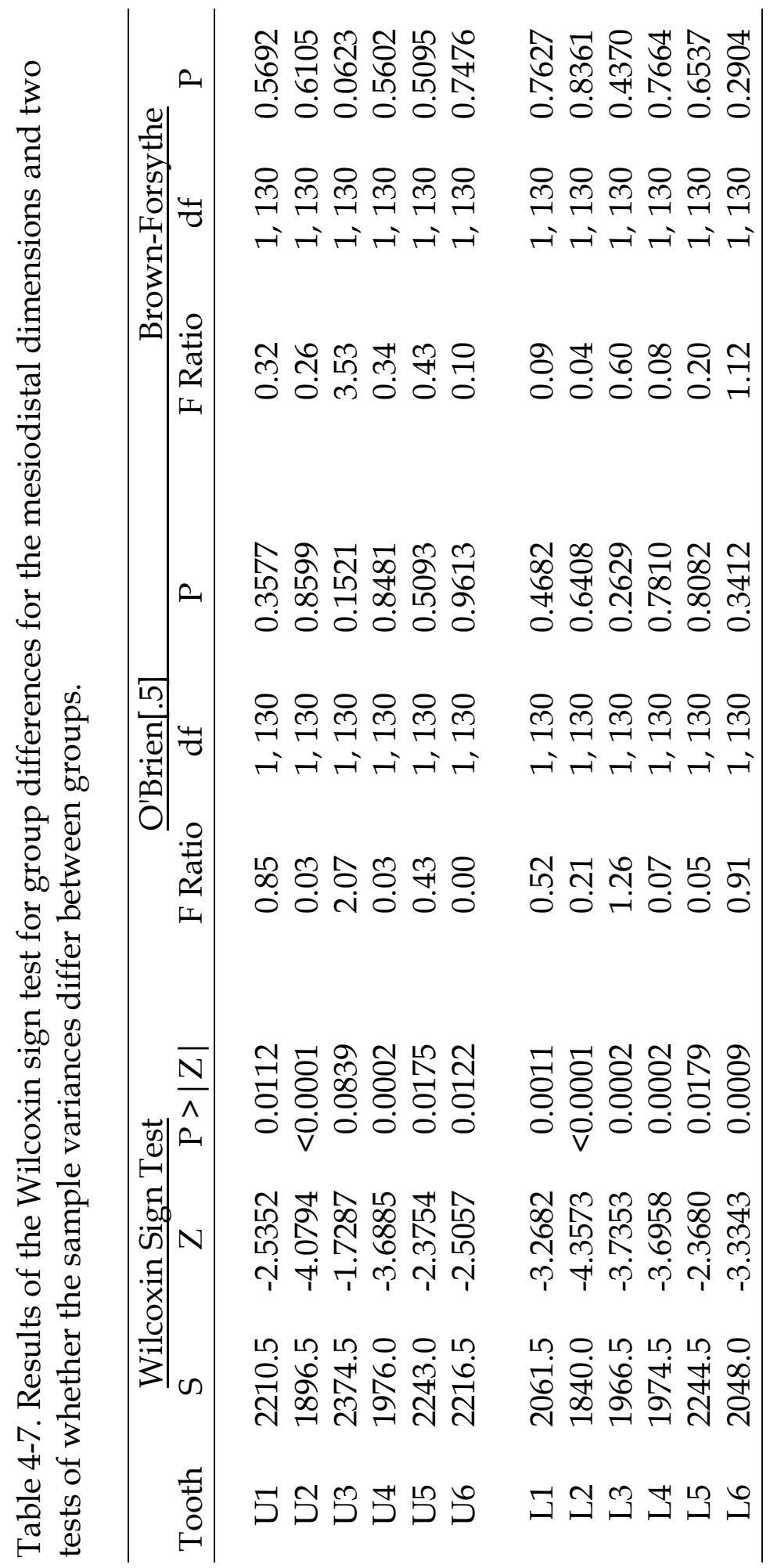




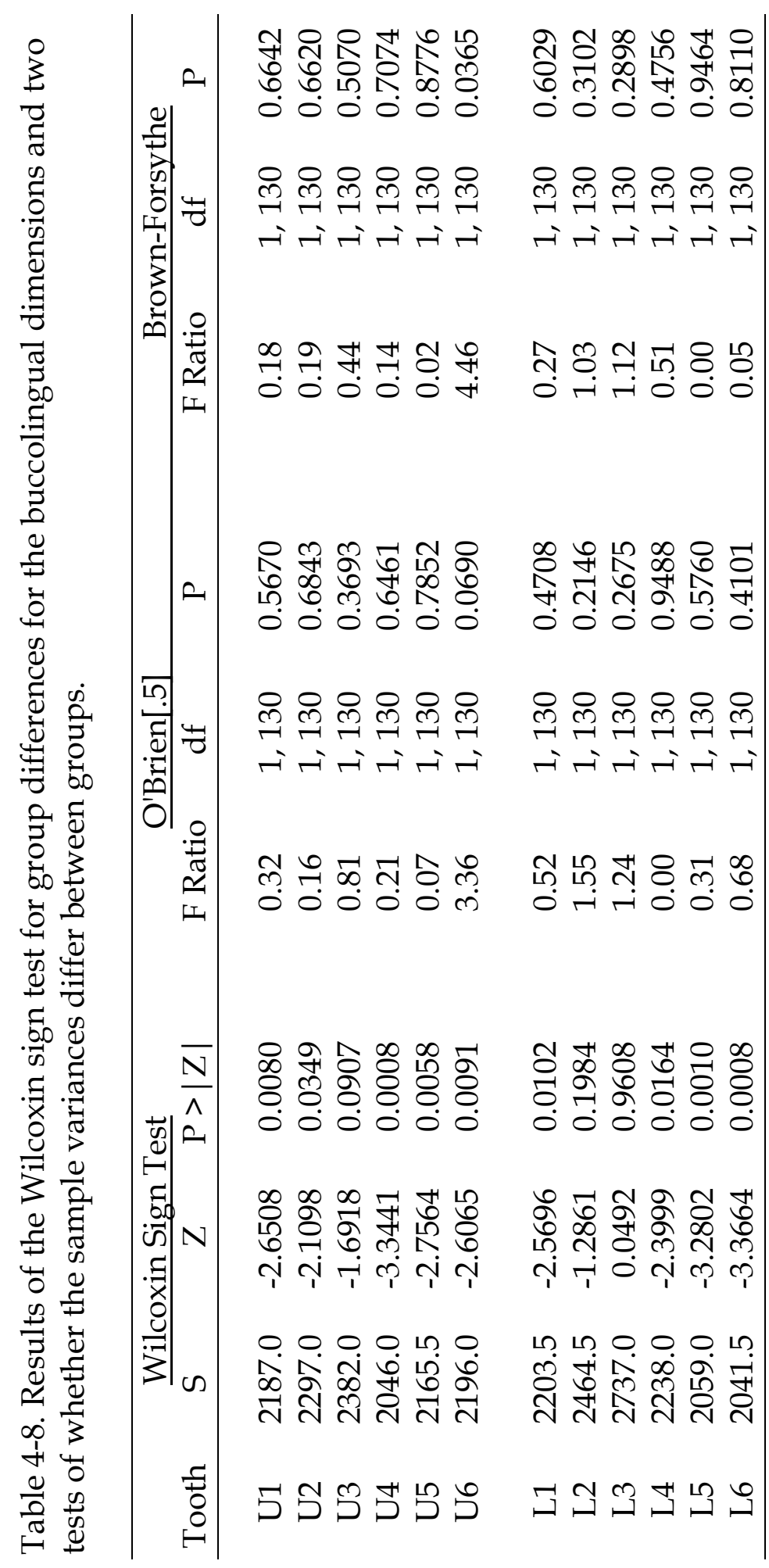


significance with larger sample sizes, but, comparably, there is no suggestion of any patterned size difference between groups for the lower canine ( $\mathrm{P}=0.96$ by the Wilcoxon test). This leaves this canine dimension as the most decidedly indifferent variable of the 24 tested. This exception seems noteworthy if only because of the strong, positive statistical intercorrelations commonly seen among all mesiodistal and buccolingual crown dimensions (e.g., Potter et al. 1968; Henderson 1975).

\section{$\underline{\text { Sample Variances }}$}

The inferential tests (above) consistently show that, when a significant size difference occurs, the orthodontically treated sample exhibits the larger mean size. One possibility is that the treated sample has larger means because of a few measurements in each variable with unusually large dimensions. For example, it is well appreciated that tooth-size abnormalities predispose for occlusal disharmonies (e.g., Bolton 1958, 1962). Unusually large or small specimens in a sample would have the effect of increasing the sample range and sample variance. In passing, the inclusion of outliers that inflate the sample variance correspondingly bias the ANOVA tests described above. On the other hand, calculations of the nonparametric tests in the prior sections shows that the parametric tests are reliable.

This possibility of unequal variances was tested using two complementary 
tests for homogeneity of variances, namely the O'Brien's test and the BrownForsythe test. Both of these were calculated using the JMP statistical platform. The conclusion from these several tests (Tables 4-7, 4-8) is that the variances are statistically homogeneous for all 24 variables. In other words, in conjunction with the other tests, the influence is that the two samples differ because tooth sizes in the orthodontically treated sample are shifted upward en masse; the differences cannot be viewed as due to leverage effects of a scattering of abnormally large specimens in the treated sample.

\section{Crown Size Proportionalities}

Good occlusion depends on teeth in the two arches properly interdigitating (e.g., Lundström 1955; Ramfjord and Ash 1971). In turn, sound interdigitation requires harmonious mesiodistal tooth crown diameters in order for the teeth to mesh properly. This issue of size proportionality is the basis for Bolton $(1958,1962)$ and subsequent researcher's evaluations of tooth size discrepancies (e.g., Crosby and Alexander 1989; Freeman et al. 1996). In this vein, the question occurs whether the risk of malocclusion depends not just on tooth size (which modulates the risk of TSASD), but also on crown size proportionalities that interfere with proper coupling of the teeth.

Differences in proportionalities between the two groups - those with naturally-occurring good occlusions and those with malocclusions - were tested 
by looking for differences in the bivariate ratios of pairs of teeth. For example, does the ratio of I1 to I2 crown widths in the maxilla differ statistically between these two groups?

Using formulae developed in an Excel spreadsheet, we calculated all of the mesiodistal ratios (12 teeth, 66 ratios) and then used one-way ANOVA to test for differences between the two groups. Of course, some of these ratios are of limited relevance either clinically or biologically, but they were all tested for completeness.

\section{$\underline{\text { Mesiodistal Ratios }}$}

Table 4-9 lists the ANOVA results for the 66 mesiodistal ratios. Twelve of these $(12 / 66 ; 18 \%$ ) are significant at $\mathrm{P}<0.05$ (no correction for multiple comparisons), which exceeds the number expected from chance alone. Of much more relevance, certain tooth types - notably the maxillary lateral incisorfrequently recur among the significant ratios. Also of note, the over-arching theme of these several differences is that proportionately bigger teeth are a risk factor for a person being in the malocclusion group.

\section{Maxillary Lateral Incisor}

Inspection of Table 4-9 shows that 7 of the 12 significant statistical results involve the upper lateral incisor. In this series of American whites, having a 
Table 4-9. Univariate tests for group differences in mesiodistal tooth size ratios.

\begin{tabular}{|c|c|c|c|c|c|c|c|c|c|}
\hline \multirow[b]{3}{*}{ Ratio } & & & & & & & \multicolumn{3}{|c|}{ Analysis of Variance } \\
\hline & \multicolumn{3}{|c|}{ No Treatment } & \multicolumn{3}{|c|}{ Treatment Group } & \multirow[b]{2}{*}{ F Ratio } & \multirow[b]{2}{*}{$\mathrm{P}$} & \multirow{2}{*}{$\begin{array}{c}\mathrm{R} \\
\text { Square }\end{array}$} \\
\hline & $\mathrm{n}$ & $\bar{x}$ & se & $\mathrm{n}$ & $\bar{x}$ & se & & & \\
\hline U5/U6 & 41 & 0.643 & 0.007 & 91 & 0.646 & 0.005 & 0.12 & 0.7253 & 0.10 \\
\hline U4/U6 & 41 & 0.654 & 0.007 & 91 & 0.667 & 0.004 & 2.78 & 0.0978 & 2.09 \\
\hline U3/U6 & 41 & 0.754 & 0.007 & 91 & 0.749 & 0.004 & 0.38 & 0.5402 & 0.29 \\
\hline U2/U6 & 41 & 0.639 & 0.009 & 91 & 0.669 & 0.006 & 7.80 & $\underline{0.0060}$ & 5.66 \\
\hline U1/U6 & 41 & 0.831 & 0.009 & 91 & 0.838 & 0.006 & 0.45 & $\overline{0.5044}$ & 0.34 \\
\hline U4/U5 & 41 & 1.017 & 0.008 & 91 & 1.035 & 0.006 & 3.18 & 0.0768 & 2.39 \\
\hline U3/U5 & 41 & 1.174 & 0.011 & 91 & 1.163 & 0.007 & 0.69 & 0.4065 & 0.53 \\
\hline U2/U5 & 41 & 0.995 & 0.012 & 91 & 1.038 & 0.008 & 8.33 & 0.0046 & 6.02 \\
\hline U1/U5 & 41 & 1.294 & 0.014 & 91 & 1.301 & 0.010 & 0.20 & 0.6584 & 0.15 \\
\hline U3/U4 & 41 & 1.156 & 0.010 & 91 & 1.125 & 0.007 & 6.06 & 0.0151 & 4.45 \\
\hline $\mathrm{U} 2 / \mathrm{U} 4$ & 41 & 0.980 & 0.012 & 91 & 1.004 & 0.008 & 2.99 & 0.0861 & 2.25 \\
\hline U2/U3 & 41 & 0.850 & 0.010 & 91 & 0.893 & 0.007 & 13.41 & $\underline{0.0004}$ & 9.35 \\
\hline U1/U4 & 41 & 1.273 & 0.014 & 91 & 1.259 & 0.009 & 0.73 & $\overline{0.3936}$ & 0.56 \\
\hline U1/U3 & 41 & 1.104 & 0.010 & 91 & 1.120 & 0.007 & 1.74 & 0.1896 & 1.32 \\
\hline U1/U2 & 41 & 1.304 & 0.013 & 91 & 1.257 & 0.008 & 9.45 & $\underline{0.0026}$ & 6.77 \\
\hline L1/L2 & 41 & 0.919 & 0.007 & 91 & 0.911 & 0.005 & 1.11 & 0.2948 & 0.84 \\
\hline L1/L3 & 41 & 0.790 & 0.008 & 91 & 0.786 & 0.005 & 0.19 & 0.6601 & 0.15 \\
\hline L1/L4 & 41 & 0.760 & 0.007 & 91 & 0.756 & 0.005 & 0.25 & 0.6155 & 0.19 \\
\hline L1/L5 & 41 & 0.744 & 0.007 & 91 & 0.750 & 0.005 & 0.40 & 0.5295 & 0.30 \\
\hline L1/L6 & 41 & 0.489 & 0.004 & 91 & 0.495 & 0.003 & 1.38 & 0.2423 & 1.05 \\
\hline L2/L3 & 41 & 0.860 & 0.007 & 91 & 0.863 & 0.005 & 0.15 & 0.6951 & 0.12 \\
\hline L2/L4 & 41 & 0.828 & 0.008 & 91 & 0.831 & 0.005 & 0.10 & 0.7521 & 0.08 \\
\hline L2/L5 & 41 & 0.810 & 0.009 & 91 & 0.824 & 0.006 & 1.91 & 0.1690 & 1.45 \\
\hline L2/L6 & 41 & 0.532 & 0.005 & 91 & 0.544 & 0.003 & 4.08 & 0.0455 & 3.04 \\
\hline L3/L4 & 41 & 0.964 & 0.008 & 91 & 0.964 & 0.006 & 0.00 & 0.9725 & 0.00 \\
\hline L3/L5 & 41 & 0.943 & 0.009 & 91 & 0.956 & 0.006 & 1.59 & 0.2094 & 1.21 \\
\hline L3/L6 & 41 & 0.620 & 0.005 & 91 & 0.631 & 0.004 & 3.00 & 0.0856 & 2.26 \\
\hline L4/L5 & 41 & 0.979 & 0.007 & 91 & 0.993 & 0.005 & 2.35 & 0.1274 & 1.78 \\
\hline L4/L6 & 41 & 0.644 & 0.006 & 91 & 0.656 & 0.004 & 2.70 & 0.1028 & 2.03 \\
\hline L5/L6 & 41 & 0.659 & 0.006 & 91 & 0.662 & 0.004 & 0.21 & 0.6510 & 0.16 \\
\hline
\end{tabular}


Table 4-9. Continued.

\begin{tabular}{|c|c|c|c|c|c|c|c|c|c|}
\hline \multirow[b]{3}{*}{ Ratio } & \multirow{2}{*}{\multicolumn{3}{|c|}{$\underline{\text { No Treatment }}$}} & \multirow{2}{*}{\multicolumn{3}{|c|}{ Treatment Group }} & \multicolumn{3}{|c|}{ Analysis of Variance } \\
\hline & & & & & & & & & $\mathrm{R}$ \\
\hline & $\mathrm{n}$ & $\bar{x}$ & se & $\mathrm{n}$ & $\bar{x}$ & se & F Ratio & $\mathrm{P}$ & Square \\
\hline L1/U6 & 41 & 0.511 & 0.006 & 91 & 0.519 & 0.004 & 1.25 & 0.2659 & 0.95 \\
\hline L1/U5 & 41 & 0.796 & 0.009 & 91 & 0.806 & 0.006 & 0.89 & 0.3469 & 0.68 \\
\hline L1/U4 & 41 & 0.783 & 0.008 & 91 & 0.779 & 0.005 & 0.17 & 0.6841 & 0.13 \\
\hline L1/U3 & 41 & 0.679 & 0.006 & 91 & 0.693 & 0.004 & 3.76 & 0.0548 & 2.81 \\
\hline L1/U2 & 41 & 0.802 & 0.008 & 91 & 0.778 & 0.006 & 5.58 & $\underline{0.0196}$ & 4.12 \\
\hline L1/U1 & 41 & 0.615 & 0.005 & 91 & 0.620 & 0.003 & 0.62 & 0.4316 & 0.48 \\
\hline L2/U6 & 41 & 0.557 & 0.006 & 91 & 0.570 & 0.004 & 3.71 & 0.0561 & 2.78 \\
\hline L2/U5 & 41 & 0.867 & 0.010 & 91 & 0.886 & 0.007 & 2.54 & 0.1137 & 1.91 \\
\hline L2/U4 & 41 & 0.853 & 0.008 & 91 & 0.857 & 0.006 & 0.14 & 0.7060 & 0.11 \\
\hline L2/U3 & 41 & 0.739 & 0.006 & 91 & 0.762 & 0.004 & 8.59 & $\underline{0.0040}$ & 6.20 \\
\hline L2/U2 & 41 & 0.874 & 0.009 & 91 & 0.856 & 0.006 & 2.84 & $\overline{0.0945}$ & 2.14 \\
\hline L2/U1 & 41 & 0.670 & 0.005 & 91 & 0.681 & 0.003 & 3.58 & 0.0605 & 2.68 \\
\hline L3/U6 & 41 & 0.648 & 0.006 & 91 & 0.661 & 0.004 & 3.38 & 0.0681 & 2.54 \\
\hline L3/U5 & 41 & 1.009 & 0.010 & 91 & 1.027 & 0.007 & 2.25 & 0.1357 & 1.70 \\
\hline L3/U4 & 41 & 0.993 & 0.009 & 91 & 0.993 & 0.006 & 0.00 & 0.9518 & 0.00 \\
\hline L3/U3 & 41 & 0.860 & 0.006 & 91 & 0.884 & 0.004 & 10.22 & $\underline{0.0017}$ & 7.29 \\
\hline L3/U2 & 41 & 1.018 & 0.012 & 91 & 0.993 & 0.008 & 3.11 & $\overline{0.0802}$ & 2.34 \\
\hline L3/U1 & 41 & 0.781 & 0.007 & 91 & 0.791 & 0.005 & 1.42 & 0.2357 & 1.08 \\
\hline L4/U6 & 41 & 0.674 & 0.007 & 91 & 0.687 & 0.005 & 2.75 & 0.1000 & 2.07 \\
\hline L4/U5 & 41 & 1.048 & 0.010 & 91 & 1.067 & 0.006 & 2.73 & 0.1007 & 2.06 \\
\hline L4/U4 & 41 & 1.031 & 0.007 & 91 & 1.032 & 0.005 & 0.00 & 0.9582 & 0.00 \\
\hline L4/U3 & 41 & 0.894 & 0.008 & 91 & 0.919 & 0.006 & 5.89 & 0.0166 & 4.34 \\
\hline L4/U2 & 41 & 1.058 & 0.013 & 91 & 1.033 & 0.009 & 2.65 & 0.1061 & 2.00 \\
\hline L4/U1 & 41 & 0.812 & 0.009 & 91 & 0.823 & 0.006 & 1.09 & 0.2990 & 0.83 \\
\hline L5/U6 & 41 & 0.689 & 0.007 & 91 & 0.693 & 0.005 & 0.25 & 0.6170 & 0.19 \\
\hline L5/U5 & 41 & 1.071 & 0.009 & 91 & 1.076 & 0.006 & 0.18 & 0.6738 & 0.14 \\
\hline L5/U4 & 41 & 1.055 & 0.008 & 91 & 1.041 & 0.005 & 2.13 & 0.1468 & 1.61 \\
\hline L5/U3 & 41 & 0.915 & 0.009 & 91 & 0.927 & 0.006 & 1.16 & 0.2826 & 0.89 \\
\hline L5/U2 & 41 & 1.082 & 0.013 & 91 & 1.041 & 0.009 & 6.44 & $\underline{0.0123}$ & 4.72 \\
\hline L5/U1 & 41 & 0.830 & 0.009 & 91 & 0.830 & 0.006 & 0.01 & 0.9398 & 0.00 \\
\hline L6/U6 & 41 & 1.046 & 0.008 & 91 & 1.048 & 0.005 & 0.08 & 0.7836 & 0.06 \\
\hline L6/U5 & 41 & 1.629 & 0.015 & 91 & 1.629 & 0.010 & 0.00 & 0.9853 & 0.00 \\
\hline L6/U4 & 41 & 1.604 & 0.015 & 91 & 1.576 & 0.010 & 2.38 & 0.1252 & 1.80 \\
\hline L6/U3 & 41 & 1.391 & 0.012 & 91 & 1.402 & 0.008 & 0.64 & 0.4238 & 0.49 \\
\hline L6/U2 & 41 & 1.644 & 0.019 & 91 & 1.576 & 0.013 & 8.83 & $\underline{0.0035}$ & 6.36 \\
\hline L6/U1 & 41 & 1.261 & 0.011 & 91 & 1.255 & 0.008 & 0.24 & $\overline{0.6246}$ & 0.18 \\
\hline
\end{tabular}


mesiodistally broad UI2 is a risk factor for malocclusion. Detailing these results:

1. UI2 is $64 \%$ as wide as the maxillary first molar (U6) in the untreated group, but significantly broader $(67 \%)$ in the malocclusion sample.

2. UI2 is just about as big mesiodistally as the maxillary second premolar $(\mathrm{U} 2 / \mathrm{U} 5=99.5 \%)$ in the untreated group, but significantly broader than this premolar (104\%) in the malocclusion sample.

3. UI2 is proportionately smaller than the maxillary canine $(\mathrm{U} 2 / \mathrm{U} 3=85 \%)$ in the untreated group, but significantly broader $(89 \%)$ in the malocclusion group.

4. UI2 is broader in relation to the maxillary central incisor in the malocclusion group. Table 4-9 lists the ratio as UI2/UI1, but the difference is easier to appreciate when UI2 is expressed as a percentage of UI 1 width: UI2 is $77 \%$ as wide as UI1 in the untreated sample, but a significantly greater percentage $(80 \%)$ of UI1 width in the malocclusion sample. The theme, again, is that greater tooth mass - specifically greater mesiodistal widths requiring proportionately more arch perimeter-increase the risk of malocclusion.

5. UI2 is significantly broader than the mandibular central incisor in the malocclusion group. In the untreated sample UI2 is $125 \%$ the width of LI2 (inverting the ratio listed in Table 4-9), but this relationship increases to 129\% in the malocclusion group. One can appreciate that this greater size 
difference could prevent proper coupling of teeth in the anterior segment in the malocclusion group.

6. UI2 is a significantly greater proportion of the width of the mandibular second premolar (96\%) in the malocclusion sample than in the untreated sample $(92 \%)$.

7. UI2 is a significantly greater proportion of the width of the mandibular first molar (63\%) in the malocclusion sample than in the untreated group (61\%). These several recurrences of one variable (UI2) among the 12 tooth types tested is not at all surprising since all mesiodistal and buccolingual crown dimensions are positively intercorrelated (e.g., Potter et al. 1968; Harris and Bailit 1988).

Statistically, a large crown dimension of one tooth is predictive of (significantly correlated with) large dimensions of other teeth.

It is worth interjecting here that the importance of the width of UI2 may be a function of the group studied. That is, comparatively small UI2 crown widths is a feature distinctive of Caucasians (e.g., Moorrees 1957; Lasker and Lee 1957; Harris and Rathbun 1991). Other racial groups have appreciably broader lateral incisors, so the importance of UI2 seen in this analysis may not relate to tooth-size occlusal problems in other ethnic groups. 


\section{Maxillary Canine}

Aside from UI2 (Table 4-9), the other dimension that contributes to multiple significant group differences is the maxillary canine. Four ratios that depend on upper canine width are significant:

1. Reversing the relationship discussed above from UI2, the canine is comparatively narrower in the malocclusion group $(112 \%)$ than the untreated group $(118 \%)$ relative to UI2. This interpretation likely is faulty, though, because the several other ratios show that the main difference is with size of the lateral incisor.

2. The mandibular lateral incisor is significantly narrower (74\%) relative to U3 in the untreated group than in the sample that required treatment $(76 \%)$.

3. Width of $\mathrm{U} 3$ relative to that of the mandibular canine is significantly different between groups because the lower canine is $86 \%$ of the width of U3 in the untreated group, but broader $(88 \%)$ in the malocclusion group.

4. The mandibular first premolar is significantly narrower ( $89 \%)$ relative to L3 in the untreated sample than in the group that required treatment (92\%).

\section{$\underline{\text { Buccolingual Crown Ratios }}$}

It is easy to visualize how differences in mesiodistal crown size can lead to malocclusions (notably TSASD) because these crown dimensions contribute directly to space required. It is not at all apparent how buccolingual crown sizes 
are involved. Still, the work of Sheldon Peck and collaborators (1972a,b; 1975) has strongly colored the specialty's perception of the potential importance of the buccolingual dimension or, at the least, tooth crown proportions (e.g., Shah et al. 2003, 2005).

We collected buccolingual (BL) crown diameters in the present study specifically to assess these earlier contentions, and Table 4-10 lists the bivariate BL crown size ratios. Nine of these 66 combinations (14\%) have significantly different ratios in the two groups (no correction for multiple comparisons). Inspection shows that these significant differences are strongly clustered in the anterior segment of the arches, notably the mandibular canine (which accounts for 8 of the 9 significant ratios).

Results show that the relative sizes (i.e., size ratios) are significantly different between the two occlusal groups for the mandibular canine and each of the maxillary incisors, canine, and premolars, namely L3/U1, L3/U2, L3/U3, L3/U4, and L3/U5. It is informative to recall that the mean buccolingual dimension of L3 is almost identical - a mean of $7.6 \mathrm{~mm}$ - in both groups. Consequently, these differences in relative size can be viewed as differences in the other BL diameters relative to the common canine dimension of $7.6 \mathrm{~mm}$. In these cases, the smaller the ratio, the larger the BL crown diameter of the tooth in the denominator.

For example, the L3/U5 ratio has the largest $\mathrm{F}$ ratio of any of the 66 ratios 
Table 4-10. Univariate tests for group differences in buccolingual tooth size ratios.

\begin{tabular}{|c|c|c|c|c|c|c|c|c|c|}
\hline \multirow[b]{3}{*}{ Ratio } & \multirow{2}{*}{\multicolumn{3}{|c|}{ No Treatment }} & \multirow{2}{*}{\multicolumn{3}{|c|}{$\underline{\text { Treatment Group }}$}} & \multicolumn{3}{|c|}{ Analysis of Variance } \\
\hline & & & & & & & & & $\mathrm{R}$ \\
\hline & $\mathrm{n}$ & $\overline{\mathrm{x}}$ & se & $\mathrm{n}$ & $\overline{\mathrm{x}}$ & se & F Ratio & $\mathrm{P}$ & Square \\
\hline U5/U6 & 41 & 0.821 & 0.007 & 91 & 0.828 & 0.004 & 0.85 & 0.3574 & 0.65 \\
\hline U4/U6 & 41 & 0.797 & 0.007 & 91 & 0.811 & 0.005 & 2.94 & 0.0886 & 2.21 \\
\hline U4/U5 & 41 & 0.971 & 0.006 & 91 & 0.981 & 0.004 & 1.70 & 0.1947 & 1.29 \\
\hline U3/U6 & 41 & 0.720 & 0.007 & 91 & 0.719 & 0.005 & 0.00 & 0.9686 & 0.00 \\
\hline U3/U5 & 41 & 0.878 & 0.008 & 91 & 0.870 & 0.006 & 0.59 & 0.4423 & 0.45 \\
\hline U3/U4 & 41 & 0.904 & 0.008 & 91 & 0.888 & 0.005 & 3.19 & 0.0764 & 2.40 \\
\hline U2/U6 & 41 & 0.547 & 0.007 & 91 & 0.551 & 0.005 & 0.18 & 0.6684 & 0.14 \\
\hline $\mathrm{U} 2 / \mathrm{U} 5$ & 41 & 0.667 & 0.008 & 91 & 0.667 & 0.006 & 0.01 & 0.9414 & 0.00 \\
\hline $\mathrm{U} 2 / \mathrm{U} 4$ & 41 & 0.688 & 0.008 & 91 & 0.680 & 0.005 & 0.58 & 0.4470 & 0.45 \\
\hline U2/U3 & 41 & 0.762 & 0.009 & 91 & 0.767 & 0.006 & 0.21 & 0.6437 & 0.17 \\
\hline U1/U6 & 41 & 0.609 & 0.007 & 91 & 0.616 & 0.005 & 0.64 & 0.4269 & 0.49 \\
\hline U1/U5 & 41 & 0.743 & 0.009 & 91 & 0.745 & 0.006 & 0.04 & 0.8415 & 0.03 \\
\hline $\mathrm{U} 1 / \mathrm{U} 4$ & 41 & 0.765 & 0.009 & 91 & 0.760 & 0.006 & 0.24 & 0.6267 & 0.18 \\
\hline U1/U3 & 41 & 0.847 & 0.009 & 91 & 0.857 & 0.006 & 0.77 & 0.3812 & 0.59 \\
\hline U1/U2 & 41 & 1.117 & 0.012 & 91 & 1.120 & 0.008 & 0.05 & 0.8266 & 0.04 \\
\hline L1/L2 & 41 & 0.942 & 0.007 & 91 & 0.961 & 0.004 & 5.91 & $\underline{0.0164}$ & 4.35 \\
\hline L1/L3 & 41 & 0.775 & 0.009 & 91 & 0.807 & 0.006 & 8.18 & $\underline{0.0049}$ & 5.92 \\
\hline L1/L4 & 41 & 0.751 & 0.009 & 91 & 0.750 & 0.006 & 0.00 & 0.9698 & 0.00 \\
\hline L1/L5 & 41 & 0.702 & 0.008 & 91 & 0.698 & 0.006 & 0.17 & 0.6777 & 0.13 \\
\hline L1/L6 & 41 & 0.568 & 0.007 & 91 & 0.574 & 0.004 & 0.45 & 0.5023 & 0.35 \\
\hline L2/L3 & 41 & 0.824 & 0.009 & 91 & 0.840 & 0.006 & 2.33 & 0.1292 & 1.76 \\
\hline L2/L4 & 41 & 0.799 & 0.010 & 91 & 0.782 & 0.007 & 2.03 & 0.1568 & 1.54 \\
\hline L2/L5 & 41 & 0.747 & 0.009 & 91 & 0.727 & 0.006 & 3.44 & 0.0659 & 2.58 \\
\hline L2/L6 & 41 & 0.604 & 0.007 & 91 & 0.598 & 0.005 & 0.57 & 0.4515 & 0.44 \\
\hline L3/L4 & 41 & 0.971 & 0.012 & 91 & 0.933 & 0.008 & 6.48 & $\underline{0.0121}$ & 4.75 \\
\hline L3/L5 & 41 & 0.908 & 0.011 & 91 & 0.868 & 0.007 & 9.47 & $\underline{0.0025}$ & 6.79 \\
\hline L3/L6 & 41 & 0.735 & 0.009 & 91 & 0.713 & 0.006 & 3.76 & 0.0546 & 2.81 \\
\hline L4/L5 & 41 & 0.936 & 0.006 & 91 & 0.931 & 0.004 & 0.34 & 0.5590 & 0.26 \\
\hline L4/L6 & 41 & 0.758 & 0.008 & 91 & 0.766 & 0.005 & 0.75 & 0.3887 & 0.57 \\
\hline L5/L6 & 41 & 0.811 & 0.007 & 91 & 0.823 & 0.005 & 2.07 & 0.1531 & 1.56 \\
\hline L1/U6 & 41 & 0.514 & 0.006 & 91 & 0.519 & 0.004 & 0.48 & 0.4914 & 0.36 \\
\hline
\end{tabular}

Continued 
Table 4-10. Continued.

Analysis of Variance

No Treatment $\quad$ Treatment Group $\quad \mathrm{R}$

\begin{tabular}{|c|c|c|c|c|c|c|c|c|c|}
\hline Ratio & $\mathrm{n}$ & $\overline{\mathrm{x}}$ & se & $\mathrm{n}$ & $\overline{\mathrm{x}}$ & se & F Ratio & $\mathrm{P}$ & Square \\
\hline L1/U5 & 41 & 0.627 & 0.008 & 91 & 0.628 & 0.005 & 0.03 & 0.8639 & 0.02 \\
\hline L1/U4 & 41 & 0.646 & 0.008 & 91 & 0.641 & 0.005 & 0.26 & 0.6144 & 0.20 \\
\hline L1/U3 & 41 & 0.715 & 0.008 & 91 & 0.723 & 0.006 & 0.57 & 0.4525 & 0.43 \\
\hline L1/U2 & 41 & 0.944 & 0.013 & 91 & 0.946 & 0.009 & 0.01 & 0.9283 & 0.01 \\
\hline L1/U1 & 41 & 0.846 & 0.011 & 91 & 0.846 & 0.007 & 0.00 & 0.9524 & 0.00 \\
\hline L2/U6 & 41 & 0.546 & 0.007 & 91 & 0.541 & 0.004 & 0.43 & 0.5111 & 0.33 \\
\hline L2/U5 & 41 & 0.666 & 0.008 & 91 & 0.654 & 0.005 & 1.45 & 0.2306 & 1.10 \\
\hline L2/U4 & 41 & 0.686 & 0.008 & 91 & 0.668 & 0.005 & 3.68 & 0.0574 & 2.75 \\
\hline L2/U3 & 41 & 0.760 & 0.009 & 91 & 0.753 & 0.006 & 0.53 & 0.4669 & 0.41 \\
\hline L2/U2 & 41 & 1.004 & 0.014 & 91 & 0.985 & 0.009 & 1.37 & 0.2433 & 1.05 \\
\hline L2/U1 & 41 & 0.900 & 0.011 & 91 & 0.881 & 0.008 & 1.91 & 0.1699 & 1.44 \\
\hline L3/U6 & 41 & 0.664 & 0.008 & 91 & 0.646 & 0.006 & 3.31 & 0.0711 & 2.48 \\
\hline L3/U5 & 41 & 0.811 & 0.010 & 91 & 0.781 & 0.007 & 5.89 & $\underline{0.0166}$ & 4.34 \\
\hline L3/U4 & 41 & 0.835 & 0.010 & 91 & 0.797 & 0.007 & 9.93 & $\underline{0.0020}$ & 7.10 \\
\hline L3/U3 & 41 & 0.924 & 0.010 & 91 & 0.898 & 0.007 & 5.04 & $\underline{0.0264}$ & 3.73 \\
\hline L3/U2 & 41 & 1.222 & 0.018 & 91 & 1.176 & 0.012 & 4.51 & $\underline{0.0355}$ & 3.36 \\
\hline L3/U1 & 41 & 1.095 & 0.014 & 91 & 1.052 & 0.010 & 6.06 & $\underline{0.0151}$ & 4.46 \\
\hline L4/U6 & 41 & 0.686 & 0.007 & 91 & 0.694 & 0.005 & 0.84 & 0.3624 & 0.64 \\
\hline L4/U5 & 41 & 0.836 & 0.008 & 91 & 0.839 & 0.005 & 0.12 & 0.7323 & 0.09 \\
\hline L4/U4 & 41 & 0.861 & 0.007 & 91 & 0.855 & 0.005 & 0.39 & 0.5326 & 0.30 \\
\hline L4/U3 & 41 & 0.954 & 0.011 & 91 & 0.967 & 0.008 & 0.79 & 0.3765 & 0.60 \\
\hline L4/U2 & 41 & 1.259 & 0.018 & 91 & 1.265 & 0.012 & 0.07 & 0.7978 & 0.05 \\
\hline L4/U1 & 41 & 1.129 & 0.015 & 91 & 1.132 & 0.010 & 0.02 & 0.8790 & 0.02 \\
\hline L5/U6 & 41 & 0.733 & 0.007 & 91 & 0.745 & 0.005 & 1.85 & 0.1761 & 1.40 \\
\hline L5/U5 & 41 & 0.894 & 0.008 & 91 & 0.901 & 0.005 & 0.58 & 0.4468 & 0.45 \\
\hline L5/U4 & 41 & 0.921 & 0.008 & 91 & 0.919 & 0.005 & 0.05 & 0.8175 & 0.04 \\
\hline L5/U3 & 41 & 1.022 & 0.012 & 91 & 1.038 & 0.008 & 1.26 & 0.2638 & 0.96 \\
\hline L5/U2 & 41 & 1.348 & 0.019 & 91 & 1.359 & 0.013 & 0.21 & 0.6478 & 0.16 \\
\hline L5/U1 & 41 & 1.209 & 0.017 & 91 & 1.216 & 0.011 & 0.12 & 0.7287 & 0.09 \\
\hline L6/U6 & 41 & 0.905 & 0.006 & 91 & 0.906 & 0.004 & 0.02 & 0.8829 & 0.02 \\
\hline L6/U5 & 41 & 1.104 & 0.011 & 91 & 1.097 & 0.007 & 0.34 & 0.5601 & 0.26 \\
\hline L6/U4 & 41 & 1.138 & 0.011 & 91 & 1.119 & 0.007 & 2.24 & 0.1373 & 1.69 \\
\hline L6/U3 & 41 & 1.262 & 0.014 & 91 & 1.263 & 0.009 & 0.01 & 0.9330 & 0.01 \\
\hline L6/U2 & 41 & 1.666 & 0.023 & 91 & 1.653 & 0.015 & 0.23 & 0.6287 & 0.18 \\
\hline L6/U1 & 41 & 1.493 & 0.019 & 91 & 1.479 & 0.013 & 0.40 & 0.5268 & 0.31 \\
\hline
\end{tabular}


calculated in Table 4-10 because the mean ratio differs the most between the two groups. The ratio is 0.835 in the untreated group, meaning that L3 (the mandibular canine) buccolingual dimension is $83.5 \%$ the size of U5 (the maxillary second premolar). In contrast, this ratio is 0.797 in the orthodontic group, meaning that L3 is $79.7 \%$ of U5. Again, since L3 happens to be the same size in both groups $(\bar{x}=7.6 \mathrm{~mm})$, the untreated group-with the lower L3/U5 ratio-has the smaller BL mean size of U5. Mean BL size of U5 is $9.44 \mathrm{~mm}$ in the untreated group and $9.77 \mathrm{~mm}$ in the treated group. In sum, all of the five significant ratios involving L3 (L3/U1, L3/U2, L3/U3, L3/U4, L3/U5) are caused by significantly larger BL dimensions of the denominator variable in the malocclusion group.

Two significant BL ratios involve the mandibular central incisor (Table 410), namely L1/L2 and L1/L3. These both stem from L1 being disproportionately large buccolingually in the malocclusion group, so L1 is a greater proportion of the denominator variable.

\section{$\underline{\text { MD/BL Ratios }}$}

The crown index - a ratio of crown length to breadth (e.g., Jacobson 1982) - has long been used to characterize crown shape, and it is relevant here because Peck and Peck (1972a,b) focused attention on the MD/BL ratios of the mandibular incisor as a risk factor for anterior crowding (also Smith et al. 1982; 
see Shah et al. 2003). Specifically, Peck and Peck found that the MD crown widths of the mandibular incisors were significantly narrower in their perfectalignment sample but BL dimensions were significantly larger (Fig. 2-1). Predictably, then, the MD/BL index was smaller (i.e., greater BL size to MD size) in their perfect-alignment sample. Peck and Peck (1972b) argued that the crown index of lower incisors should be assessed, and teeth with small MD/BL indexes might well benefit from selective interproximal reduction, which they suggested be termed reproximation, though "interproximal reduction" seems to be a more popular term today. Reducing a tooth's MD dimension causes the MD/BL ratio to diminish. Clinically, reproximation obviously reduces the arch space required to properly align the tooth and it also can alter crown form (see, e.g., Rhee and Nahm 2000), so there is greater contact area and, perhaps, a more stable orthodontic result (e.g., Freitas et al. 2006).

The two key issues here are (1) whether the results from Peck and Peck $(1972 a, b)$ can be reproduced in the present study and (2) whether the crown index (MD/BL) of any other tooth types discriminates statistically between the two occlusal groups. Table 4-11 lists descriptive statistics for the crown index of each of the 12 tooth types studied in this project, along with one-way ANOVA testing for a group difference.

Two of the crown indices differ significantly between groups, namely the mandibular lateral incisor and the, mandibular canine. (In passing, it is worth 


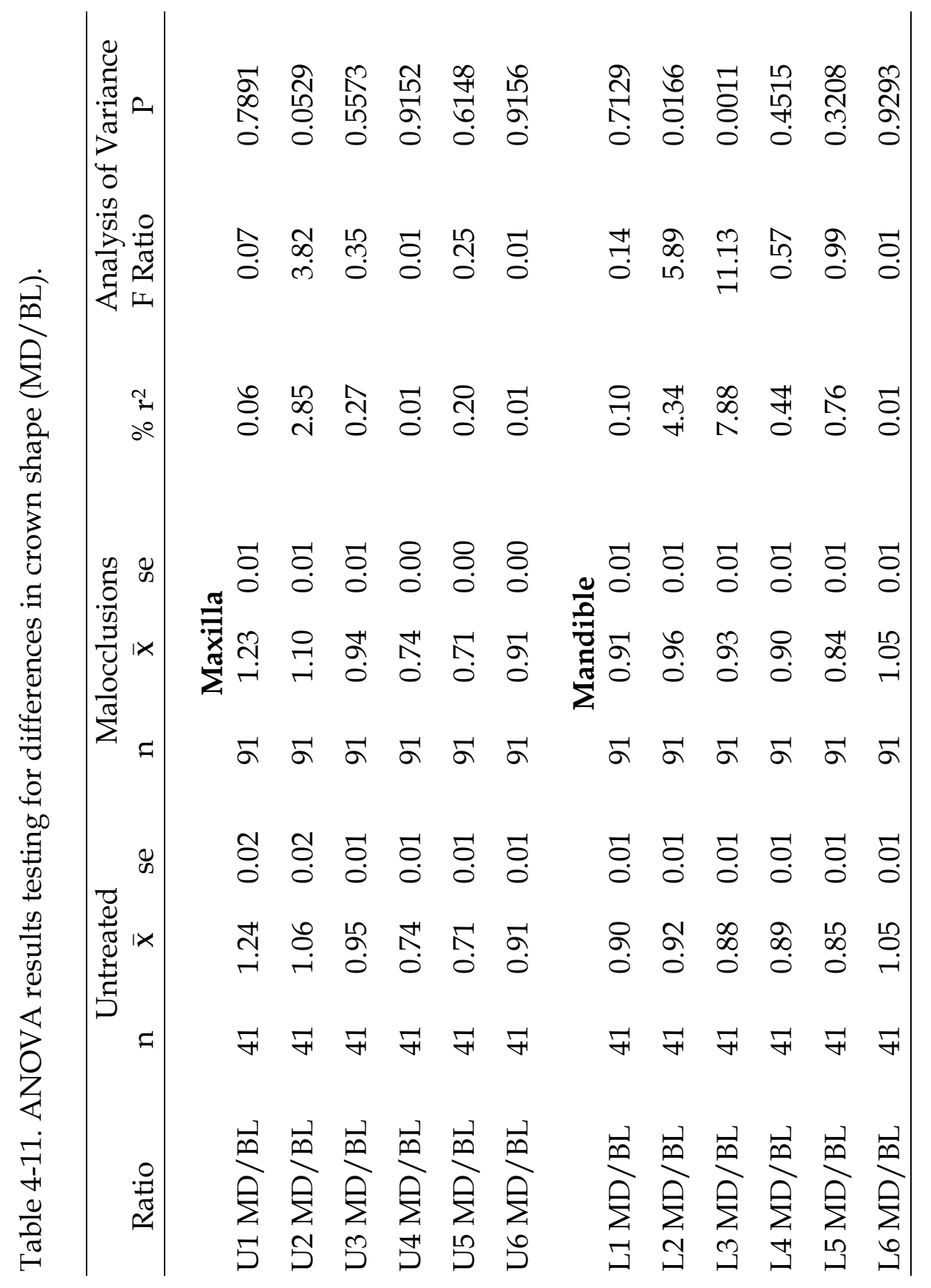


noting that the difference for the maxillary lateral incisor is "close" to being significant statistically, $0.10>\mathrm{P}>0.05)$. In each case (L2, L3, and U2), the $\mathrm{MD} / \mathrm{BL}$ crown index is higher in the malocclusion group. A "different" index is not in itself informative because a higher index can result from a larger numerator, smaller denominator, or both. The relevant group meansabstracted from prior tables - are listed in Table 4-12, and it becomes evident that the controlling differences are along the mesiodistal axis. That is, the crown indexes are larger for L2 and L3 in the malocclusion group because their MD crown breadths are larger (not because their BL dimensions differ much).

From the results in Table 4-11, it can be inferred (1) that the crown index is significantly higher for L2 in the malocclusion group, which agrees with the results of Peck and Peck (1972a,b), (2) that the present results do not support Peck and Peck's findings for L1, (3) that significant differences in keeping with Peck and Peck's model occur here for L3, and (4) that differences in crown indexes are not common elsewhere in the dentition, though the results for $\mathrm{U} 2$ are suggestive.

Peck and Peck's findings that the crown index (i.e., MD to BL size ratio) is a risk factor is intriguing because there is no obvious explanation of how or why a tooth crown's potential buccolingual size could impact TSASD. One issue revolves around the widespread, positive intercorrelations of crown dimension (e.g., Moorrees and Reed 1964). Figure 4-5 illustrates two complementary 
Table 4-12. Mean crown dimensions of the teeth with different crown indexes between groups.

\begin{tabular}{|c|c|c|c|c|}
\hline \multirow[b]{2}{*}{ Tooth } & \multicolumn{2}{|c|}{ Good Occlusion } & \multicolumn{2}{|c|}{ Malocclusion } \\
\hline & MD & BL & $\mathrm{MD}$ & BL \\
\hline Lateral Incisor & 5.78 & 6.28 & 6.08 & 6.38 \\
\hline Canine & 6.73 & 7.64 & 7.06 & 7.62 \\
\hline
\end{tabular}



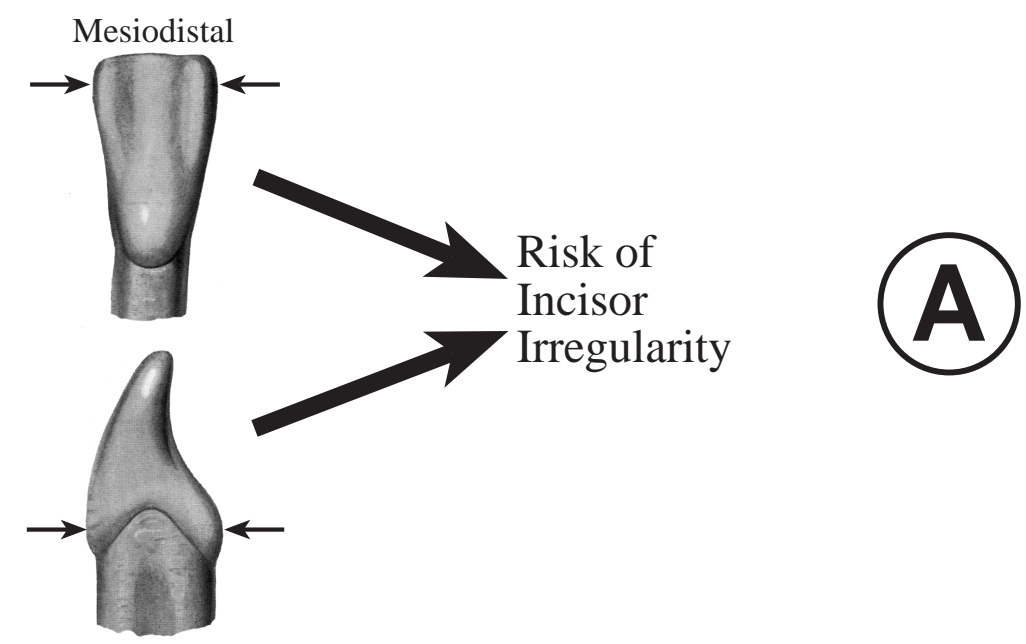

Buccolingual

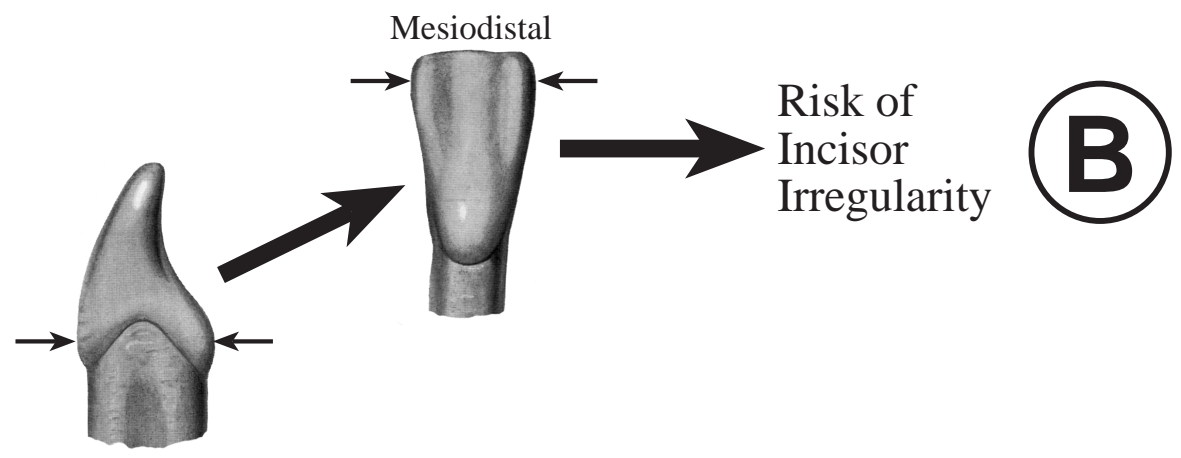

Buccolingual

Fig. 4-5. A schematic illustration of two complementary scenarios of how crown dimensions influence the risk of TSASD. See text for details. 
pathways by which crown index can be associated with the risk of incisor irregularity (or, more generally, TSASD). In the top scheme (A), a tooth crown's $\mathrm{MD}$ and $\mathrm{BL}$ dimensions are predictive of TSASD. This seems to be the model proposed by Peck and Peck (1972a,b), where they make no distinction between the etiological source or relative importance of the MD and BL diameters in affecting crown index which, in turn, influences the risk of TSASD. That is, they reported that incisors with a lower index occurred in their perfect-alignment sample, and they implied that differences in either (or both) crown axes could be involved. Clinically, of course, one needs to address the large MD incisor diameter since this affects directly TSASD, and can be modified with judicious reproximation.

The second scenario is depicted in Figure 4-5 (scenario B), and the key difference is that size of the BL dimension acts indirectly through the MD dimension to affect the risk of TSASD. That is, MD and BL crown dimensions are positively (and statistically significantly) intercorrelated for all tooth types (e.g., Henderson 1975; Harris and Bailit 1988). For example, Harris and Bailit list the correlation between the MD and BL dimensions of the mandibular central incisor at $\mathrm{r}=+0.37$, which is comparable to the $\mathrm{r}=+0.45$ found in the present study. These statistical associations presumably reflect biological, developmental interrelationships between the two main axes of crown size. Our preferred scenario (Fig. 4-5, scenario B) is that TSASD is influenced by a tooth's 
mesiodistal crown diameter, which is, of course, the central issue in achieving proper tooth alignment. The buccolingual crown dimension also is statistically associated with TSASD, but only because BL size is correlated with MD size. In other words, BL size covaries with TSASD, but only indirectly because of its association with MD size.

Statistically, there are various ways of evaluating these two scenarios (Fig. 4-5), such as path analysis or stepwise discriminant analysis. We have chosen the nominal logistic analysis, where, for each of 12 tooth types measured, the question was whether the MD size of a tooth type and/or its BL dimension was predictive of whether a person was in the good-occlusion category or, otherwise, was in the orthodontic treatment group. This method occasionally is termed the nominal logisitic "personality" of the generalized linear model. Peck and Peck's research focused specifically on the mandibular incisors, but we have extended the analysis to look at all 12 tooth types (Table 4-13).

We describe the analysis for the maxillary central incisor in detail in order to make the method clearer. The nominal logistic method tests whether the distributions of continuous variables (i.e., the MD and/or BL crown dimensions) differ significantly between two categories, namely the sample with naturallyoccurring good occlusions versus those who required orthodontic treatment. For the maxillary central incisor, the overall (model) test is highly significant $\left(\chi^{2}=\right.$ $11.5 ; \mathrm{P}=0.0031)$, indicating that one or both of the predictor variables is 


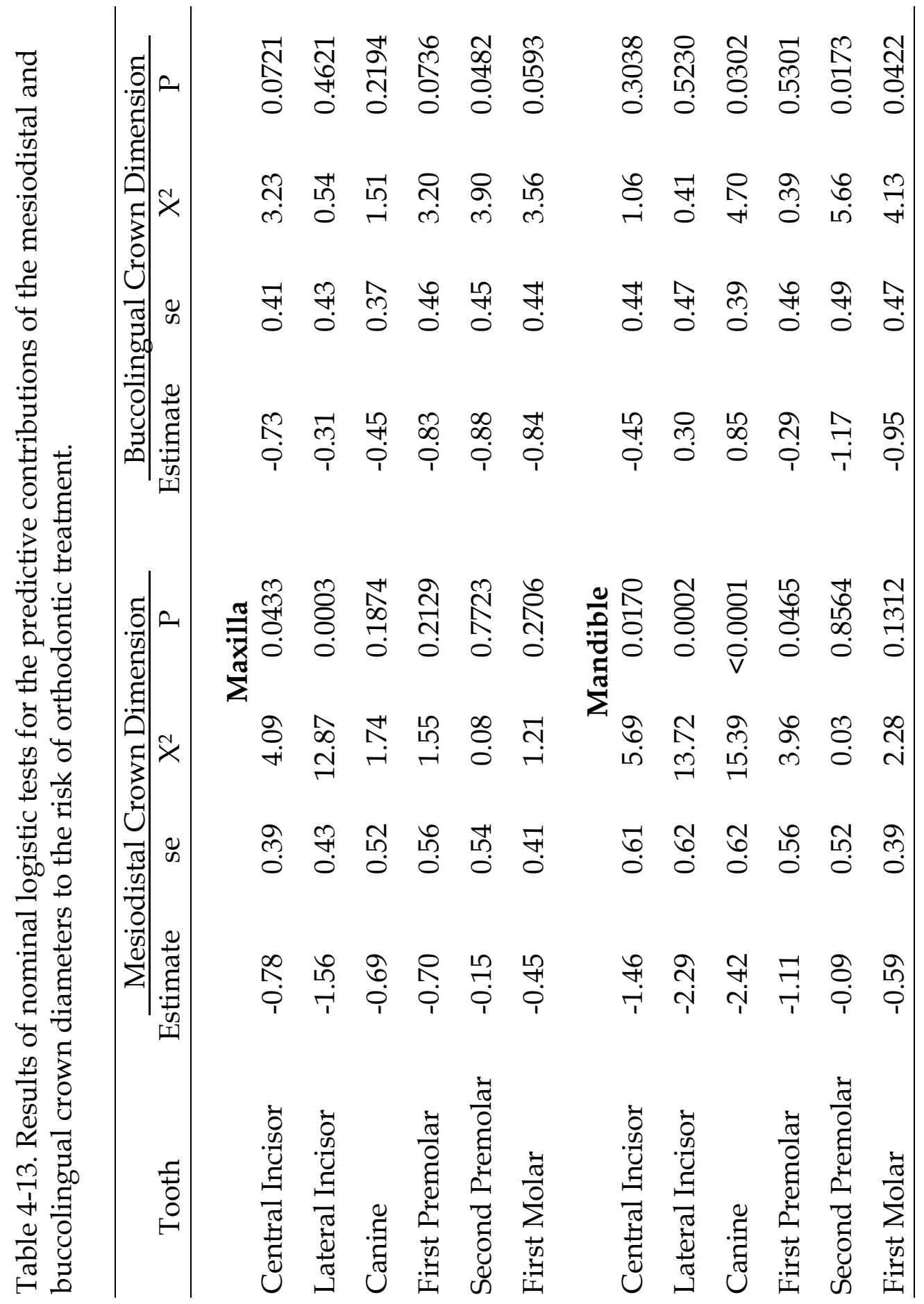


statistically significant. As shown in the first data line in Table 4-13, the group difference for the mesiodistal diameter achieves significance $(P=0.0433)$, and inspection shows (as described previously) that this tooth's MD dimension is larger in the group treated orthodontically $(\bar{x}=8.93 \mathrm{~mm}$ in the treated sample; $\bar{x}$ $=8.63 \mathrm{~mm}$ in the good-occlusion sample). Having accounted for this variation, the logistic model shows that the BL dimension is not predictive of group allocation, that there is no significant BL size difference once the MD information is used. As such, these data for UI1 are in concert with scenario B in Figure 4-5.

Results in Table 4-13 show that (1) for 4 of the 12 tooth types (UC, UP1, UM1, and LP1) neither crown dimension significantly discriminates between the two groups, (2) four tests - on the four incisor types - find a significant association for the MD dimension but not buccolingually, (3) the four molar types show, conversely, that BL widths are marginally predictive (while the MD lengths are not), and (4) the mandibular canine seems unique in that both the MD and BL dimensions carry independent significant information. Collectively, then, there are several outcomes of this analysis, so the results need to be examined in more detail.

The four incisor tooth types can be examined together because their results are the same. In each instance, the MD diameter is predictive but the $\mathrm{BL}$ diameter is not. Again, these statistical results support scenario B in Figure 4-5. This result seems intuitive: MD width contributes directly to a person's TSASD, 
whereas size of the buccolingual dimension seems irrelevant to how the incisors are aligned in the supporting alveolar bone. These tests of the four incisor types - and particularly the results for the mandibular incisors - are immediately relevant to Peck and Peck's (1972a,b) interpretation of the lower incisor's crown index. Our results (Table 4-13) show that mesiodistal crown width is a significant predictor of TSASD, but, once that information is accounted for, BL dimensions are of no consequence. These results, again, support scenario B in Figure 4-5.

As regards the canines (Table 4-13), quite different results are obtained for the maxillary and mandibular tooth type. In the maxilla, neither MD nor BL size was predictive. In the mandible, they both were. In the mandible, the MD width is very highly significant; indeed, it has the largest $\chi^{2}$ of any of the 24 tests in the table. In addition, though, BL size also is significantly associated with the risk of malocclusion. We have no explanation for this latter finding.

Tests for the first premolars in each arcade are negative; neither MD nor BL size is predictive. In contrast, the BL diameters (but not the MD sizes) of the second premolar in each arch are predictive of the person's group classification, with larger BL mean sizes in the group that was treated orthodontically.

As with the second premolars, the first molars have significantly broader BL dimensions in the treated group than in the sample with naturally-occurring good occlusions. Likewise, the cause of this association is unclear. These results 
for the second premolars and first molars imply that a scenario opposite to that in Figure 4-5 (scenario B) is operating-where BL crown breadth somehow is modulating the risk of orthodontic need (broader P2 and broader M1 occur in the malocclusion sample), and the MD dimensions are simply "carried along" because $\mathrm{MD}$ and $\mathrm{BL}$ dimensions are positively intercorrelated.

Regardless of which scenario is appropriate for a given tooth type (Fig. 45), none of the results (excepting those for LC) support Peck and Peck's hypothesis that the crown index (MD/BL) is the salient factor. Certainly for the four incisor tooth types, it is evident that MD size is the proximate cause of TSASD in the anterior segment, and that BL dimensions figure in the model only so far as they are developmentally intercorrelated with MD crown size.

\section{$\underline{\text { Tooth Size Segments }}$}

Since so many of the univariate mesiodistal results are statistically significant - with larger mean sizes in the malocclusion sample - it is predictable that summary dimensions (i.e., the sums of individual teeth) would be at least as discriminating. This is shown in Table 4-14 where six summary dimensions are compared between the two groups, namely (1) total maxillary anterior diameters (twice the summation of UI1, UI2 and UC), (2) total maxillary posterior diameters (summation of UP1, UP2 and UM1), (3) maxillary total (twice the summation of UI1 through UM1), (4) total mandibular anterior diameters (twice 
Table 4-14. Tests for group differences in mesiodistal ratios of groupings of crown dimensions.

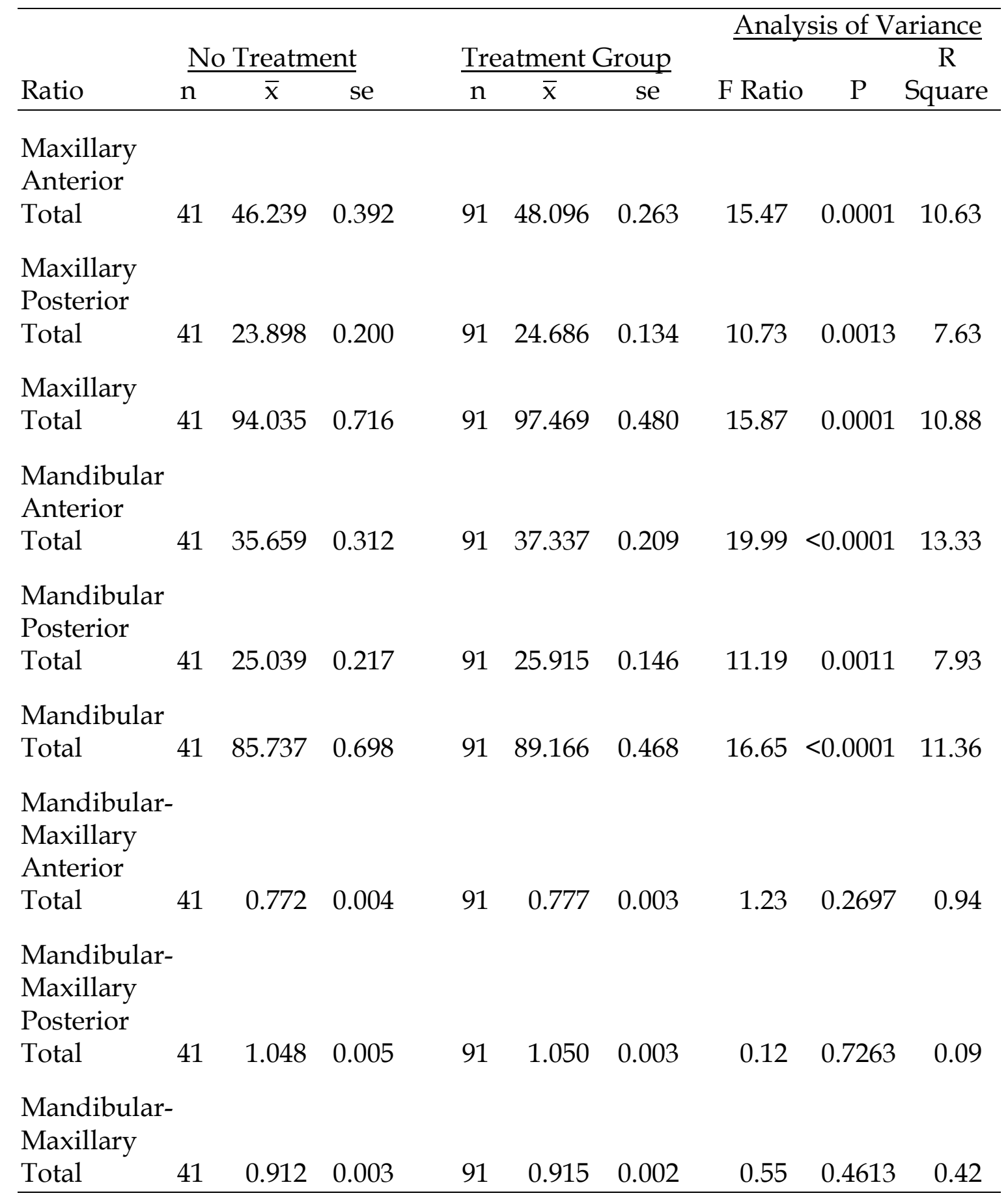


the summation of LI1, LI3 and LC), (5) total mandibular posterior diameters (summation of LP1, LP2 and LM1), and (6) mandibular total (twice the summation of LI1 through LM1). The intent of multiplying some of these sums by two was to mimic the duplication of teeth in the two quadrants of a dental arcade. In addition (Table 4-14), we also evaluated maxillary-mandibular ratios of these tooth crown sums.

Results of the one-way ANOVA show that all six sums are highly significantly different between the two groups, with the larger means consistently occurring in the malocclusion group. These composite measures augment and extend the univariate results that mesiodistal crown diameters are, on average, larger in the sample that required orthodontic intervention to correct the malocclusion. In contrast, the three inter-arch ratios tested in Table 4-14 are patently nonsignificant. In other words, the ratio of composite, summary crown sizes between the two arches does not differ, through tooth size itself certainly does.

The same set of nine composite comparisons were calculated for the buccolingual crown diameters (Table 4-15). Comparable with the MD results, the composite BL dimensions are significantly larger in the malocclusion sample. Specifically, five of the six tests show that BL measures are highly significantly larger in the malocclusion group $(\mathrm{P}<0.01)$. The exception for these BL measures is summary BL size of the mandibular anterior teeth, where the mean is 
Table 4-15. Tests for group differences in buccolingual ratios of groupings of crown dimensions.

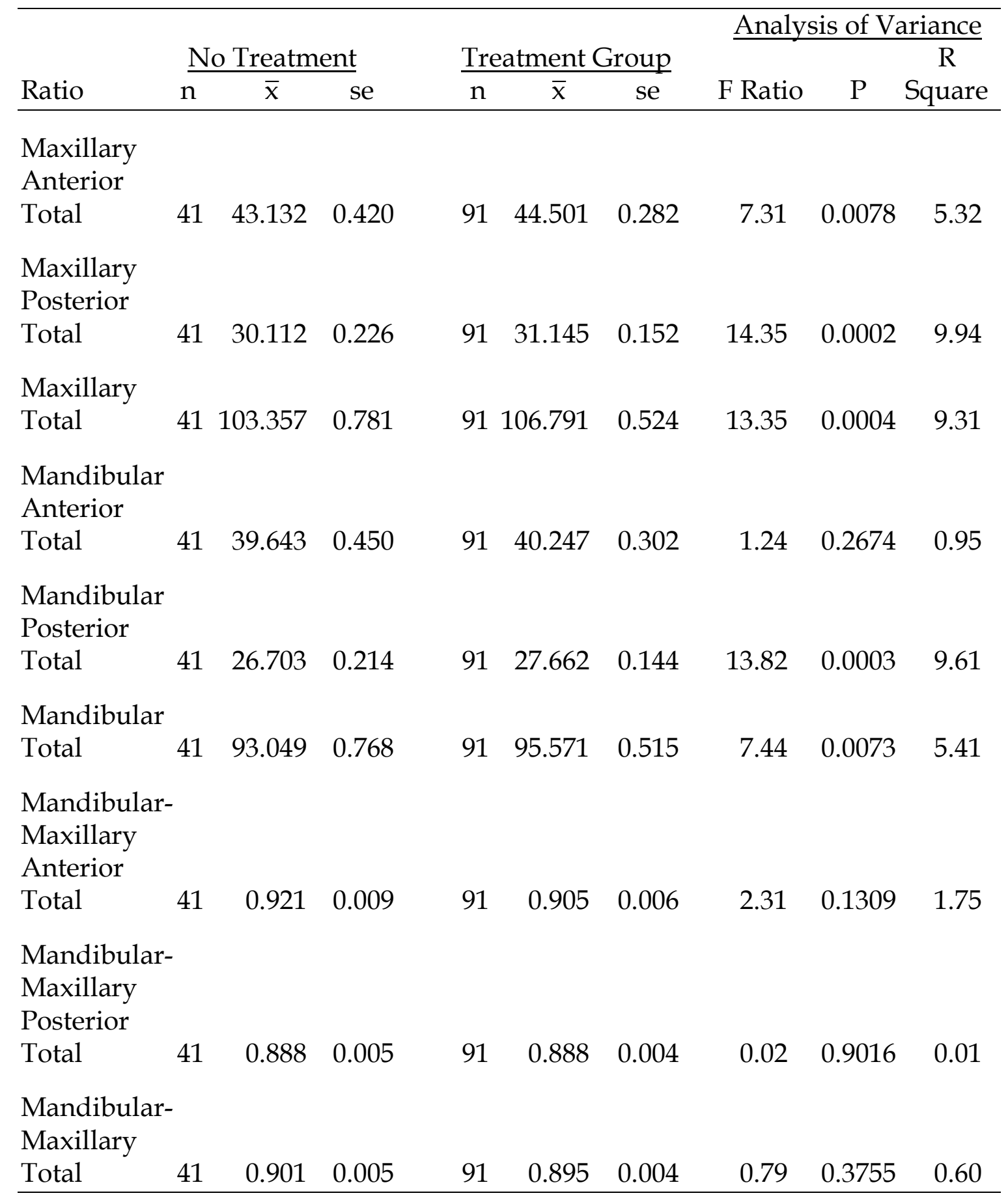


nonsignificantly larger $(P=0.27)$ in the malocclusion sample. As with results for the MD summations, the three inter-arch ratios of BL dimensions are not statistically different between the two groups.

\section{$\underline{\text { Multivariable Analyses }}$}

Because tooth crown dimensions are highly intercorrelated, much of the informational content of the individual variables is statistically redundant. Multivariable statistics resolve the issue of repeatedly assessing redundant information among dimensions by expressing the information as orthogonal (uncontrolled) contributions of the individual variables to the group differences (e.g., Cooley and Lohnes 1971; Morrison 1976). We describe here the results of two multivariable procedures, namely MANOVA (multivariate analysis of variance) and, more informatively, stepwise discriminant functions analysis.

The MANOVA results are provided primarily for completeness since we have already documented that the majority of the univariate tests are significantly different (e.g., Tables 4-5 and 4-6), so it follows that the same statistical information taken en masse will likewise generate a statistically significant difference between groups.

Inputting the 24 crown dimensions (and choosing to examine "sum" for the MANOVA), yields an F ratio of 17.0 with $\mathrm{df}$ of 1 and 130, $\mathrm{P}<<0.0001$. Again, this highly significant result is predictable since the multivariable approach 
capitalizes on all of the (nonredundant) differences between groups for the 24 univariate results, several of which are highly significant when taken individually. Of more interest is the discriminant functions analysis because it identifies the prime contributors to the intergroup difference.

Tooth dimensions per individual can be numerous (e.g., Potter et al. 1968; Hillson et al. 2005), but they typically are positively intercorrelated, so the data among dimensions are statistically redundant. One common method of eliminating this redundancy and, as well, searching for the most discriminating subset of variables that distinguishes two or more groups is stepwise discriminant functions analysis (e.g., Cooley and Lohnes 1971).

The protocol is first to evaluate each of the potential predictor variables (tooth crown dimensions) in terms of their univariate $\mathrm{F}$ ratios. The single most discriminating variable (i.e., the one with the largest $\mathrm{F}$ ratio) is selected at step one, then all of the other variables are reassessed to determine their $\mathrm{F}$ ratios after accounting for the use of the variable selected at step one. At step two, the variable with the largest $\mathrm{F}$ ratio (contingent on use of the already-selected variable) is entered into the model, and the F ratios of the remaining variables are recalculated. This stepwise procedure is followed until no other significant $F$ ratio remains among the unselected variables. There are other strategies, but, with forward and backward stepping, one normally arrives at the subset of mostdiscriminating variables. 
Table 4-16 lists the univariate $\mathrm{F}$ ratios for the 24 tooth crown diameters at step zero, asking the question of which dimensions maximally discriminate between the two groups - those with naturally-occurring good occlusions and those that warranted orthodontic treatment. It is apparent that numerous dimensions differ significantly between the groups; indeed, these results are very similar to the results using univariate analysis of variance (though the assumptions of the univariate tests and of the GLM method used here differ). All but three of the 24 crown dimensions exhibit statistical significance, with that for the mesiodistal diameter of maxillary lateral incisor (I2) being the largest $(\mathrm{F}=$ 21.0). What becomes noteworthy at step two, after the variance due to MD U2 is accounted for, is that most of the variables have no additional information that helps discriminate between the two groups. This dramatic reduction-from most variables being significant to most being nonsignificant -is due to the statistical redundancy (biological interrelationships) among the tooth sizes. As shown in Table 4-17, just two of the remaining 23 variables have statistically independent information that significantly improves discrimination compared to using MD U2 alone (i.e., BL U4 and BL L6). Of these two, BL L6 has the higher F ratio $(\mathrm{F}=5.58 ; \mathrm{P}=0.02)$, so it is entered at step two.

What is evident after MD U2 and BL L6 have been entered and the F ratios of the remaining 22 variables are recalculated (Table 4-18) is that none of the other crown dimensions has significant discriminating power, so the stepwise 
Table 4-16. Stepwise discriminant functions analysis: results at step zero. ${ }^{1}$

\begin{tabular}{lrc}
\hline Dimension & F Ratio & $\mathrm{P}$ \\
\hline MDU1 & & \\
MDU2 & 2.22 & 0.004846 \\
MDU3 & 3.94 & 0.000010 \\
MDU4 & 11.77 & 0.049196 \\
MDU5 & 4.78 & 0.000806 \\
MDU6 & 6.37 & 0.030555 \\
MDL1 & 10.91 & 0.012837 \\
MDL2 & 18.30 & 0.001238 \\
MDL3 & 15.44 & 0.000036 \\
MDL4 & 11.65 & 0.000138 \\
MDL5 & 5.73 & 0.000857 \\
MDL6 & 8.71 & 0.018067 \\
BLU1 & 7.36 & 0.003758 \\
BLU2 & 4.73 & 0.007589 \\
BLU3 & 3.69 & 0.031505 \\
BLU4 & 14.11 & $\mathbf{0 . 0 5 6 8 1 0}$ \\
BLU5 & 9.01 & 0.000259 \\
BLU6 & 9.14 & 0.003213 \\
BLL1 & 5.50 & 0.003021 \\
BLL2 & 1.32 & 0.020492 \\
BLL3 & 0.03 & $\mathbf{0 . 2 5 2 0 1 7}$ \\
BLL4 & 8.03 & $\mathbf{0 . 8 6 8 8 7 7}$ \\
BLL5 & 12.29 & 0.005342 \\
BLL6 & 10.89 & 0.000626 \\
\hline
\end{tabular}

${ }^{1}$ The three nonsignificant differences are printed in bold type 
Table 4-17. Stepwise discriminant functions analysis: results at step one, after entering MD U2.

\begin{tabular}{lrc}
\hline Dimension & F Ratio & $\mathrm{P}$ \\
\hline MDU1 & 0.00 & 0.968270 \\
MDU2 & 21.05 & 0.000010 \\
MDU3 & 0.02 & 0.899228 \\
MDU4 & 1.50 & 0.223054 \\
MDU5 & 0.03 & 0.872930 \\
MDU6 & 1.99 & 0.161212 \\
MDL1 & 0.57 & 0.453091 \\
MDL2 & 3.15 & 0.078105 \\
MDL3 & 3.24 & 0.074345 \\
MDL4 & 1.79 & 0.183925 \\
MDL5 & 0.14 & 0.708241 \\
MDL6 & 1.38 & 0.242931 \\
BLU1 & 3.62 & 0.059322 \\
BLU2 & 0.81 & 0.370710 \\
BLU3 & 0.15 & 0.697974 \\
BLU4 & 4.91 & 0.028391 \\
BLU5 & 1.22 & 0.271306 \\
BLU6 & 3.46 & 0.065004 \\
BLL1 & 0.77 & 0.380959 \\
BLL2 & 0.02 & 0.900606 \\
BLL3 & 0.96 & 0.330024 \\
BLL4 & 1.19 & 0.277957 \\
BLL5 & 2.88 & 0.091893 \\
BLL6 & 5.58 & 0.019666 \\
\hline
\end{tabular}


Table 4-18. Stepwise discriminant functions analysis: results at step two, after entering MD $\mathrm{U} 2$ and BL L6.

\begin{tabular}{lrc}
\hline Dimension & F Ratio & $\mathrm{P}$ \\
\hline MDU1 & 0.51 & 0.475133 \\
MDU2 & 15.28 & 0.000149 \\
MDU3 & 0.99 & 0.321692 \\
MDU4 & 0.15 & 0.695004 \\
MDU5 & 0.61 & 0.435525 \\
MDU6 & 0.06 & 0.808494 \\
MDL1 & 0.01 & 0.913558 \\
MDL2 & 0.84 & 0.360519 \\
MDL3 & 0.73 & 0.396052 \\
MDL4 & 0.28 & 0.599800 \\
MDL5 & 0.37 & 0.541800 \\
MDL6 & 0.02 & 0.880240 \\
BLU1 & 2.61 & 0.108518 \\
BLU2 & 0.47 & 0.492700 \\
BLU3 & 0.08 & 0.773442 \\
BLU4 & 1.92 & 0.168726 \\
BLU5 & 0.12 & 0.733867 \\
BLU6 & 0.48 & 0.489314 \\
BLL1 & 0.01 & 0.915666 \\
BLL2 & 0.85 & 0.359567 \\
BLL3 & 3.03 & 0.084221 \\
BLL4 & 0.01 & 0.917321 \\
BLL5 & 0.28 & 0.595264 \\
BLL6 & 5.58 & 0.019666 \\
\hline
\end{tabular}


procedure is halted.

The point of this exercise is that all of the statistically useful information from among the original 24 crown dimensions is effectively encapsulated within just two dimensions (MD U2 and BL L6) because the statistical variation between the two groups is redundant in the other 22 variables due to their positive intercorrelations.

Commonly, discriminant functions analysis is used to develop equations that maximally distinguish between the groups being studied, but that is of little value here. Instead, it is worth noting in passing that these two variables by themselves correctly allocate $67 \%(89 / 132)$ of the cases as to whether they are from the naturally-occurring good occlusion group or the treatment group. Moreover, of these two significant predictors (MD U2 and BL L6), variation in the size of MD U2 is far more informative. If MD U2 is used alone, it correctly allocates $66 \%$ of the subjects to the correct group (87/132), so the addition of BL L6 slightly improves the accuracy of the predictive equation, but not to any practical degree.

\section{Principal Components Analysis}

One characteristic of tooth crown diameters is the positive statistical intercorrelations among them (e.g., Potter et al. 1968; Harris and Bailit 1988). This tendency is apparent in the present dataset (Table 4-19). This table lists all of the 


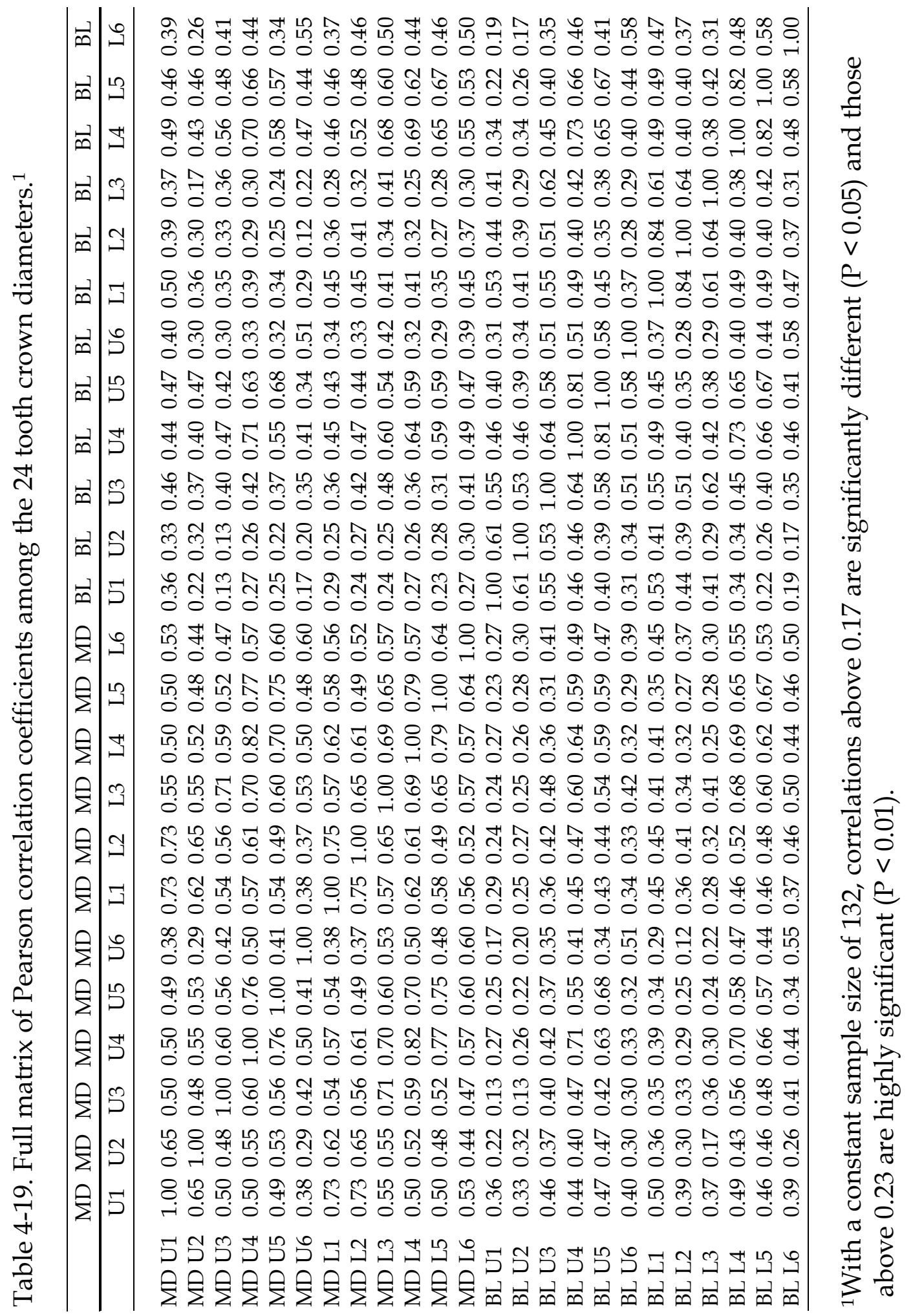


pairwise Pearson product-moment correlations among the 24 crown diameters. Scanning the matrix shows that all 276 correlations are positive, indicating that all crown sizes positively covary (meaning that there is considerable statistical redundancy among them). Because the sample size ( $\mathrm{n}=132$ individuals) is constant, it is easy to judge which coefficients are significantly different from zero (Table 25 in Rohlf and Sokal 1981). Correlations at least 0.17 or greater are significantly different from zero $(\mathrm{P}<0.05)$, and correlations at least 0.23 or larger are highly significant $(\mathrm{P}<0.01)$. Perusal of the matrix discovers that just three $(3 / 276)$ correlations are not significant, namely (1) MD of U3 with BL of U1 ( $r=$ 0.13), (2) MD of U2 with BL of U2 ( $r=0.13)$, and (3) MD of U6 with BL of L2 ( $r=$ $0.12)$.

The numerous, often high positive intercorrelations in this matrix (Table 4-19) reflect the considerable statistical and, by inference, biological redundancy of these variables. In other words, "tooth size" can be viewed as a dentitionwide, systematic function of an individual: People with one large tooth diameter are likely to exhibit large dimensions of all the other teeth and vice versa for those with small crown diameters (Harris 2003).

Principal components analysis (e.g., Gorsuch 1983) is used here to assess the canonical structure of this matrix of intercorrelations. Principal components were extracted from the covariance matrix without rotation. Only the first eigenvalue exceeds one (Table 4-20), but we retained the first seven eigenvalues, 
Table 4-20. Unrotated results of principal components analysis on the 24 crown dimensions ( $\mathrm{n}=91$ individuals).

\begin{tabular}{lrrrrrrr}
\hline Tooth & I & II & III & IV & \multicolumn{1}{c}{ V } & \multicolumn{1}{c}{ VI } & \multicolumn{1}{c}{ VII } \\
\hline & & \multicolumn{7}{c}{ Mesiodistal } \\
U1 & 0.223 & -0.008 & 0.435 & 0.093 & 0.162 & -0.168 & 0.038 \\
U2 & 0.211 & -0.145 & 0.501 & -0.158 & 0.169 & -0.299 & 0.058 \\
U3 & 0.147 & -0.098 & 0.096 & 0.103 & -0.111 & -0.074 & -0.215 \\
U4 & 0.232 & -0.200 & -0.028 & -0.128 & -0.117 & 0.109 & -0.145 \\
U5 & 0.200 & -0.197 & 0.031 & -0.157 & -0.061 & 0.085 & -0.157 \\
U6 & 0.189 & -0.157 & -0.215 & 0.448 & 0.347 & 0.247 & -0.197 \\
L1 & 0.138 & -0.073 & 0.246 & 0.043 & 0.044 & -0.014 & 0.010 \\
L2 & 0.154 & -0.062 & 0.264 & 0.068 & 0.021 & -0.102 & 0.015 \\
L3 & 0.200 & -0.109 & 0.038 & 0.085 & -0.061 & -0.047 & -0.201 \\
L4 & 0.234 & -0.221 & 0.016 & -0.093 & -0.116 & 0.196 & -0.038 \\
L5 & 0.223 & -0.230 & -0.021 & -0.071 & -0.128 & 0.257 & -0.012 \\
L6 & 0.231 & -0.123 & 0.049 & 0.250 & 0.132 & 0.372 & 0.029 \\
& & & & & & & \\
U1 & 0.142 & 0.354 & 0.045 & -0.237 & 0.205 & 0.360 & 0.074 \\
U2 & 0.139 & 0.277 & 0.040 & -0.289 & 0.335 & 0.313 & 0.152 \\
U3 & 0.219 & 0.345 & -0.040 & -0.041 & 0.155 & -0.103 & -0.435 \\
U4 & 0.274 & 0.063 & -0.291 & -0.286 & -0.003 & -0.091 & -0.062 \\
U5 & 0.263 & 0.017 & -0.240 & -0.334 & 0.041 & -0.306 & -0.017 \\
U6 & 0.173 & 0.094 & -0.259 & 0.179 & 0.436 & -0.388 & 0.097 \\
L1 & 0.185 & 0.283 & 0.124 & 0.148 & -0.146 & 0.088 & 0.328 \\
L2 & 0.147 & 0.308 & 0.157 & 0.132 & -0.245 & 0.052 & 0.275 \\
L3 & 0.193 & 0.448 & 0.012 & 0.263 & -0.424 & -0.060 & -0.385 \\
L4 & 0.265 & -0.086 & -0.191 & -0.088 & -0.203 & 0.020 & 0.227 \\
L5 & 0.250 & -0.095 & -0.203 & 0.011 & -0.251 & -0.158 & 0.345 \\
L6 & 0.165 & -0.026 & -0.187 & 0.376 & 0.078 & -0.105 & 0.298 \\
Eigenvalue & 3.327 & 0.679 & 0.394 & 0.358 & 0.329 & 0.241 & 0.208 \\
Percent & 48.932 & 9.986 & 5.801 & 5.263 & 4.841 & 3.543 & 3.061 \\
Cumulative & & & & & & & \\
Percent & 48.932 & 58.918 & 64.719 & 69.983 & 74.824 & 78.366 & 81.427 \\
\hline & & & & & & &
\end{tabular}


which collectively account for $80 \%$ of the total shared variance. Principal component one (PC One) is graphical in Figure 4-6, which shows the loadings of the variables on the first (major) canonical axis of variation. With PCA, these loadings are both the correlation coefficients and the standardized regression coefficients between the variables and the axis. With PC I, all of loadings are positive and roughly of the same strength. Commonly (e.g., Potter et al. 1968) this first canonical axis is "overall size," and that is the situation here.

Since the first canonical axis accounts for about half (48.9\%) of the total shared variance, the subsequent axes are small, and we have not investigated their patterns of variation in detail. PC II (Fig. 4-7) is a polarity between mesiodistal variables (with negative loadings) and buccolingual variables (mostly with positive loadings). PC III (Fig. 4-8) is an orthogonal (statistically independent) axis of variation with larger positive weights for mesiodistal incisor widths against larger negative weights on buccolingual premolar and molar diameters. PC IV (Fig. 4-9) is essentially a measure of molar size, with large loadings on the four first molar dimensions. The premolar dimensions, in contrast, mostly have negative loadings. PC V (Fig. 4-10) is complex, but fundamentally a contrast between molar size (positive loadings) and premolar size (mostly negative loadings). PC VI (Fig. 4-11) is a contrast (opposite signs of the loadings) between mesiodistal and buccolingual dimensions. PC VII (Fig. 412) has the highest loadings on the buccolingual variables, especially for the 


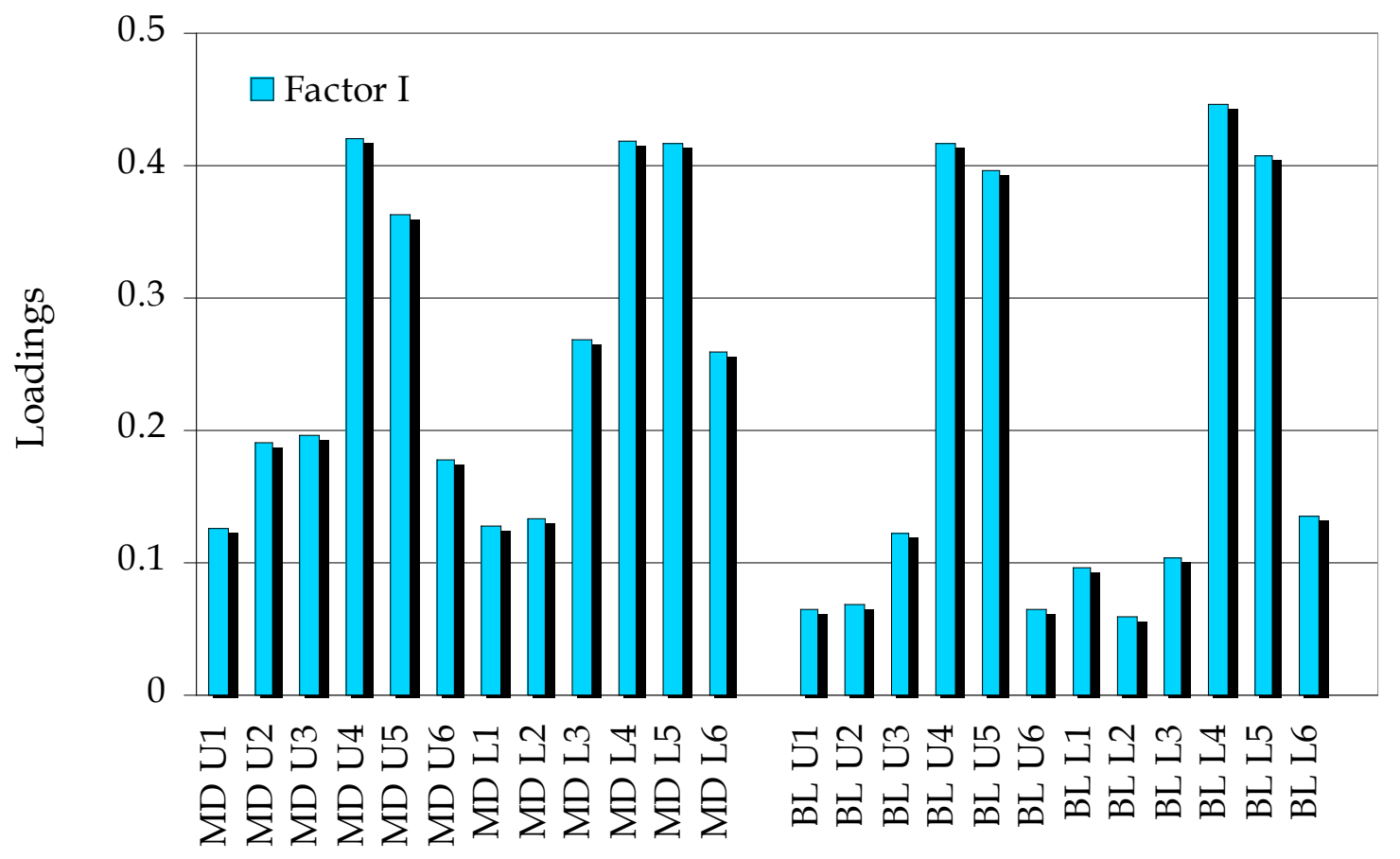

Fig. 4-6. Loadings of the 24 crown size variables on Factor I. 


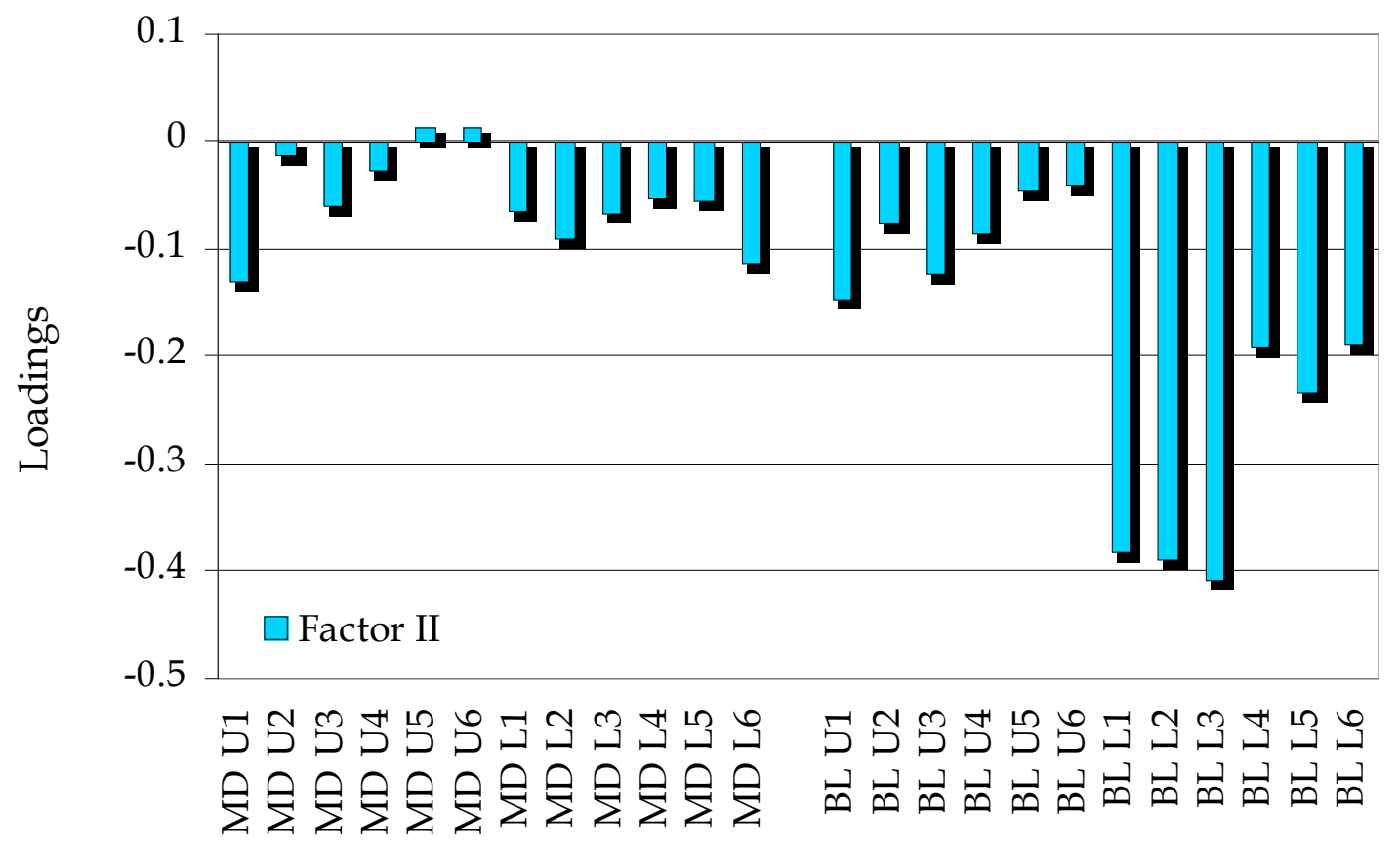

Fig. 4-7. Loadings of the 24 crown size variables on Factor II. 


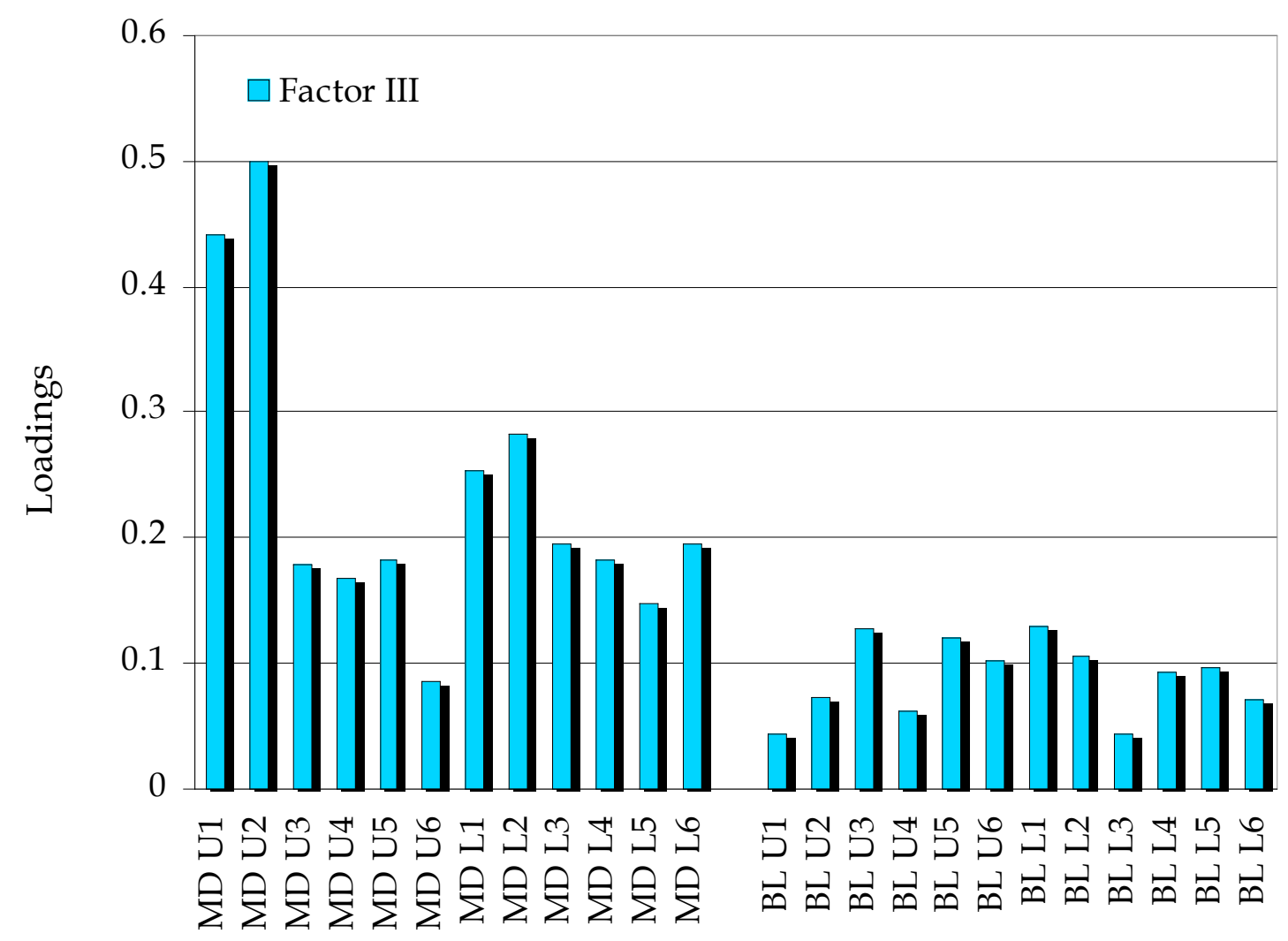

Fig. 4-8. Loadings of the 24 crown size variables on Factor III. 


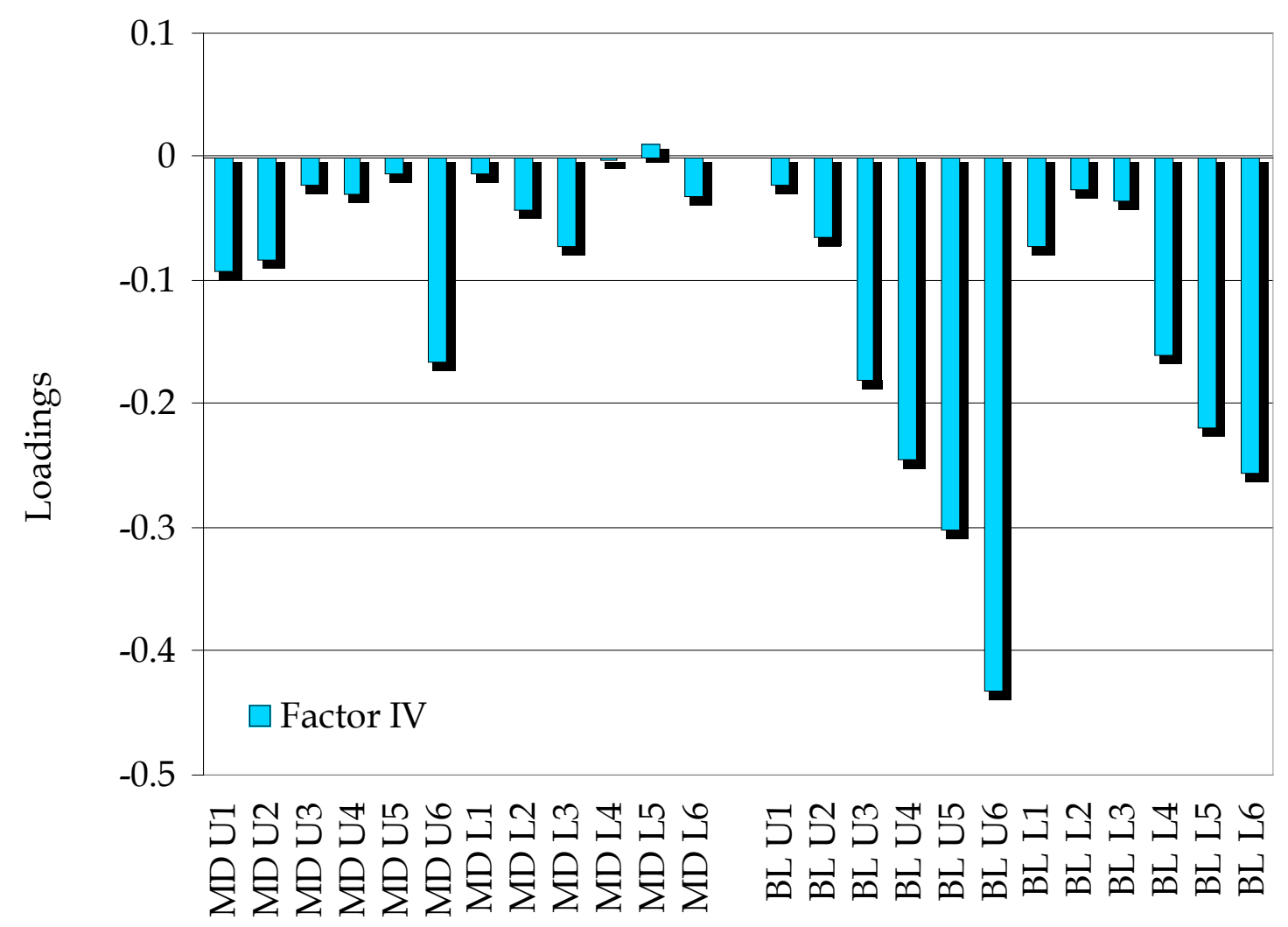

Fig. 4-9. Loadings of the 24 crown size variables on Factor IV. 


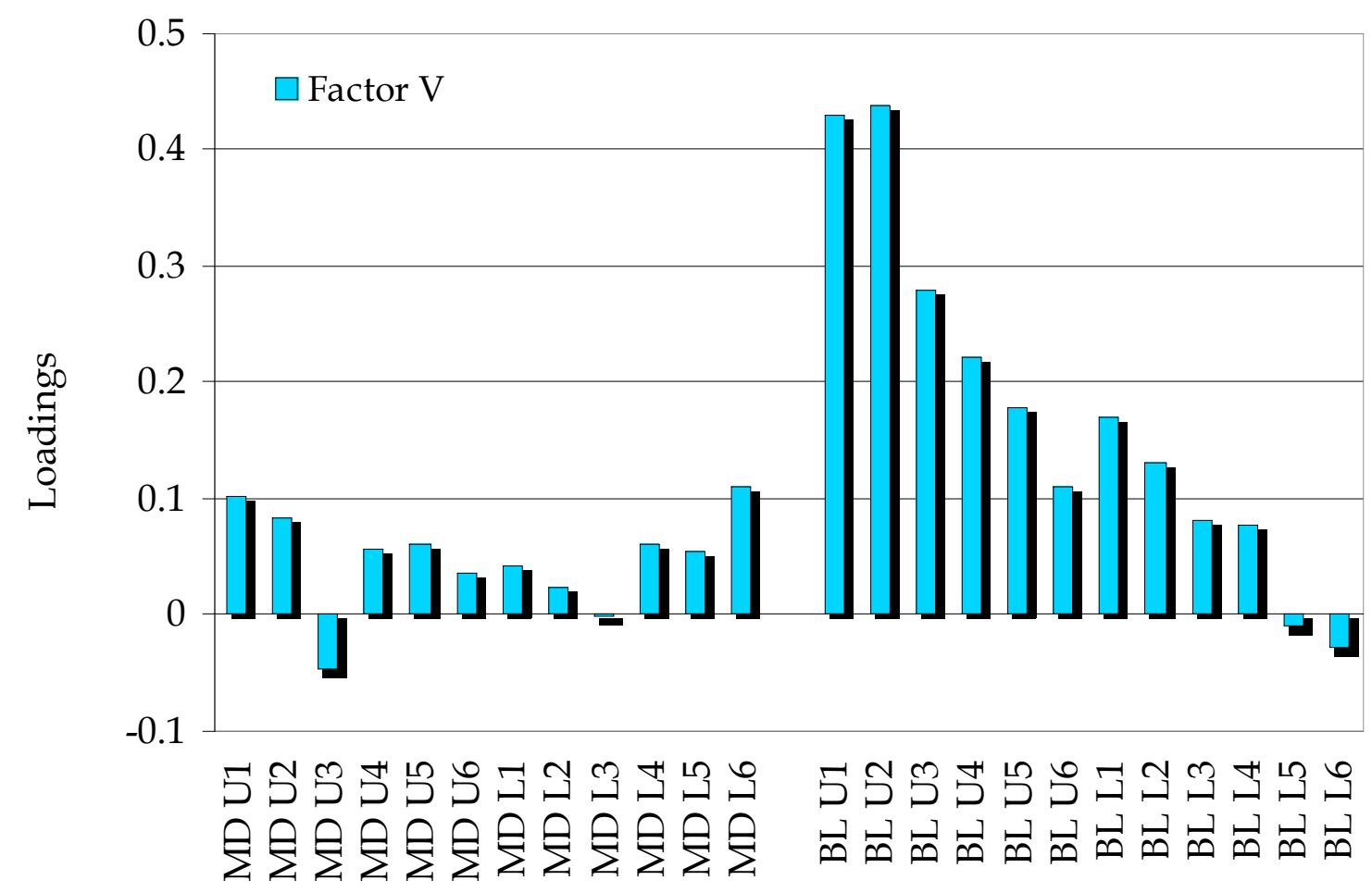

Fig. 4-10. Loadings of the 24 crown size variables on Factor V. 


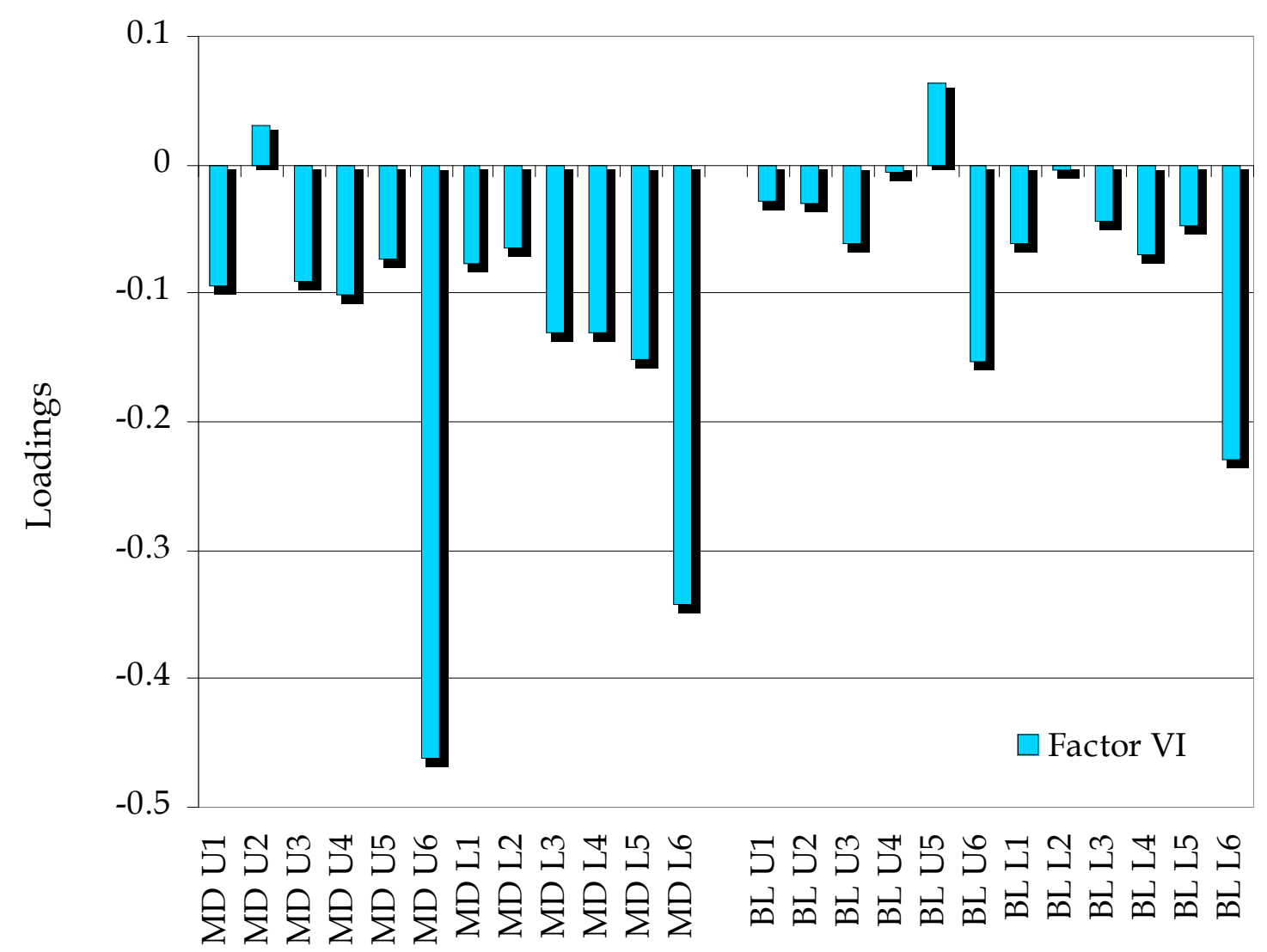

Fig. 4-11. Loadings of the 24 crown size variables on Factor VI. 


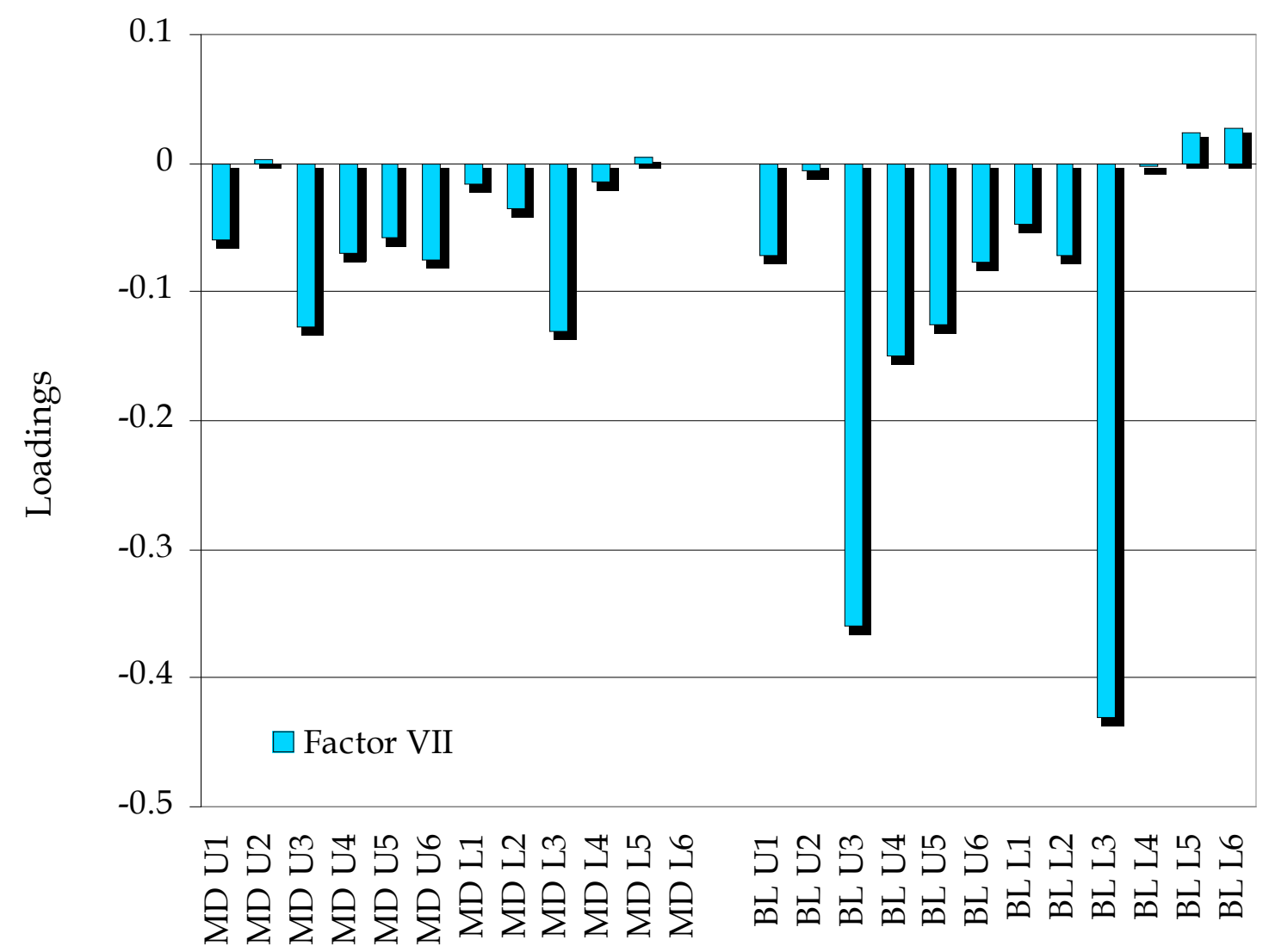

Fig. 4-12. Loadings of the 24 crown size variables on Factor VII. 
canines (negative loadings).

One strength of principal components analysis is that the axes are orthogonal (statistically independent of one another). PC scores were calculated for each individual and Table 4-21 shows the results of testing for differences between those with naturally-occurring good occlusions versus those treated orthodontically. The key result is the highly significant difference for PC I ( P < 0.0001), with small (negative) scores for those with naturally-occurring good occlusions contrasted with high (positive) scores for the treated sample. 


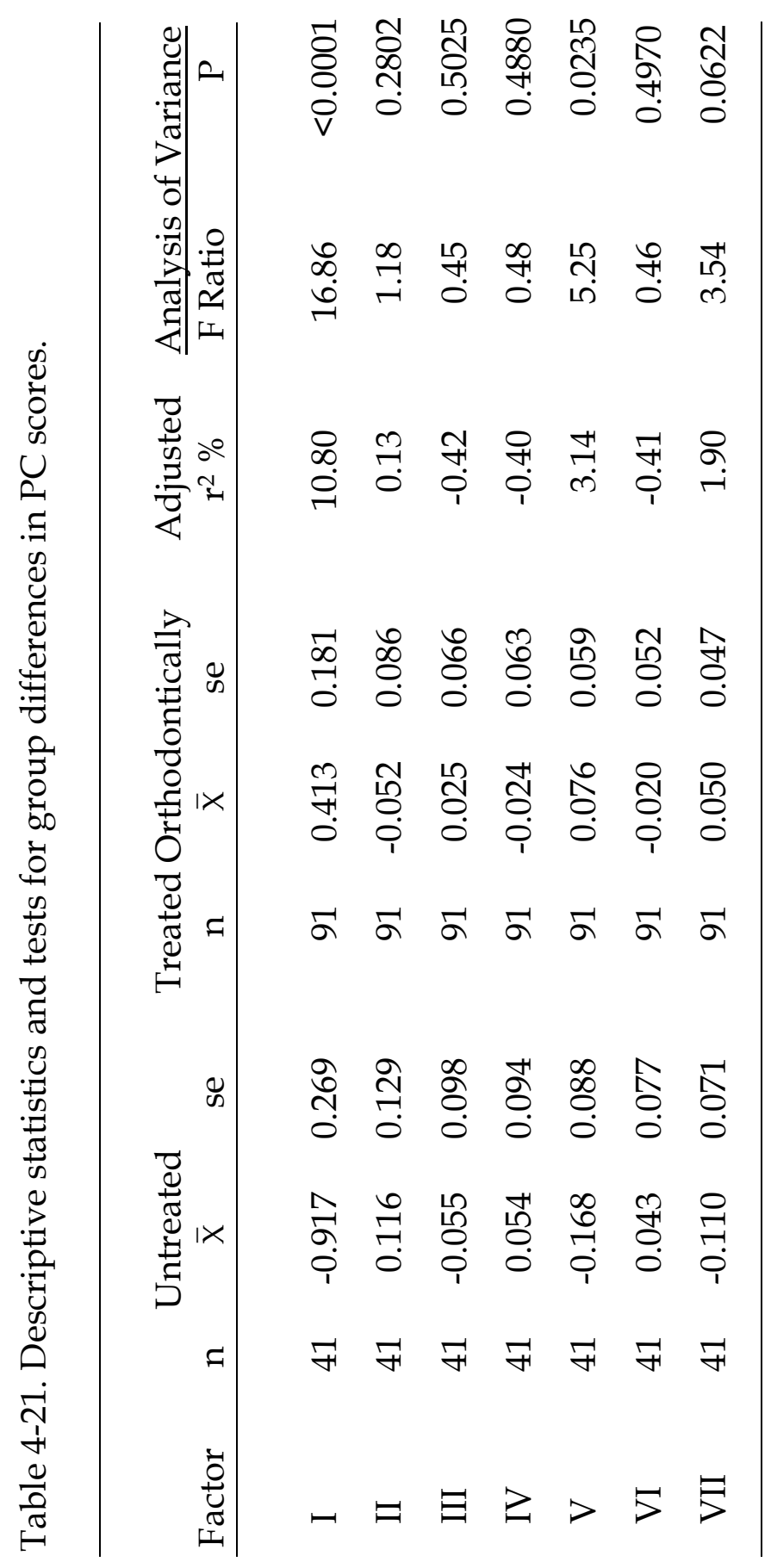




\section{CHAPTER 5}

\section{DISCUSSION}

\section{$\underline{\text { Malocclusion }}$}

Malocclusion is an increasingly common, multifactorial problem in industrialized countries (e.g., Corruccini 1984, 1999; Proffit 1986, 1998). Many malocclusions are some combination of skeletal and dental disharmonies (e.g., Ackerman and Proffit 1969; Proffit and Ackerman 1973), but the most prevalent problem involves insufficient supporting bone (arch size) to accommodate the ideal arrangement of teeth (tooth size), creating tooth-size arch-size discrepancies (TSASD). Although the causes of dental malocclusion are obscure in most instances, one contributing factor appears to be tooth size. That is, going back to some of the earliest large, quantified studies on the topic (e.g., Seipel 1946;

Lundström 1949), it is evident that crowding - TSASD—is now a leading issue in many malocclusions. Historically, caries was so rampant that tooth loss was a preeminent cause of malocclusions (e.g., Weinberger 1926), but caries-prevention programs have minimized this cause. Nowadays, the competing forces of smaller supporting bones—brought about by reduced masticatory stress (e.g., Watt and Williams 1951) and secular trends toward increasing tooth size (reviewed, e.g., in Kieser et al. 1987; Harris et al. 2001; Lindsten 2003)—lead to high frequencies of TSASD in westernized populations. 
The present study was conducted to determine whether tooth crown dimensions (mesiodistal and buccolingual) differed in a sample of young adult males with naturally-occurring good occlusions versus a second sample of otherwise similar individuals who required full-banded orthodontic treatment. This study design was unique in that (1) unlike many previous studies, we limited our focus to males (which controlled for tooth-size differences between males and females), (2) we examined buccolingual as well as mesiodistal tooth crown dimensions, and (3) we examined all classes of teeth in the dentition, incisors, canines, premolars, and molars.

\section{$\underline{\text { Absolute Dental Size }}$}

Consider that tooth-size arch-size problems can—very broadly—be ascribed to one of two problems. One is that there is not adequate supporting bone to accommodate the mesiodistal diameters of the teeth. This is a problem of absolute size. Earlier erupting teeth commandeer so much of the available arch space, that later erupting teeth are moved into ectopic positions, creating TSASD and the consequent need for orthodontic therapy. Because of the strong statistical interrelations among crown dimensions (e.g., Moorrees and Reed 1964; Harris and Bailit 1988), the various teeth within an individual tend to be large or small to similar degrees, so tooth size per se often is expressed as a generalized, dentition-wide problem. 
In this vein, there is a long but scattered history of orthodontists implicating large tooth sizes as an etiological factor in TSASD. These publications were reviewed in some detail in the Review of Literature chapter. For convenience, key findings are summarized in Table 5-1. Some previous studies found the mesiodistal width of the mandibular incisor teeth to be significantly greater in subjects with anterior dental crowding as compared to subjects with ideal anterior alignment (e.g., Peck and Peck 1972a,b; Norderval et al. 1975; Adams 1982). In contrast, others have been unable to distinguish between crowded and noncrowded dentitions on the basis of mesiodistal tooth dimensions (e.g., Howe et al. 1983; Gilmore and Little 1984).

One niggling problem that researchers have repeatedly had difficulty with is (A) testing for the influence of tooth size on the risk of malocclusion while (B) accounting for the fact that tooth dimensions are sexually dimorphic (e.g., Garn et al. 1967). That is, tooth crowns are, on the average, 3 to $6 \%$ larger in men than in women, so combining male and female subjects in a test of whether tooth size influences TSASD confounds the results. Finding, for example, that a sample with malocclusion has larger tooth sizes than a sample with naturally-occurring good occlusion is in itself uninformative because sexual dimorphism clouds the results. Perhaps women, with smaller crown sizes were over- represented in the "good" occlusion group and men, with larger teeth, were over-represented in the "malocclusion" group. A statistical difference is confounded because the 
Table 5-1: Prior studies investigating mesiodistal tooth diameters in relation to occlusion.

\begin{tabular}{|c|c|c|c|}
\hline Reference & Comparison & Results & $\begin{array}{c}\text { Sexes } \\
\text { Separated }\end{array}$ \\
\hline $\begin{array}{l}\text { Adams } \\
1982\end{array}$ & $\begin{array}{l}\text { Crowded vs. } \\
\text { noncrowded } \\
\text { (Mx \& Md 6-6) }\end{array}$ & Crowded teeth significantly larger & Yes \\
\hline $\begin{array}{c}\text { Al- } \\
\text { Khateeb, } \\
\text { Abu } \\
\text { Alhaija } \\
2002\end{array}$ & $\begin{array}{l}4 \text { malocclusion } \\
\text { groups } \\
\text { (Mx \& Md 6-6) }\end{array}$ & $\begin{array}{c}\text { Significant differences between } \\
\text { malocclusions }\end{array}$ & Yes \\
\hline $\begin{array}{l}\text { Alkofide, } \\
\text { Hashim } \\
2002\end{array}$ & $\begin{array}{l}4 \text { malocclusion } \\
\text { groups } \\
\text { (Mx \& Md 6-6) }\end{array}$ & No difference in Bolton ratios & No \\
\hline $\begin{array}{l}\text { Bernabé, } \\
\text { Flores-Mir } \\
2006\end{array}$ & $\begin{array}{l}\text { Crowded vs. } \\
\text { noncrowded } \\
\text { (Mx \& Md 6-6) }\end{array}$ & $\begin{array}{l}\text { MD larger, BL no change, } \\
\text { MD/BL ratio increased in crowded }\end{array}$ & No \\
\hline $\begin{array}{l}\text { Corruccini } \\
1990\end{array}$ & $\begin{array}{l}\text { Aboriginals vs. } \\
\text { contemporaries } \\
\text { (deciduous \& } \\
\text { permanent) }\end{array}$ & $\begin{array}{l}\text { No difference in tooth size; } \\
\text { small jaws in crowded arches }\end{array}$ & No \\
\hline $\begin{array}{l}\text { Doris et al. } \\
\quad 1981\end{array}$ & $\begin{array}{l}\text { Mild vs. severe } \\
\text { crowding (Mx } \\
\text { \& Md 5-5) }\end{array}$ & Crowded teeth significantly larger & No \\
\hline $\begin{array}{l}\text { Hashim, } \\
\text { Al } \\
\text { Ghamdi } \\
2005\end{array}$ & $\begin{array}{l}4 \text { classes of } \\
\text { malocclusion } \\
\text { versus normal } \\
\text { occlusion } \\
\text { (Mx \& Md 6-6) }\end{array}$ & Malocclusion teeth significantly larger & No \\
\hline
\end{tabular}


Table 5-1. Continued

\begin{tabular}{|c|c|c|c|}
\hline Reference & Comparison & Results & $\begin{array}{c}\text { Sexes } \\
\text { Separated }\end{array}$ \\
\hline $\begin{array}{l}\text { Howe et } \\
\text { al. } 1983\end{array}$ & $\begin{array}{l}\text { Major vs. minor crowding } \\
(\mathrm{Mx} \& \mathrm{Md} 6-6)\end{array}$ & $\begin{array}{l}\text { No difference tooth size; } \\
\text { arch width significant }\end{array}$ & Yes \\
\hline $\begin{array}{l}\text { Laino et } \\
\text { al. } 2003\end{array}$ & $\begin{array}{l}3 \text { malocclusion groups } \\
(\mathrm{Mx} \& \mathrm{Md} \text { 6-6) }\end{array}$ & No significant difference & No \\
\hline $\begin{array}{l}\text { McCann, } \\
\text { Burden } \\
1996\end{array}$ & $\begin{array}{c}\text { Bimaxillary protrusive vs. } \\
\text { non-protrusive }\end{array}$ & $\begin{array}{l}\text { Bimaxillary protrusive } \\
\text { teeth significantly larger }\end{array}$ & Yes \\
\hline $\begin{array}{l}\text { Melo et al. } \\
\quad 2001\end{array}$ & $\begin{array}{l}\text { Crowded vs. noncrowded } \\
\qquad(\mathrm{Mx} \& \mathrm{Md} \mathrm{A}-\mathrm{E})\end{array}$ & $\begin{array}{l}\text { Crowded teeth } \\
\text { significantly larger }\end{array}$ & No \\
\hline Mills 1964 & $\begin{array}{l}\text { Crowded vs. noncrowded } \\
\qquad(\mathrm{Mx} I 1 \& \mathrm{I} 2)^{*}\end{array}$ & $\begin{array}{l}\text { No difference in tooth } \\
\text { size }\end{array}$ & Males \\
\hline $\begin{array}{l}\text { Norderval } \\
\text { et al. } 1975\end{array}$ & $\begin{array}{l}\text { Crowded vs. noncrowded } \\
\qquad(\mathrm{Mx} \& \mathrm{Md} 3-3)\end{array}$ & $\begin{array}{l}\text { Crowded teeth } \\
\text { significantly larger }\end{array}$ & No \\
\hline $\begin{array}{l}\text { Peck, Peck } \\
\text { 1972a,b }\end{array}$ & $\begin{array}{l}\text { Crowded vs. noncrowded } \\
\text { (Md 2-2) }\end{array}$ & $\begin{array}{l}\text { MD larger, BL smaller } \\
\text { with crowding }\end{array}$ & Females \\
\hline $\begin{array}{c}\text { Radnzic } \\
1988\end{array}$ & $\begin{array}{l}\text { Crowded vs. noncrowded } \\
(\mathrm{Mx} \& \mathrm{Md} \text { 6-6) }\end{array}$ & $\begin{array}{l}\text { No difference in tooth } \\
\text { size; arch length } \\
\text { decreased with crowding }\end{array}$ & Males \\
\hline $\begin{array}{l}\text { Seipel } \\
1946\end{array}$ & $\begin{array}{l}\text { Crowded vs. mean value; } \\
\text { spacing vs. mean value }\end{array}$ & $\begin{array}{l}\text { No difference in } \\
\text { crowded; small teeth } \\
\text { significant in spacing }\end{array}$ & No \\
\hline $\begin{array}{l}\text { Shah et al. } \\
2003\end{array}$ & $\begin{array}{l}\text { Crowded vs. noncrowded } \\
(\mathrm{Mx} \& \mathrm{Md} 2-2)\end{array}$ & No difference & Yes \\
\hline
\end{tabular}


Table 5-1. Continued

\begin{tabular}{lccc}
\hline Reference & Comparison & Results & $\begin{array}{c}\text { Sexes } \\
\text { Separated }\end{array}$ \\
\hline Tsai 2003 & $\begin{array}{c}\text { Crowded vs. spacing } \\
\text { (anterior primary teeth) }\end{array}$ & $\begin{array}{c}\text { No difference in tooth } \\
\text { size; }\end{array}$ & No \\
& Arch width significant & \\
\hline
\end{tabular}

*Incisor irregularity measured from entire dental arches (M1-M1) in determining arch width. 
researcher cannot distinguish whether the observed difference is due to sexual dimorphism, a true effect of tooth size on TSASD, or some combination of the two.

Two obvious solutions in terms of research designs are (1) to test for differences within each sex separately or (2) to use statistical methods (such as two-way ANOVA) that control for sexual dimorphism. The present study addressed this issue of sexual dimorphism in tooth size by limiting the scope to studying just males.

As reported in the Results chapter, a statistically significant correlation between absolute tooth size and dental crowding occurs in the present study. Large teeth were positively associated with crowding. Of the 24 tooth crown diameters measured (both mesiodistal and buccolingual crown dimensions of all 12 tooth types, excluding second and third molars), 23 were significantly larger in the orthodontically treated sample as compared to a sample with naturallyoccurring good occlusions (Figs. 4-1 and 4-2). Because the results are consistent and pervasive across all tooth types, it can be inferred that absolute tooth size is a risk factor for malocclusion in our sample.

Comparing our results with previous studies, it is relevant to note that, of the 13 studies that compared tooth crown widths (mesiodistal and/or buccolingual) between crowded and noncrowded dentitions, seven (Seipel 1946; Norderval et al. 1975; Doris et al. 1981; Gilmore and Little 1984; Melo et al. 2001; 
Tsai 2003; Hashim and Al Ghamdi 2005) conducted statistical analyses with sexes pooled. As noted previously, such studies may be confounded due to the sexual dimorphism in tooth size. Of the six studies that separated the sexes for analyses, two found results in accord — more or less—with the present study (Adams 1982; Peck and Peck 1972a,b), while the remaining four found no significant difference in tooth size between crowded and noncrowded dentitions (Howe et al. 1983; Mills 1964; Radnzic 1988; Shah et al. 2003).

With one notable exception, our findings were consistent with those of Peck and Peck (1972a,b). In concert, both studies found significantly smaller mesiodistal crown dimensions in their group with naturally-occurring good occlusion, suggesting that mesiodistal crown diameter is a risk factor for malocclusion. In contrast, Peck and Peck found that buccolingual crown dimensions were actually larger in their perfectly aligned sample. They concluded that both mesiodistal and buccolingual crown dimensions were significant predictors of mandibular incisor crowding, although inversely related. Their results suggested that the ratio of mesiodistal to buccolingual tooth width was the most important predictor of TSASD and that mesiodistal and buccolingual crown dimensions contributed independently to TSASD. Following this reasoning, one would be unable to distinguish whether greater mesiodistal or lesser buccolingual crown dimensions led to TSASD in a specific individual. As described in our Results chapter, it is intuitive that the mesiodistal crown 
dimension contributes directly to TSASD, yet size of the buccolingual dimension seems irrelevant. Indeed, results from the present study suggest that larger buccolingual crown dimensions of all tooth types were positively correlated with crowding simply due to their high positive correlation with mesiodistal crown dimensions (e.g., Fig. 4-5; also see Henderson 1975; Harris and Bailit 1988). In other words, buccolingual size covaries with TSASD, but only indirectly because of its association with mesiodistal size. Moreover, when the statistical variance due to mesiodistal size was removed from statistical tests in the present study, buccolingual dimensions showed limited statistical significance in relation to dental crowding (only the buccolingual dimension of the mandibular first molar was informative). This led us to infer that scenario " $\mathrm{B}$ " is the true situation as regards TSASD (Fig. 4-5).

It is worth mentioning that the present study design was fundamentally different from that of Gilmore and Little (1984). Their sample was composed mainly of orthodontically treated patients who were studied 10 years postretention. They did not have a control group of naturally well-occluded individuals without a history of orthodontic treatment. Rather, their wellaligned subjects were those who had not relapsed 10 years after some form of treatment (e.g., comprehensive orthodontic therapy or extraction of four premolars). In essence, they were searching for differences in tooth crown dimensions in subjects who all began with some degree of TSASD. Even the 30 
subjects in their study who were not treated orthodontically had four premolars extracted for TSASD. It is not surprising that no statistically significant difference was found in tooth crown dimensions (i.e., mesiodistal, buccolingual, or $\mathrm{MD} / \mathrm{BL}$ ratios).

Mills (1964) found a significant association between dental crowding and decreased arch width. His sample consisted of 230 midshipmen at the United States Naval Academy in Annapolis, Maryland. He measured crowding from first molar to first molar and arch width between canines, first premolars and second premolars. Mesiodistal tooth width was only measured for the maxillary central and lateral incisors and considered to be representative of dental size overall. Although our findings do not support Mills' findings for the maxillary lateral incisor, it is difficult to make any other comparisons because Mills did not measure mesiodistal crown dimensions of any other teeth.

In a smaller sample, Radnzic (1988) found no significant association between mesiodistal crown dimensions and dental crowding in two ethnic groups (British and Pakistani analyzed separately) both living in Rochdale, England. Rather, he found that decreases in arch length and arch perimeter were significantly related to dental crowding. Although mesiodistal dimensions were consistently larger in the mandibular arches of crowded subjects, it is possible that he was unable to find a statistically significant difference due to his small 
sample size ( $\mathrm{n}=15$ after dividing his two groups into subgroups with and without dental crowding).

Howe et al. (1983) also were unable to find a statistically significant difference in the mesiodistal dimensions of maxillary or mandibular teeth (M1 through M1) in males or females on the basis of the presence or absence of dental crowding. Their crowded group had a mean age of 19.6 years, whereas their noncrowded group had a mean age of 15.6 years. Conceivably, their negative findings could be due to the 4-year age difference in their samples. Little et al. $(1981,1988)$ and Driscoll-Gilliland et al. (2001) found that dental crowding increased with age. Howe et al. did find that noncrowded dental arches were statistically significantly larger. Apart from the age difference between the two groups, it is difficult to account for the differences between their findings compared to those of the present study.

Findings of the present study also contradict those of Shah et al. (2003). Their study examined orthodontically untreated subjects with varying degrees of crowding and found no difference in "crown shape" (defined as the MD/BL ratio). Unfortunately, since they did not report individual crown dimensions, it is unknown how the mesiodistal and buccolingual crown dimensions compare to our data before the ratios were calculated. Furthermore, because the present study found that buccolingual dimensions were positively correlated with mesiodistal dimensions (though the magnitude of differences between crowded 
and noncrowded arches was much smaller among buccolingual dimensions), it follows that a ratio of the two would not vary to a significant degree. The two studies were looking for basically different information (i.e., tooth shape versus tooth size).

Another noteworthy difference of the present study was with Norderval et al. (1975), who found that the maxillary lateral incisor was statistically insignificantly larger in a sample with optimum interdigitation. Because their study was conducted in Norway and the ethnic background of their subjects was not provided, this difference could be confounded by ethnic differences in the samples. By comparison, the present study was limited to American whites. As

previously noted, it is well-documented that small maxillary lateral incisor width is a distinctive feature in Caucasians (e.g., Moorrees 1957; Lasker and Lee 1957; Harris and Rathbun 1991). Presuming that Norderval's sample was of similar Caucasian extraction; this difference may be more aptly described as an issue of proper "coupling," which is discussed in the following section dealing with dental proportionality.

\section{Dental Proportionality}

In contrast to absolute tooth size, a complementary condition is occasionally encountered in orthodontic patients, where one tooth type —commonly the maxillary lateral incisors in whites—is disproportionately 
small, which creates a so-called Bolton discrepancy (e.g., Bolton 1958, 1962). This difference in tooth-size proportionality is the second sort of problem that creates malocclusions - here because the small tooth disrupts the normal inter-tooth coupling of teeth within and between the two dental arches.

Previous authors have investigated the issue of dental proportionality and the Bolton Index, and their findings were discussed in detail in Review of Literature. Most authors agree that a tooth-size analysis (e.g., a Bolton analysis) should routinely be incorporated into orthodontic treatment planning (Freeman et al. 1996). However, one factor that leads to different findings is which tooth types were measured in the various studies. For instance, several studies only considered the four mandibular incisors (Peck and Peck 1972a,b) or the maxillary and mandibular anterior six teeth (Norderval et al. 1975). As such, although they were able to detect absolute differences in tooth size as it relates to lower TSASD, they did not address the issue of proportionality of tooth size as an etiological factor in malocclusion. In that sense, the present study provides a novel approach.

In order to test for differences in tooth-size proportionalities in the present study, two steps were taken: (1) six teeth were measured in each arch (incisors, canines, premolars, and first molars), and (2) statistical methods (MANOVA and stepwise discriminant functions analysis) were employed to resolve the issue of repeatedly assessing statistically redundant information. Specifically, we wanted 
to know which tooth crown dimensions contributed most to the potential toothsize disproportionality that led to TSASD. As reported in the Results chapter (Table 4-11), we found that the mesiodistal dimension of the maxillary lateral incisor contributed most to this source of TSASD, followed by the buccolingual dimension of the mandibular first molar (although this second dimension was much less informative). Larger values of the mesiodistal dimension of $\mathrm{U} 2$ were significantly associated with TSASD.

Apart from studies that addressed strictly Bolton discrepancies (e.g., Sperry et al. 1977; Crosby and Alexander 1989; Freeman et al. 1996), few authors have considered proportionality as an issue related to TSASD. Some studies have considered proportionality in the context of malocclusion (e.g., Alkofide and Hashim 2002; Laino et al. 2003); however, these studies are limited because they did not consider subjects with naturally-occurring good occlusions. Since all of the subjects had malocclusions, it was not surprising that no statistically significant differences were observed.

One study with similar methodology as ours was Bernabé and Flores-Mir (2006). They used MANOVA to compare mesiodistal and buccolingual crown dimensions in crowded versus noncrowded arches and also considered the MD/BL ratio. Akin to the present study, they found significantly greater overall mesiodistal crown dimensions in dental arches with more crowding. However, no difference was observed for buccolingual dimensions. It follows, then, that 
the $\mathrm{MD}$ to $\mathrm{BL}$ ratio increased with the presence of crowding (since the numerator- the mesiodistal dimension—increased, whereas the denominator the buccolingual dimension - remained unchanged).

\section{Secular Changes in Arch Size}

Although the present study does not address differences in arch size between crowded and noncrowded subjects, several prior studies have alluded to a potential secular trend in arch size reduction in consequence to an increasingly refined dietary consistency and decreased masticatory stress during development. In the present study, arch size comparisons were not feasible because pretreatment dental casts of orthodontically treated subjects were unavailable. As such, we were unable to assess arch dimensions of subjects who required orthodontic treatment to resolve TSASD. Simply because we were unable to comment on the potential differences in arch dimensions, does not imply that we do not acknowledge their possible contribution to TSASD.

Watt and Williams (1951) were among the first to investigate the influence of environmental factors such as dietary consistency and muscle activity on jaw size, and similar findings have been reported more recently (e.g., Beecher and Corruccini 1981; Maki et al. 2002; Mavropoulos et al. 2005). Watt and Williams tested the relative effects of masticatory function on the growth and development of the mandible and maxilla of the rat. The inference is that results of their study 
on rats are applicable to humans. They found that rats that consumed a harder diet developed significantly larger and heavier bony jaws than otherwise similar rats that subsisted on a softer diet. They concluded that function, as influenced by differences in the physical consistency of food, was an important factor in the growth and development of the jaws.

Extending this comparison to a human context, Corruccini (1984) took a unique approach to the investigation of the effect of dietary consistency on occlusal development and the severity of malocclusion. Reviewing results from seven different cultures, Corruccini compared two populational components within each, (1) an industrially modernized group and (2) a sociotechnologically preindustrial group. In each comparison, Corruccini found that the more modernized group— that subsisted on a softer, more refined diet—exhibited greater occlusal variation (i.e., malocclusion). Because the transition from predominately good to predominately poor occlusion repeatedly occurred within one to two generations, the suggestion of a genetic etiology was not tenable. Indeed, Corruccini suggested a secular trend in decreased jaw size leading to malocclusion in modernized populations occurred, an important aspect of which is increased TSASD. 


\section{Secular Changes in Tooth Size}

Viewing TSASD from a different perspective, it is also plausible that better health and nutrition have led to secular increases in tooth size. In fact, several prior studies have alluded to such a trend (e.g., Garn et al. 1967; Lavelle 1973; Kieser et al. 1987; Harris et al. 2001). We propose that a complete understanding of the causes of TSASD needs to rely on unraveling the complex interactions between secular increases in tooth size coupled with concomitant decreases in jaw size.

Whatever the precise cause, the result is an increased and increasing manpower need for orthodontists since the incidence of TSASD is suggested to have increased as well (Warren and Bishara 2003). Over the short-term, the dental profession and specifically the orthodontic specialty reaps the "benefits" of increased demand for treatment. Obviously, though, the long-term solution viewed as a matter of public health is to seek means of intercepting and preventing the development of TSASD. No such prospects currently are on the horizon. Animal studies, as reviewed above, suggest that enhanced masticatory stress might result in greater alveolar bone proliferation in childhood and adolescence, but how to achieve that is unknown—largely because compliance with any sort of exercise program would be trivial. 


\section{$\underline{\text { Resolving TSASD }}$}

Having demonstrated that mesiodistal tooth size is a statistically significant risk factor for malocclusion, how to manage TSASD clinically becomes germane. The issue of proper coupling of the teeth often arises during the final "detailing" phase of orthodontic treatment (Poling 1999). Ideal buccal segment occlusion is admittedly difficult to achieve, especially in first-premolar extraction cases where the risk of Bolton discrepancies is higher (Saatçi and Yukay 1997). Additionally, there may be insufficient or excessive overjet and/or overbite. If the orthodontist performed a tooth-size analysis during the treatment planning phase, these problems should have been (1) anticipated, (2) discussed with the patient, and (3) managed through an appropriate course of treatment. Thus, the issue becomes, what are the appropriate clinical strategies for managing TSASD?

Howe et al. (1983) proposed that treatment to resolve TSASD should be directed at (1) reducing tooth mass, (2) increasing the dental arch dimensions, or (3) a combination of both. If TSASD is an issue of proportionality (e.g., small maxillary lateral incisors), there is an accord among orthodontists that a rational solution is to restore (via operative means) the maxillary lateral incisors to their "appropriate" mesiodistal dimensions and/or to perform interproximal reduction on the lower incisors (i.e., "reproximation" as proposed by Peck and Peck 1972a,b). The maximum amount of anterior interproximal reduction 
recommended by Fields (1981) is 2.0 to $2.5 \mathrm{~mm}$ across the maxillary anterior six teeth. On the other hand, Hussels and Nanda (1987) considered interproximal reduction a last resort when favorable overjet could not be created via establishment of proper mesiodistal and labiolingual angulation of the teeth. They reasoned that injudicious or heavy stripping could create conditions that may be difficult to rectify when the problems primarily result from "improper" angulation. Moreover, even in instances where the size of incisors on the right and left sides is different, they argue that problems may be minimized by increasing the angulation of the smaller tooth.

The more common issue arises, however, with the scenario where TSASD is due to relatively small dental arches and relatively large teeth (i.e., issues of absolute size). Extraction of permanent teeth to decrease mesiodistal tooth structure and expansion of the maxillary dental arch (as proposed by Howe et al. 1983) are antipodal yet conventional treatment strategies employed today. Depending on the degree of TSASD, one strategy may be more appropriate than the other. Profitt (2000) proposes that $5 \mathrm{~mm}$ of mesiodistal discrepancy is a clinically useful dividing line between extraction and nonextraction treatment protocols.

Regardless of an orthodontist's particular management perspective about TSASD, the bottom-line is (1) to recognize during treatment planning that the problem exists and (2) to present treatment options as well as their associated 
risks and benefits to patients at the start of treatment. We support the notion that a tooth-size arch-size analysis should be an integral part of each orthodontic assessment.

\section{$\underline{\text { Future Research Considerations }}$}

As is evident by this point in the presentation, this study design tested for tooth-size differences between two groups, (1) those with naturally-occurring good occlusions versus (2) those who have been treated orthodontically. A weakness here is our inability to scale the severity of the malocclusion within the treated group. We suppose that TSASD is distributed along a continuum from none, through minor, to severe. It would be insightful to determine whether tooth size is distributed in a similar fashion—where those with mild TSASD have mildly larger crown diameters, while those with severe TSASD tend to have the largest crown sizes. Finding a "dose-response" relationship between crown size and the degree of TSASD would help refine the association established here.

The anticipated relationship is shown in Figure 5-1. It is evident from numerous studies of crown dimensions (e.g., Kieser 1990) that crown sizes are normally distributed in a population. Likewise, TSASD exhibits a quasi-normal distribution within orthodontic samples. The present study simply dichotomized TSASD (Fig. 5-1) into those with effectively no discrepancy versus those where TSASD was large enough to merit orthodontic treatment. This was 


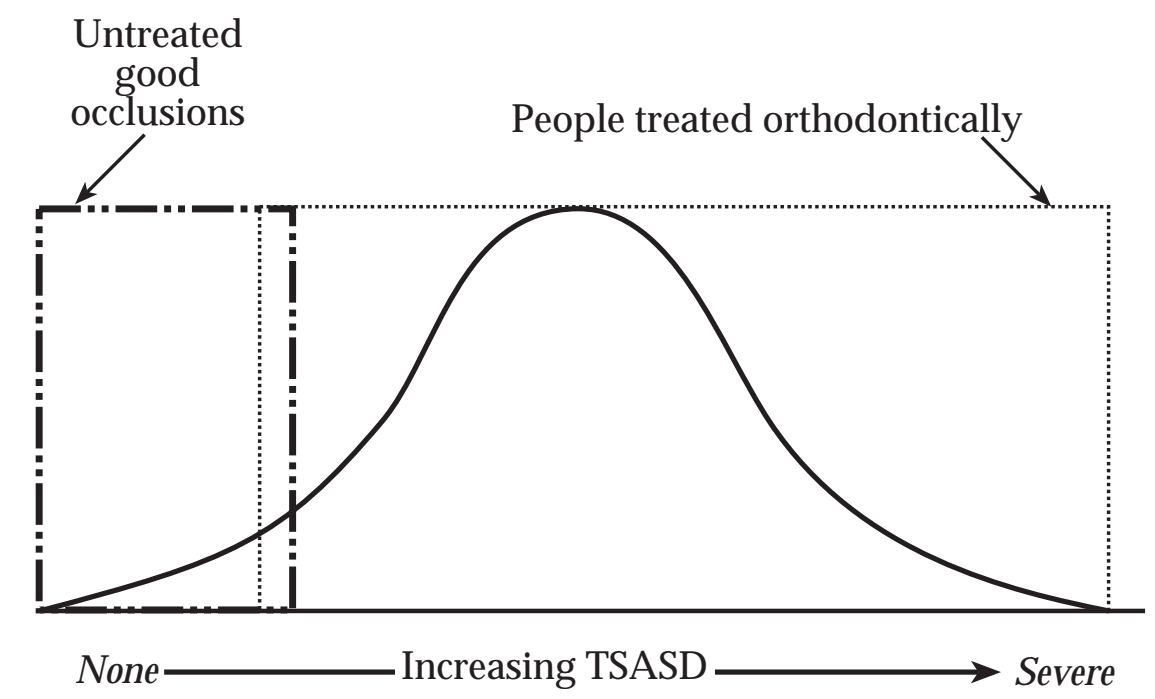

Fig. 5-1. Schematic view of the perceived relationship between tooth crown size (the normal curve) and the imposed dichotomy of those treated or untreated orthodontically because of TSASD. We speculate that there ought to be a positive association between tooth size and the degree of TSASD if the latter had been measured on a graded scale. 
necessary because we had no measure of the TSASD of the treated cases. It would be informative if a "dose-response" relationship could be documented between crown size and the severity of TSASD. This latter approach could be performed in a sample from an orthodontic practice, especially in the private sector when subjects requiring little correction would be included. This also would permit the study of females as well as males where it seems that females (and/or their parents) are more likely to seek treatment for comparatively minor TSASD issues. 


\section{CHAPTER 6}

\section{SUMMARY AND CONCLUSIONS}

The causes of dental malocclusion are obscure as regards most children. Here we investigated the influence of tooth size as one contributing factor. The purpose was to determine whether people with bigger tooth crown dimensions were at a greater risk of having malocclusions assessed as tooth-size arch-size discrepancies (TSASD). Large crown dimensions could be described in the general sense (absolute size) or relative sense (proportionalities between tooth types). We compared mesiodistal and buccolingual crown diameters in a sample of young adult males with naturally-occurring good occlusions versus a sample of otherwise similar individuals who required orthodontic treatment to correct their malocclusion. Data were collected by one observer, with repeatability error of only $0.07 \mathrm{~mm}$, and the group differences were analyzed for statistical significance. Major findings are:

1. Both mesiodistal and buccolingual crown dimensions tend to be significantly larger in orthodontically treated versus untreated subjects. Indeed, average tooth size is significantly larger in the treated sample for 23 of the 24 variables tested. The buccolingual width of the mandibular canine was the single exception, where the mean size was nonsignificantly larger in the untreated sample $(P=0.87)$. 
2. In support of Peck and Peck's findings, mesiodistal and buccolingual diameters differed between treated and untreated subjects. Mesiodistal crown diameters were larger in crowded individuals; however, in contrast to Peck and Peck's findings, we found that buccolingual diameters also were consistently larger in crowded dentitions.

3. Controlling for intercorrelations among the data using multivariate statistics, only mesiodistal crown diameters were clinically relevant, or independently predictive of crowding. The data show that buccolingual crown dimensions contribute only indirectly to TSASD due to their high positive correlations with mesiodistal diameters. As such, the MD/BL ratios were not predictive of crowding. This finding is at odds with Peck and Peck, who suggested that mesiodistal and buccolingual crown dimensions contributed independently and directly to TSASD.

4. The present analysis indicates that buccolingual dimensions are larger in the TSASD sample only because they are positively intercorrelated with the mesiodistal dimensions. Clearly, it is the tooth's mesiodistal size that affects space required.

5. Having confirmed that large variation in tooth crown size is a risk factor for TSASD, three clinical solutions are available to the orthodontist for resolving TSASD: (1) reducing tooth mass, (2) increasing the dental arch dimensions, or (3) a combination of the two. Ideally, treatment techniques that increase 
alveolar bone growth during development would be the least invasive management strategy - and therefore preferable, but this currently is not within our treatment options. 
LIST OF REFERENCES 
Ackerman JL, Proffit WR. The characteristics of malocclusion: a modern approach to classification and diagnosis. Am J Orthod 1969;56:443-54.

Adams CP. A comparison of 15 year old children with excellent occlusion and with crowding of the teeth, Angle Class I malocclusion, in respect of face size and shape and tooth size. Swed Dent J Suppl 1982;15:11-26.

Al-Khateeb SN, Abu Alhaija ESJ. Tooth size discrepancies and arch parameters among different malocclusions in a Jordanian sample. Angle Orthod 2006;76:459-65.

Alkofide E, Hashim H. Intermaxillary tooth size discrepancies among different malocclusion classes: a comparative study. J Clin Pediatr Dent 2002;26:383-7.

Basaran G, Selek M, Hamamci O, Akku Z. Intermaxillary Bolton tooth size discrepancies among different malocclusion groups. Angle Orthod 2006;76:26-30.

Beecher RM, Corruccini RS. Effects of dietary consistency on craniofacial and occlusal development in the rat. Angle Orthod 1981;51:61-9.

Begg PR. Begg orthodontic theory and technique. Philadelphia: WB Saunders, 1971.

Begg PR. Stone age man's dentition: with reference to anatomically correct occlusion, the etiology of malocclusion, and a technique for its treatment. Am J Orthod 1954;40:298-312, 373-83, 462-75, 517-31. 
BeGole EA, Fox DL, Sadowsky C. Analysis of change in arch form with premolar expansion. Am J Orthod Dentofacial Orthop 1998;113:307-15.

Bernabé E, Flores-Mir C. Intra-arch occlusal indicators ofcrowding in the permanent dentition. Am J Orthod Dentofacial Orthop 2005;128:220-5.

Bernabé E, Flores-Mir C. Dental morphology and crowding: a multivariate approach. Angle Orthod 2006;76:20-5.

Bishara SE, Khadivi P, Jakobsen JR. Changes in tooth size-arch length relationships from the deciduous to the permanent dentition: a longitudinal study. Am J Orthod Dentofacial Orthop 1995;108:607-13.

Bishara SE, Treder JE, Jakobsen JR. Facial and dental changes in adulthood. Am J Orthod Dentofacial Orthop 1994;106:175-86.

Bolton WA. Disharmony in tooth size and its relation to the analysis and treatment of malocclusion. Am J Orthod 1958;28:113-30.

Bolton WA. The clinical application of a tooth size analysis. Am J Orthod 1962;48:504-29.

Cooley WW, Lohnes PR. Multivariate data analysis. New York: John Wiley \& Sons, Inc., 1971.

Corruccini RS. An epidemiologic transition in dental occlusion in world populations. Am J Orthod 1984;86:419-26.

Corruccini RS. Australian aboriginal tooth succession, interproximal attrition, and Begg's theory. Am J Orthod Dentofacial Orthop 1990;97:349-57. 
Corruccini RS. How anthropology informs the orthodontic diagnosis of malocclusions' causes. Lewiston, NY: Edwin Mellen Press, 1999.

Corruccini RS, Kaul SS. Epidemiological transition and anthropology of minor chronic non-infectious diseases. Med Anthropol 1984;7:36-50.

Crosby DR, Alexander CG. The occurrence of tooth size discrepancies among different malocclusion groups. Am J Orthod Dentofacial Orthop 1989;95:457-61.

Dahlberg AA. The changing dentition of man. J Am Dent Assoc 1945;32:676-90.

Dahlberg AA. The dentition of the American Indian. In: Laughlin WS, editor. The physical anthropology of the American Indian. New York: Viking Fund Inc, 1951.

Dahlberg G. Statistical methods for medical and biological students. London: George Allen \& Unwin, Ltd, 1940.

Doris JM, Bernard BW, Kuftinec MM. A biometric study of tooth size and dental crowding. Am J Orthod 1981;79:326-36.

Driscoll-Gilliland J, Buschang PH, Behrents RG. An evaluation of growth and stability in untreated and treated subjects. Am J Orthod Dentofacial Orthop 2001;120:588-97.

Freeman JE, Maskeroni AJ, Lorton L. Frequency of Bolton tooth-size discrepancies among orthodontic patients. Am J Orthod DentofacialOrthop 1996;110:24-7. 
Freitas MR, Castro RC, Janson G, Freitas KM, Henriques JF. Correlation between mandibular incisor crown morphologic index and postretention stability. Am J Orthod Dentofacial Orthop 2006;129:559-61.

Freund RJ, Littell RC. SAS ${ }^{\oplus}$ systems for regression, 2nd ed. Cary, NC: SAS Institute Inc, 1991.

Garn SM, Lewis AB, Kerewsky RS. Genetic control of sexual dimorphism in tooth size. J Dent Res 1967;46:963-72.

Garn SM, Lewis AB, Kerewsky RS. Sex difference in tooth size. J Dent Res 1964;43:306.

Garn SM, Lewis AB, Kerewsky RS. Sexual dimorphism in the buccolingual tooth diameter. J Dent Res 1966;45:1819.

Garn SM, Lewis AB, Kerewsky RS. Third molar agenesis and variation in size of the remaining teeth. Nature 1964;201:839.

Gilmore CA, Little RM. Mandibular incisor dimensions and crowding. Am J Orthod 1984;86:493-502.

Gorush R. Factor analysis, 2nd ed. Hillsdale: Lawrence Erlbaum Publishers, 1983.

Harman HH. Modern factor analysis, 3rd ed. Chicago: University of Chicago Press, 1976.

Harris EF. Where's the variance? variance components in tooth sizes of the permanent dentition. Dental Anthropology 2003;16:84-94. 
Harris EF, Bailit HL. A Principal components analysis of human odontometrics. Am J Phys Anthropol 1988;75:87-99.

Harris EF, Potter RH, Lin J. A secular trend in tooth size in urban Chinese assessed from two-generation family data. Am J Phys Anthropol 2001;115:312-8.

Harris EF, Rathbun TA. Ethnic differences in the apportionment of tooth sizes. In: Kelley MA, Larsen CS, editors. Advances in dental anthropology. New York: Alan R. Liss, Inc, 1991.

Hartsfield JK. Genetics and orthodontics. In: Graber TM, Vanarsdall RL, Vig KWL, editors. Orthodontics: current principles and techniques, 4th ed. St. Louis: Elsevier Mosby, 2005.

Hashim HA, Al-Ghamdi S. Tooth width and arch dimensions in normal and malocclusion samples: an odontometric study. J Contemp Dent Pract 2005;6:36-51.

Henderson AM. Dental field theory: an application to primate evolution. Ph.D. dissertation, University of Colorado, Boulder, 1975.

Hillson S, FitzGerald C, Flinn H. Alternative dental measurements: proposals and relationships with other measurements. Am J Phys Anthropol $2005 ; 126: 413-26$.

Hopkins WG. Measures of reliability in sports medicine and science. Sports Med 2000;30:1-15. 
Howe RP, McNamara JA Jr, O'Connor KA. An examination of dental crowding and its relationship to tooth size and arch dimension. Am J Orthod 1983;83:363-73.

Jacobson A. The dentition of the South African Negro. Anniston, AL: Higginbotham, Inc, 1982.

Kaiser HF. The varimax criterion for analytic rotation in factor analysis. Psychometrika 1958;23:187-200.

Keene A, Engel G. The mandibular dental arch, part IV: prediction and prevention of lower anterior relapse. Angle Orthod 1979;49:173-80.

Kelly JE, Harvey CR. An assessment of the occlusion of youths 12-17 years. United States Public Health Service, 1977 (Vital and Health Statistics, series 11, no. 162).

Kieser JA. Human adult odontometrics: the study of variation in adult tooth size. New York: Cambridge University Press, 1990.

Laino A, Quaremba G, Paduano S, Stanzione S. Prevalence of tooth-size discrepancy among different malocclusion groups. Prog Orthod 2003;4:3744.

Lasker GW, Lee MMC. Racial traits in the human dentition. J Forensic Sci 1957;2:401-19.

Lavelle CLB. Maxillary and mandibular tooth size in different racial groups and in different occlusion categories. Am J Orthod 1972;6:29-37. 
Lavelle CLB. Variation in the secular changes in the teeth and dental arches. Am J Orthod 1973;43:412-21.

Lindsten R. Secular changes in tooth size and dental arch dimensions in the mixed dentition. Swed Dent J Suppl 2003;157:1-89.

Little RM. The irregularity index: a quantitative score of mandibular anterior alignment. Am J Orthod 1975;68:554-63.

Little RM, Riedel RA, Årtun J. An evaluation of changes in mandibular anterior alignment from 10 to 20 years postretention. Am J Orthod Dentofacial Orthop 1988;93:423-8.

Lundström A. An investigation of 202 pairs of twins regarding fundamental factors in the aetiology of malocclusion. Dent Rec 1949;69:251-64.

Lundström A. Intermaxillary tooth width ratio and tooth alignment in occlusion. Acta Odontol Scand 1955;12:266-92.

Maki K, Nishioka T, Shioiri E, Takahashi T, Kimura M. Effects of dietary consistency on the mandible of rats at the growth stage: computed x-ray densitometric and cephalometric analysis. Angle Orthod 2002;72:468-75.

Mavropoulos A, Ammann P, Bresin A, Kiliaridis S. Masticatory demands induce region-specific changes in mandibular bone density in growing rats. Angle Orthod 2005; 75:625-30.

McCann J, Burden DJ. An investigation of tooth size in Northern Irish people with bimaxillary dental protrusion. Eur J Orthod 1996;18:617-21. 
McNamara JA Jr, Ribbens KA, editors. Naso-respiratory function and craniofacial growth. Monograph 9, Craniofacial Growth Series. Ann Arbor: Center for Human Growth and Development, University of Michigan, 1979.

Melo L, Ono Y, Takagi Y. Indicators of mandibular dental crowding in the mixed dentition. Pediatr Dent 2001;23:118-22.

Mills LF. Arch width, arch length, and tooth size in young adult males. Angle Orthod 1964;34:124-9.

Moorrees CFA. The Aleut dentition: a correlative study of dental characteristics in an Eskimoid people. Cambridge: Harvard University Press, 1957.

Moorrees CFA, Reed RB. Correlations of tooth size. Arch Oral Biol 1964;9:685-97.

Morrison DF. Multivariate statistical methods, 2nd ed. New York: McGraw-Hill Book Company, 1976.

Norderval K, Wisth PJ, Böe OE. Mandibular anterior crowding in relation to tooth size and craniofacial morphology. Scand J Dent Res 1975;83:267-73.

Paredes V, Gandia JL, Cibrian R. Do Bolton's ratios apply to a Spanish population? Am J Orthod Dentofacial Orthop 2006;129:428-30.

Peck S. Tooth size, tooth stability, and the master's thesis. Am J Orthod Dentofacial Orthop 2007;131:3-4.

Peck S, Peck H. A time for change of tooth numbering systems. J Dent Ed 1993;57:643-7. 
Peck S, Peck H. Crown dimensions and mandibular incisor alignment. Angle Orthod 1972;42:148-53.

Perini TA, de Oliveira GL, Ornellas JS, Oliveira FP. Technical error of measurement in anthropometry. Rev Bras Med Esporte 2005;11:86-90.

Potter RHY, Yu P-L, Dahlberg AA, Merritt AD, and Conneally PM. Genetic studies of tooth size factors in Pima Indian families. Am J Hum Genet 1968;20:89-99.

Proffit WR. Contemporary orthodontics, 3rd ed. St Louis: Mosby Year Book, 1999.

Proffit WR. On the aetiology of malocclusion. The Northcroft lecture, 1985 presented to the British Society for the Study of Orthodontics, Oxford, April 18, 1985. Br J Orthod 1986;13:1-11.

Proffit WR, Ackerman JL. Rating the characteristics of malocclusion: a systematic approach for planning treatment. Am J Orthod 1973;64:258-69.

Radnzic D. Dental crowding and its relationship to mesiodistal crown diameters and arch dimensions. Am J Orthod Dentofacial Orthop 1988;94:50-6.

Rhee SH, Nahm DS. Triangular-shaped incisor crowns and crowding. Am J Orthod Dentofacial Orthop 2000;118:624-8.

Rohlf FJ, Sokal RR. Statistical tables, 2nd ed. New York: WH Freeman and Company, 1981. 
Seipel C. Variation in tooth position: a metric study of variation and adaptation in the deciduous and permanent dentitions. Swed Dent J 1946;39:1-176. Shah AA, Elcock C, Brook AH. Incisor crown shape and crowding. Am J Orthod Dentofacial Orthop 2003;123:562-7.

Siegel S, Castellan NJ. Nonparametric statistics for the behavioral sciences, 2nd ed. New York: McGraw-Hill, 1988.

Smith RJ, Davidson WM, Gipe DP. Incisor shape and incisor crowding: a reevaluation of the Peck and Peck ratio. Am J Orthod 1982;82:231-5.

Sokal RR, Rohlf FJ. Biometry: the principles and practice of statistics in biological research, 3rd ed. San Francisco: WH Freeman and Company, 1995.

Sperry TP, Worms FW, Isaacson RJ, Speidel TM. Tooth-size discrepancy in mandibular prognathism. Am J Orthod 1977;72:183-90.

Tsai HH. Dental crowding in primary dentition and its relationship to arch and crown dimensions. ASDC J Dent Child 2003;70:164-9.

Tukey JW. Exploratory data analysis. Reading, MA: Addision-Wesley, 1977.

Warren JJ, Bishara SE. Comparison of dental arch measurements in the primary dentition between contemporary and historic samples. Am J Orthod Dentofacial Orthop 2001;119:211-5.

Warren JJ, Bishara SE, Yonezu T. Tooth size arch length relationships in the deciduous dentition: a comparison between contemporary and historical samples. Am J Orthod Dentofacial Orthop 2003;123:614-9. 
Watt DG, Williams HM. The effects of the physical consistency of food on the growth and development of the mandible and maxilla of the rat. Am J Orthod 1951;37:895-928.

Weinberger BW. Orthodontics: an historical review of its origin and evolution. 2 vols. St Louis: CV Mosby Company, 1926.

Winer BJ, Brown DR, Michels KM. Statistical principles in experimental design, 3rd ed. New York: McGraw-Hill, 1991. 


\section{APPENDIX}

\section{DESCRIPTIVE STATISTICS}


Table A-1. Comparison of descriptive statistics for mesiodistal diameter of UI1 for the two groups, namely those with naturally-occurring good occlusions and those who received orthodontic treatment. The treated group mean is $3.46 \%$ larger than that of the untreated group.

\begin{tabular}{lcc}
\hline \multicolumn{1}{c}{ Statistic } & $\begin{array}{c}\text { Good } \\
\text { Occlusion }\end{array}$ & $\begin{array}{c}\text { Treated } \\
\text { Orthodontically }\end{array}$ \\
$\mathrm{n}$ & 41 & 91 \\
Mean & 8.64 & 8.93 \\
$\mathrm{sd}$ & 0.51 & 0.57 \\
$\mathrm{se}$ & 0.08 & 0.06 \\
minimum & 7.65 & 7.64 \\
maximum & 9.63 & 10.35 \\
$\mathrm{~L}_{1}$ & 8.47 & 8.81 \\
L2 & 8.80 & 9.05 \\
Variance $\left(\mathrm{s}^{2}\right)$ & 0.26 & 0.33 \\
Skewness $\left(\mathrm{g}_{1}\right)$ & -0.09 & 0.20 \\
Kurtosis $\left(\mathrm{g}_{2}\right)$ & -0.58 & -0.24 \\
CV & 5.90 & 6.42 \\
\hline
\end{tabular}


Table A-2. Comparison of descriptive statistics for mesiodistal diameter of UI2 for the two groups, namely those with naturally-occurring good occlusions and those who received orthodontic treatment. The treated group mean is $7.23 \%$ larger than that of the untreated group.

\begin{tabular}{lcc}
\hline \multicolumn{1}{c}{ Statistic } & $\begin{array}{c}\text { Good } \\
\text { Occlusion }\end{array}$ & $\begin{array}{c}\text { Treated } \\
\text { Orthodontically }\end{array}$ \\
\hline $\mathrm{n}$ & 41 & 91 \\
Mean & 6.65 & 7.13 \\
$\mathrm{sd}$ & 0.57 & 0.55 \\
$\mathrm{se}$ & 0.09 & 0.06 \\
minimum & 5.19 & 6.08 \\
maximum & 7.66 & 8.84 \\
L1 & 6.47 & 7.01 \\
L2 & 6.83 & 7.24 \\
Variance $\left(\mathrm{s}^{2}\right)$ & 0.32 & 0.31 \\
Skewness $\left(\mathrm{g}_{1}\right)$ & -0.19 & 0.51 \\
Kurtosis $\left(\mathrm{g}_{2}\right)$ & -0.11 & 0.22 \\
CV & 8.51 & 7.75 \\
\hline
\end{tabular}


Table A-3. Comparison of descriptive statistics for mesiodistal diameter of UC for the two groups, namely those with naturally-occurring good occlusions and those who received orthodontic treatment. The treated group mean is $1.91 \%$ larger than that of the untreated group.

\begin{tabular}{lcc}
\hline \multicolumn{1}{c}{ Statistic } & $\begin{array}{c}\text { Good } \\
\text { Occlusion }\end{array}$ & $\begin{array}{c}\text { Treated } \\
\text { Orthodontically }\end{array}$ \\
\hline $\mathrm{n}$ & 41 & 91 \\
Mean & 7.84 & 7.99 \\
$\mathrm{sd}$ & 0.44 & 0.38 \\
$\mathrm{se}$ & 0.07 & 0.04 \\
minimum & 7.06 & 7.10 \\
maximum & 8.65 & 8.94 \\
$\mathrm{~L}_{1}$ & 7.70 & 7.91 \\
L2 & 7.98 & 8.06 \\
Variance $\left(\mathrm{s}^{2}\right)$ & 0.20 & 0.14 \\
Skewness $\left(\mathrm{g}_{1}\right)$ & 0.06 & 0.09 \\
Kurtosis $\left(\mathrm{g}_{2}\right)$ & -1.00 & 0.02 \\
CV & 5.68 & 4.74 \\
\hline
\end{tabular}


Table A-4. Comparison of descriptive statistics for mesiodistal diameter of UP1 for the two groups, namely those with naturally-occurring good occlusions and those who received orthodontic treatment. The treated group mean is $4.72 \%$ larger than that of the untreated group.

\begin{tabular}{lcc}
\hline \multicolumn{1}{c}{ Statistic } & $\begin{array}{c}\text { Good } \\
\text { Occlusion }\end{array}$ & $\begin{array}{c}\text { Treated } \\
\text { Orthodontically }\end{array}$ \\
\hline $\mathrm{n}$ & 41 & 91 \\
Mean & 6.80 & 7.12 \\
$\mathrm{sd}$ & 0.49 & 0.50 \\
$\mathrm{se}$ & 0.08 & 0.05 \\
minimum & 5.97 & 6.06 \\
maximum & 8.28 & 8.42 \\
$\mathrm{~L}_{1}$ & 6.64 & 7.01 \\
L2 & 6.95 & 7.22 \\
Variance $\left(\mathrm{s}^{2}\right)$ & 0.24 & 0.25 \\
Skewness $\left(\mathrm{g}_{1}\right)$ & 1.24 & 0.00 \\
Kurtosis $\left(\mathrm{g}_{2}\right)$ & 2.13 & -0.24 \\
CV & 7.17 & 7.04 \\
\hline
\end{tabular}


Table A-5. Comparison of descriptive statistics for mesiodistal diameter of UP2 for the two groups, namely those with naturally-occurring good occlusions and those who received orthodontic treatment. The treated group mean is $2.99 \%$ larger than that of the untreated group.

\begin{tabular}{lcc}
\hline \multicolumn{1}{c}{ Statistic } & $\begin{array}{c}\text { Good } \\
\text { Occlusion }\end{array}$ & $\begin{array}{c}\text { Treated } \\
\text { Orthodontically }\end{array}$ \\
\hline $\mathrm{n}$ & 41 & 91 \\
Mean & 6.69 & 6.89 \\
$\mathrm{sd}$ & 0.45 & 0.50 \\
$\mathrm{se}$ & 0.07 & 0.05 \\
minimum & 5.77 & 5.62 \\
maximum & 7.68 & 8.46 \\
$\mathrm{~L}_{1}$ & 6.55 & 6.78 \\
L2 & 6.83 & 6.99 \\
Variance $\left(\mathrm{s}^{2}\right)$ & 0.20 & 0.25 \\
Skewness $\left(\mathrm{g}_{1}\right)$ & 0.13 & -0.04 \\
Kurtosis $\left(\mathrm{g}_{2}\right)$ & -0.07 & 0.74 \\
CV & 6.76 & 7.27 \\
\hline
\end{tabular}


Table A-6. Comparison of descriptive statistics for mesiodistal diameter of UM1 for the two groups, namely those with naturally-occurring good occlusions and those who received orthodontic treatment. The treated group mean is $2.57 \%$ larger than that of the untreated group.

\begin{tabular}{lcc}
\hline \multicolumn{1}{c}{ Statistic } & $\begin{array}{c}\text { Good } \\
\text { Occlusion }\end{array}$ & $\begin{array}{c}\text { Treated } \\
\text { Orthodontically }\end{array}$ \\
\hline $\mathrm{n}$ & 41 & 91 \\
Mean & 10.41 & 10.68 \\
$\mathrm{sd}$ & 0.57 & 0.56 \\
$\mathrm{se}$ & 0.09 & 0.06 \\
minimum & 9.32 & 9.01 \\
maximum & 11.50 & 12.09 \\
$\mathrm{~L}_{1}$ & 10.23 & 10.56 \\
L2 & 10.59 & 10.80 \\
Variance $\left(\mathrm{s}^{2}\right)$ & 0.32 & 0.32 \\
Skewness $\left(\mathrm{g}_{1}\right)$ & 0.20 & -0.06 \\
Kurtosis $\left(\mathrm{g}_{2}\right)$ & -0.81 & 0.22 \\
CV & 5.44 & 5.27 \\
\hline
\end{tabular}


Table A-7. Comparison of descriptive statistics for mesiodistal diameter of LI1 for the two groups, namely those with naturally-occurring good occlusions and those who received orthodontic treatment. The treated group mean is $4.12 \%$ larger than that of the untreated group.

\begin{tabular}{lcc}
\hline \multicolumn{1}{c}{ Statistic } & $\begin{array}{c}\text { Good } \\
\text { Occlusion }\end{array}$ & $\begin{array}{c}\text { Treated } \\
\text { Orthodontically }\end{array}$ \\
\hline $\mathrm{n}$ & 41 & 91 \\
Mean & 5.31 & 5.53 \\
$\mathrm{sd}$ & 0.37 & 0.34 \\
$\mathrm{se}$ & 0.06 & 0.04 \\
minimum & 4.64 & 4.56 \\
maximum & 6.05 & 6.19 \\
$\mathrm{~L}_{1}$ & 5.19 & 5.46 \\
L2 & 5.43 & 5.60 \\
Variance $\left(\mathrm{s}^{2}\right)$ & 0.14 & 0.12 \\
Skewness $\left(\mathrm{g}_{1}\right)$ & 0.58 & -0.60 \\
Kurtosis $\left(\mathrm{g}_{2}\right)$ & -0.38 & 0.06 \\
CV & 7.04 & 6.18 \\
\hline
\end{tabular}


Table A-8. Comparison of descriptive statistics for mesiodistal diameter of LI2 for the two groups, namely those with naturally-occurring good occlusions and those who received orthodontic treatment. The treated group mean is $5.16 \%$ larger than that of the untreated group.

\begin{tabular}{lcc}
\hline \multicolumn{1}{c}{ Statistic } & $\begin{array}{c}\text { Good } \\
\text { Occlusion }\end{array}$ & $\begin{array}{c}\text { Treated } \\
\text { Orthodontically }\end{array}$ \\
\hline $\mathrm{n}$ & 41 & 91 \\
Mean & 5.78 & 6.08 \\
$\mathrm{sd}$ & 0.35 & 0.38 \\
$\mathrm{se}$ & 0.06 & 0.04 \\
minimum & 5.15 & 5.05 \\
maximum & 6.67 & 6.84 \\
$\mathrm{~L}_{1}$ & 5.67 & 6.00 \\
L2 & 5.89 & 6.16 \\
Variance $\left(\mathrm{s}^{2}\right)$ & 0.12 & 0.14 \\
Skewness $\left(\mathrm{g}_{1}\right)$ & 0.69 & -0.55 \\
Kurtosis $\left(\mathrm{g}_{2}\right)$ & -0.02 & 0.57 \\
CV & 6.10 & 6.22 \\
\hline
\end{tabular}


Table A-9. Comparison of descriptive statistics for mesiodistal diameter of LC for the two groups, namely those with naturally-occurring good occlusions and those who received orthodontic treatment. The treated group mean is $4.78 \%$ larger than that of the untreated group.

\begin{tabular}{lcc}
\hline \multicolumn{1}{c}{ Statistic } & $\begin{array}{c}\text { Good } \\
\text { Occlusion }\end{array}$ & $\begin{array}{c}\text { Treated } \\
\text { Orthodontically }\end{array}$ \\
\hline $\mathrm{n}$ & 41 & 91 \\
Mean & 6.73 & 7.06 \\
$\mathrm{sd}$ & 0.39 & 0.46 \\
$\mathrm{se}$ & 0.06 & 0.05 \\
minimum & 5.85 & 5.75 \\
maximum & 7.52 & 8.12 \\
$\mathrm{~L}_{1}$ & 6.61 & 6.96 \\
L2 & 6.86 & 7.15 \\
Variance $\left(\mathrm{s}^{2}\right)$ & 0.15 & 0.21 \\
Skewness $\left(\mathrm{g}_{1}\right)$ & -0.08 & -0.06 \\
Kurtosis $\left(\mathrm{g}_{2}\right)$ & -0.52 & 0.29 \\
CV & 5.73 & 6.47 \\
\hline
\end{tabular}


Table A-10. Comparison of descriptive statistics for mesiodistal diameter of LP1 for the two groups, namely those with naturally-occurring good occlusions and those who received orthodontic treatment. The treated group mean is $4.72 \%$ larger than that of the untreated group.

\begin{tabular}{lcc}
\hline \multicolumn{1}{c}{ Statistic } & $\begin{array}{c}\text { Good } \\
\text { Occlusion }\end{array}$ & $\begin{array}{c}\text { Treated } \\
\text { Orthodontically }\end{array}$ \\
\hline $\mathrm{n}$ & 41 & 91 \\
Mean & 7.00 & 7.34 \\
$\mathrm{sd}$ & 0.53 & 0.51 \\
$\mathrm{se}$ & 0.08 & 0.05 \\
minimum & 6.02 & 5.94 \\
maximum & 8.79 & 8.75 \\
$\mathrm{~L}_{1}$ & 6.84 & 7.23 \\
L2 & 7.17 & 7.44 \\
Variance $\left(\mathrm{s}^{2}\right)$ & 0.28 & 0.26 \\
Skewness $\left(\mathrm{g}_{1}\right)$ & 0.89 & 0.21 \\
Kurtosis $\left(\mathrm{g}_{2}\right)$ & 2.46 & 0.46 \\
CV & 7.59 & 6.93 \\
\hline
\end{tabular}


Table A-11. Comparison of descriptive statistics for mesiodistal diameter of LP2 for the two groups, namely those with naturally-occurring good occlusions and those who received orthodontic treatment. The treated group mean is $3.26 \%$ larger than that of the untreated group.

\begin{tabular}{lcc}
\hline \multicolumn{1}{c}{ Statistic } & $\begin{array}{c}\text { Good } \\
\text { Occlusion }\end{array}$ & $\begin{array}{c}\text { Treated } \\
\text { Orthodontically }\end{array}$ \\
\hline $\mathrm{n}$ & 41 & 91 \\
Mean & 7.16 & 7.40 \\
$\mathrm{sd}$ & 0.53 & 0.51 \\
$\mathrm{se}$ & 0.08 & 0.05 \\
minimum & 6.14 & 6.31 \\
maximum & 8.75 & 9.08 \\
$\mathrm{~L}_{1}$ & 7.00 & 7.29 \\
L2 & 7.33 & 7.50 \\
Variance $\left(\mathrm{s}^{2}\right)$ & 0.28 & 0.26 \\
Skewness $\left(\mathrm{g}_{1}\right)$ & 0.51 & 0.54 \\
Kurtosis $\left(\mathrm{g}_{2}\right)$ & 0.77 & 0.81 \\
CV & 7.41 & 6.92 \\
\hline
\end{tabular}


Table A-12. Comparison of descriptive statistics for mesiodistal diameter of LM1 for the two groups, namely those with naturally-occurring good occlusions and those who received orthodontic treatment. The treated group mean is $2.86 \%$ larger than that of the untreated group.

\begin{tabular}{lcc}
\hline \multicolumn{1}{c}{ Statistic } & $\begin{array}{c}\text { Good } \\
\text { Occlusion }\end{array}$ & $\begin{array}{c}\text { Treated } \\
\text { Orthodontically }\end{array}$ \\
\hline $\mathrm{n}$ & 41 & 91 \\
Mean & 10.87 & 11.18 \\
$\mathrm{sd}$ & 0.51 & 0.58 \\
$\mathrm{se}$ & 0.08 & 0.06 \\
minimum & 9.80 & 9.65 \\
maximum & 12.30 & 12.16 \\
L1 & 10.71 & 11.06 \\
L2 & 11.03 & 11.31 \\
Variance $\left(\mathrm{s}^{2}\right)$ & 0.26 & 0.34 \\
Skewness $\left(\mathrm{g}_{1}\right)$ & 0.17 & -0.76 \\
Kurtosis $\left(\mathrm{g}_{2}\right)$ & 0.53 & 0.11 \\
CV & 4.66 & 5.22 \\
\hline
\end{tabular}


Table A-13. Comparison of descriptive statistics for buccolingual diameter of UI1 for the two groups, namely those with naturally-occurring good occlusions and those who received orthodontic treatment. The treated group mean is $3.78 \%$ larger than that of the untreated group.

\begin{tabular}{lcc}
\hline \multicolumn{1}{c}{ Statistic } & $\begin{array}{c}\text { Good } \\
\text { Occlusion }\end{array}$ & $\begin{array}{c}\text { Treated } \\
\text { Orthodontically }\end{array}$ \\
\hline $\mathrm{n}$ & 41 & 91 \\
Mean & 7.00 & 7.26 \\
sd & 0.49 & 0.53 \\
se & 0.08 & 0.06 \\
minimum & 5.81 & 5.43 \\
maximum & 8.17 & 8.42 \\
L1 & 6.84 & 7.15 \\
L2 & 7.15 & 7.37 \\
Variance $\left(\mathrm{s}^{2}\right)$ & 0.24 & 0.28 \\
Skewness $\left(\mathrm{g}_{1}\right)$ & -0.06 & -0.30 \\
Kurtosis $\left(\mathrm{g}_{2}\right)$ & 0.04 & 0.52 \\
CV & 6.97 & 7.32 \\
\hline
\end{tabular}


Table A-14. Comparison of descriptive statistics for buccolingual diameter of UI2 for the two groups, namely those with naturally-occurring good occlusions and those who received orthodontic treatment. The treated group mean is 3.36\% larger than that of the untreated group.

\begin{tabular}{lcc}
\hline \multicolumn{1}{c}{ Statistic } & $\begin{array}{c}\text { Good } \\
\text { Occlusion }\end{array}$ & $\begin{array}{r}\text { Treated } \\
\text { Orthodontically }\end{array}$ \\
$\mathrm{n}$ & 41 & 91 \\
Mean & 6.29 & 6.50 \\
$\mathrm{sd}$ & 0.53 & 0.51 \\
$\mathrm{se}$ & 0.08 & 0.05 \\
minimum & 5.16 & 5.33 \\
maximum & 7.58 & 7.58 \\
$\mathrm{~L}_{1}$ & 6.12 & 6.39 \\
$\mathrm{~L}_{2}$ & 6.46 & 6.61 \\
Variance $\left(\mathrm{s}^{2}\right)$ & 0.29 & 0.26 \\
Skewness $\left(\mathrm{g}_{1}\right)$ & 0.15 & -0.07 \\
Kurtosis $\left(\mathrm{g}_{2}\right)$ & 0.36 & -0.61 \\
CV & 8.50 & 7.83 \\
\hline
\end{tabular}


Table A-15. Comparison of descriptive statistics for buccolingual diameter of UC for the two groups, namely those with naturally-occurring good occlusions and those who received orthodontic treatment. The treated group mean is $2.52 \%$ larger than that of the untreated group.

\begin{tabular}{lcc}
\hline \multicolumn{1}{c}{ Statistic } & $\begin{array}{c}\text { Good } \\
\text { Occlusion }\end{array}$ & $\begin{array}{c}\text { Treated } \\
\text { Orthodontically }\end{array}$ \\
$\mathrm{n}$ & 41 & 91 \\
Mean & 8.28 & 8.49 \\
$\mathrm{sd}$ & 0.62 & 0.55 \\
$\mathrm{se}$ & 0.10 & 0.06 \\
minimum & 6.79 & 6.88 \\
maximum & 9.67 & 9.95 \\
$\mathrm{~L}_{1}$ & 8.08 & 8.37 \\
L2 & 8.48 & 8.60 \\
Variance $\left(\mathrm{s}^{2}\right)$ & 0.39 & 0.31 \\
Skewness $\left(\mathrm{g}_{1}\right)$ & -0.16 & 0.07 \\
Kurtosis $\left(\mathrm{g}_{2}\right)$ & 0.02 & 0.06 \\
CV & 7.52 & 6.53 \\
\hline
\end{tabular}


Table A-16. Comparison of descriptive statistics for buccolingual diameter of UP1 for the two groups, namely those with naturally-occurring good occlusions and those who received orthodontic treatment. The treated group mean is $4.46 \%$ larger than that of the untreated group.

\begin{tabular}{lcc}
\hline \multicolumn{1}{c}{ Statistic } & $\begin{array}{c}\text { Good } \\
\text { Occlusion }\end{array}$ & $\begin{array}{c}\text { Treated } \\
\text { Orthodontically }\end{array}$ \\
\hline $\mathrm{n}$ & 41 & 91 \\
Mean & 9.16 & 9.57 \\
$\mathrm{sd}$ & 0.60 & 0.57 \\
$\mathrm{se}$ & 0.09 & 0.06 \\
minimum & 7.89 & 8.00 \\
maximum & 10.23 & 10.98 \\
$\mathrm{~L}_{1}$ & 8.97 & 9.45 \\
$\mathrm{~L}_{2}$ & 9.35 & 9.69 \\
Variance $\left(\mathrm{s}^{2}\right)$ & 0.36 & 0.32 \\
Skewness $\left(\mathrm{g}_{1}\right)$ & -0.39 & -0.06 \\
Kurtosis $\left(\mathrm{g}_{2}\right)$ & -0.35 & 0.04 \\
CV & 6.57 & 5.93 \\
\hline
\end{tabular}


Table A-17. Comparison of descriptive statistics for buccolingual diameter of UP2 for the two groups, namely those with naturally-occurring good occlusions and those who received orthodontic treatment. The treated group mean is $3.50 \%$ larger than that of the untreated group.

\begin{tabular}{lcc}
\hline \multicolumn{1}{c}{ Statistic } & $\begin{array}{c}\text { Good } \\
\text { Occlusion }\end{array}$ & $\begin{array}{c}\text { Treated } \\
\text { Orthodontically }\end{array}$ \\
\hline $\mathrm{n}$ & 41 & 91 \\
Mean & 9.44 & 9.77 \\
$\mathrm{sd}$ & 0.57 & 0.59 \\
$\mathrm{se}$ & 0.09 & 0.06 \\
minimum & 7.82 & 8.39 \\
maximum & 10.45 & 11.26 \\
L1 & 9.26 & 9.65 \\
L2 & 9.62 & 9.89 \\
Variance $\left(\mathrm{s}^{2}\right)$ & 0.33 & 0.35 \\
Skewness $\left(\mathrm{g}_{1}\right)$ & -0.60 & -0.07 \\
Kurtosis $\left(\mathrm{g}_{2}\right)$ & 0.19 & -0.13 \\
CV & 6.04 & 6.05 \\
\hline
\end{tabular}


Table A-18. Comparison of descriptive statistics for buccolingual diameter of UM1 for the two groups, namely those with naturally-occurring good occlusions and those who received orthodontic treatment. The treated group mean is $2.55 \%$ larger than that of the untreated group.

\begin{tabular}{lcc}
\hline \multicolumn{1}{c}{ Statistic } & $\begin{array}{c}\text { Good } \\
\text { Occlusion }\end{array}$ & $\begin{array}{c}\text { Treated } \\
\text { Orthodontically }\end{array}$ \\
\hline $\mathrm{n}$ & 41 & 91 \\
Mean & 11.51 & 11.80 \\
$\mathrm{sd}$ & 0.60 & 0.48 \\
$\mathrm{se}$ & 0.09 & 0.05 \\
minimum & 9.82 & 10.61 \\
maximum & 12.48 & 13.10 \\
$\mathrm{~L}_{1}$ & 11.32 & 11.70 \\
$\mathrm{~L}_{2}$ & 11.70 & 11.90 \\
Variance $\left(\mathrm{s}^{2}\right)$ & 0.36 & 0.23 \\
Skewness $\left(\mathrm{g}_{1}\right)$ & -0.36 & 0.03 \\
Kurtosis $\left(\mathrm{g}_{2}\right)$ & -0.02 & -0.02 \\
CV & 5.20 & 4.03 \\
\hline
\end{tabular}


Table A-19. Comparison of descriptive statistics for buccolingual diameter of LI1 for the two groups, namely those with naturally-occurring good occlusions and those who received orthodontic treatment. The treated group mean is $3.70 \%$ larger than that of the untreated group.

\begin{tabular}{lcc}
\hline \multicolumn{1}{c}{ Statistic } & $\begin{array}{c}\text { Good } \\
\text { Occlusion }\end{array}$ & $\begin{array}{c}\text { Treated } \\
\text { Orthodontically }\end{array}$ \\
\hline $\mathrm{n}$ & 41 & 91 \\
Mean & 5.91 & 6.13 \\
$\mathrm{sd}$ & 0.46 & 0.51 \\
$\mathrm{se}$ & 0.07 & 0.05 \\
minimum & 5.08 & 4.87 \\
maximum & 6.99 & 7.37 \\
$\mathrm{~L}_{1}$ & 5.76 & 6.02 \\
$\mathrm{~L}_{2}$ & 6.05 & 6.23 \\
Variance $\left(\mathrm{s}^{2}\right)$ & 0.21 & 0.26 \\
Skewness $\left(\mathrm{g}_{1}\right)$ & 0.08 & -0.09 \\
Kurtosis $\left(\mathrm{g}_{2}\right)$ & -0.41 & -0.18 \\
CV & 7.85 & 8.31 \\
\hline
\end{tabular}


Table A-20. Comparison of descriptive statistics for buccolingual diameter of LI2 for the two groups, namely those with naturally-occurring good occlusions and those who received orthodontic treatment. The treated group mean is $1.64 \%$ larger than that of the untreated group.

\begin{tabular}{lcc}
\hline \multicolumn{1}{c}{ Statistic } & $\begin{array}{c}\text { Good } \\
\text { Occlusion }\end{array}$ & $\begin{array}{c}\text { Treated } \\
\text { Orthodontically }\end{array}$ \\
\hline $\mathrm{n}$ & 41 & 91 \\
Mean & 6.28 & 6.38 \\
$\mathrm{sd}$ & 0.41 & 0.50 \\
$\mathrm{se}$ & 0.06 & 0.05 \\
minimum & 5.54 & 4.92 \\
maximum & 7.23 & 7.52 \\
$\mathrm{~L}_{1}$ & 6.15 & 6.27 \\
$\mathrm{~L}_{2}$ & 6.41 & 6.48 \\
Variance $\left(\mathrm{s}^{2}\right)$ & 0.17 & 0.25 \\
Skewness $\left(\mathrm{g}_{1}\right)$ & -0.04 & -0.43 \\
Kurtosis $\left(\mathrm{g}_{2}\right)$ & -0.60 & 0.44 \\
CV & 6.58 & 7.85 \\
\hline
\end{tabular}


Table A-21. Comparison of descriptive statistics for buccolingual diameter of LC for the two groups, namely those with naturally-occurring good occlusions and those who received orthodontic treatment. The treated group mean is $-0.26 \%$ larger than that of the untreated group.

\begin{tabular}{lcc}
\hline \multicolumn{1}{c}{ Statistic } & $\begin{array}{c}\text { Good } \\
\text { Occlusion }\end{array}$ & $\begin{array}{c}\text { Treated } \\
\text { Orthodontically }\end{array}$ \\
\hline $\mathrm{n}$ & 41 & 91 \\
Mean & 7.64 & 7.62 \\
$\mathrm{sd}$ & 0.57 & 0.67 \\
$\mathrm{se}$ & 0.09 & 0.07 \\
minimum & 6.40 & 5.82 \\
maximum & 8.84 & 9.33 \\
$\mathrm{~L}_{1}$ & 7.46 & 7.48 \\
$\mathrm{~L}_{2}$ & 7.82 & 7.76 \\
Variance $\left(\mathrm{s}^{2}\right)$ & 0.32 & 0.45 \\
Skewness $\left(\mathrm{g}_{1}\right)$ & -0.26 & -0.26 \\
Kurtosis $\left(\mathrm{g}_{2}\right)$ & -0.14 & 0.22 \\
CV & 7.46 & 8.82 \\
\hline
\end{tabular}


Table A-22. Comparison of descriptive statistics for buccolingual diameter of LP1 for the two groups, namely those with naturally-occurring good occlusions and those who received orthodontic treatment. The treated group mean is $3.88 \%$ larger than that of the untreated group.

\begin{tabular}{lcc}
\hline \multicolumn{1}{c}{ Statistic } & $\begin{array}{c}\text { Good } \\
\text { Occlusion }\end{array}$ & $\begin{array}{c}\text { Treated } \\
\text { Orthodontically }\end{array}$ \\
\hline $\mathrm{n}$ & 41 & 91 \\
Mean & 7.88 & 8.19 \\
$\mathrm{sd}$ & 0.58 & 0.57 \\
$\mathrm{se}$ & 0.09 & 0.06 \\
minimum & 6.70 & 6.69 \\
maximum & 8.86 & 9.52 \\
$\mathrm{~L}_{1}$ & 7.70 & 8.07 \\
$\mathrm{~L}_{2}$ & 8.06 & 8.30 \\
Variance $\left(\mathrm{s}^{2}\right)$ & 0.33 & 0.33 \\
Skewness $\left(\mathrm{g}_{1}\right)$ & -0.25 & -0.02 \\
Kurtosis $\left(\mathrm{g}_{2}\right)$ & -0.97 & 0.03 \\
CV & 7.33 & 7.00 \\
\hline
\end{tabular}


Table A-23. Comparison of descriptive statistics for buccolingual diameter of LP2 for the two groups, namely those with naturally-occurring good occlusions and those who received orthodontic treatment. The treated group mean is $4.31 \%$ larger than that of the untreated group.

\begin{tabular}{lcc}
\hline \multicolumn{1}{c}{ Statistic } & $\begin{array}{c}\text { Good } \\
\text { Occlusion }\end{array}$ & $\begin{array}{c}\text { Treated } \\
\text { Orthodontically }\end{array}$ \\
\hline $\mathrm{n}$ & 41 & 91 \\
Mean & 8.43 & 8.79 \\
$\mathrm{sd}$ & 0.58 & 0.54 \\
$\mathrm{se}$ & 0.09 & 0.06 \\
minimum & 7.06 & 7.53 \\
maximum & 9.83 & 10.41 \\
$\mathrm{~L}_{1}$ & 8.24 & 8.68 \\
$\mathrm{~L}_{2}$ & 8.61 & 8.90 \\
Variance $\left(\mathrm{s}^{2}\right)$ & 0.34 & 0.29 \\
Skewness $\left(\mathrm{g}_{1}\right)$ & -0.27 & 0.20 \\
Kurtosis $\left(\mathrm{g}_{2}\right)$ & 0.72 & 0.65 \\
CV & 6.92 & 6.10 \\
\hline
\end{tabular}


Table A-24. Comparison of descriptive statistics for buccolingual diameter of LM1 for the two groups, namely those with naturally-occurring good occlusions and those who received orthodontic treatment. The treated group mean is $2.76 \%$ larger than that of the untreated group.

\begin{tabular}{lcc}
\hline \multicolumn{1}{c}{ Statistic } & $\begin{array}{c}\text { Good } \\
\text { Occlusion }\end{array}$ & $\begin{array}{c}\text { Treated } \\
\text { Orthodontically }\end{array}$ \\
\hline $\mathrm{n}$ & 41 & 91 \\
Mean & 10.40 & 10.69 \\
$\mathrm{sd}$ & 0.43 & 0.48 \\
$\mathrm{sem}$ & 0.07 & 0.05 \\
minimum & 9.46 & 9.20 \\
maximum & 11.04 & 11.52 \\
$\mathrm{~L}_{1}$ & 10.26 & 10.59 \\
$\mathrm{~L}_{2}$ & 10.53 & 10.79 \\
Variance $\left(\mathrm{s}^{2}\right)$ & 0.18 & 0.24 \\
Skewness $\left(\mathrm{g}_{1}\right)$ & -0.21 & -0.73 \\
Kurtosis $\left(\mathrm{g}_{2}\right)$ & -0.91 & 0.79 \\
CV & 4.10 & 4.54 \\
\hline
\end{tabular}




\section{VITA}

Michael Kelly Agenter was born December 28, 1971, in Minneapolis, Minnesota, the son of Donavan Michael Agenter and Vicky Lou Schiller. After graduating with a B.S. in biology and chemistry from Northern Kentucky University in Highland Heights, Kentucky (1996), Dr. Agenter started a computer graphics business in San Diego, California before resuming his education at the University of Michigan, School of Dentistry in 1998. He was married to Kelly Ann Golba of Toledo, Ohio and received his D.D.S. degree in 2002. Upon graduation, he was commissioned as a Lieutenant in the United States Navy and entered a General Practice Residency at Balboa Naval Hospital in San Diego, California. In 2003, Dr. Agenter received orders for a duty assignment at the United States Naval Hospital on the island of Guam in the South Pacific. In 2005, after fulfilling his military obligations, Dr. Agenter began orthodontic studies at The University of Tennessee Health Science Center in Memphis. Upon graduation in 2008, he anticipates entering private practice. 